Review

\title{
Smart Sensor Systems for Wearable Electronic Devices
}

\author{
Byeong Wan An ${ }^{\dagger}$, Jung Hwal Shin ${ }^{\dagger}$, So-Yun Kim, Joohee Kim, Sangyoon Ji, Jihun Park, \\ Youngjin Lee, Jiuk Jang, Young-Geun Park, Eunjin Cho, Subin Jo and Jang-Ung Park*
}

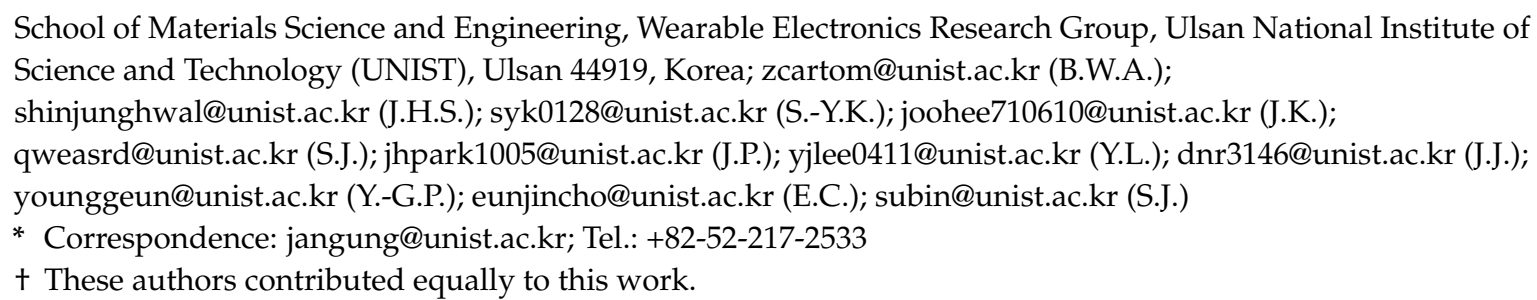

Received: 13 June 2017; Accepted: 22 July 2017; Published: 25 July 2017

\begin{abstract}
Wearable human interaction devices are technologies with various applications for improving human comfort, convenience and security and for monitoring health conditions. Healthcare monitoring includes caring for the welfare of every person, which includes early diagnosis of diseases, real-time monitoring of the effects of treatment, therapy, and the general monitoring of the conditions of people's health. As a result, wearable electronic devices are receiving greater attention because of their facile interaction with the human body, such as monitoring heart rate, wrist pulse, motion, blood pressure, intraocular pressure, and other health-related conditions. In this paper, various smart sensors and wireless systems are reviewed, the current state of research related to such systems is reported, and their detection mechanisms are compared. Our focus was limited to wearable and attachable sensors. Section 1 presents the various smart sensors. In Section 2, we describe multiplexed sensors that can monitor several physiological signals simultaneously. Section 3 provides a discussion about short-range wireless systems including bluetooth, near field communication (NFC), and resonance antenna systems for wearable electronic devices.
\end{abstract}

Keywords: smart sensor; wearable electronics; stretchable electronics; wireless sensor; healthcare

\section{Introduction}

In recent years, the average age of the world's population has been increasing, and healthcare monitoring devices have received a lot of attention because they improve the length and quality of people's lives [1]. Healthcare monitoring includes caring for the welfare of every person, which includes early diagnosis of diseases, real-time monitoring of the effects of treatment, therapy, and the general monitoring of the conditions of people's health. As a result, wearable electronic devices are receiving greater attention because of their facile interaction with the human body, such as monitoring heart rate, wrist pulse, motion, blood pressure, intraocular pressure, and other health-related conditions [2-9]. Unlike conventional health-monitoring systems (e.g., blood pressure meters), wearable electronic devices are portable, wearable, and they provide real-time, continuous, recorded data related to complex health conditions in a timely manner. Furthermore, in order to maximize the portable and wearable advantages of the wearable devices, energy harvesting devices were integrated instead of rigid and bulk batteries $[10,11]$. These characteristics of wearable electronic devices can improve the users' or patients' compliance with medical instructions and medication schedules. Since the wearable devices are wireless, the information they gather can be sent to a central 
node, such as a cell phone or a microcontroller board that can transmit the information to a medical center and display it on a screen.

In general, wearable electronic systems consist of smart sensors, wearable materials, actuators, power supplies, wireless communication modules and links, control and processing units, an interface for the user, software, and advanced algorithms for extracting data and making decisions. Thus, the systems can monitor the patient's physiological information, such as temperature, blood pressure, strain the patient may be experiencing, and the concentrations of gas, various ions, and biomolecules in the bloodstream. To be used in wearable electronic systems, the smart sensors, which are composed of flexible substrates and have embedded, conducting electrodes, must be ultrathin, low modulus, light weight, highly flexible, and stretchable.

To fabricate the smart sensors having these requirements, various studies using hybrid structures [12-14], hybrid materials [15-22], multi-dimensional carbon nanofibers [23], and nanomaterial-based electrodes [24] have been introduced. In addition, electrohydrodynamic (EHD) inkjet printing and three dimensional (3D) printing methods are widely used to make the electrodes with high-resolution and high-performance [16,25-28].

Beyond the concept of wearable appliances, sensor is rapidly evolving toward a new paradigm of deformable electronics, where sensors can be wearable into various human body parts. Wearable sensor is the most sophisticated form of deformable sensors in that it involves state-of-the-art technologies developed through the collaboration of various disciplines, ranging from materials science to electrical and mechanical engineering. As well described in some excellent previous reports in Table 1, substrate, electrode, and active materials are important building blocks of wearable sensor. The most important part for the flexibility or stretchability of the wearable sensor is the substrate. In order to realize a flexible sensor, flexible substrates such as polyethylene terephthalate (PET) and polyimide (PI) films are used $[12,18,29]$. PET film has good flexibility (flexural modulus: $8.3-14 \mathrm{GPa}$, Young's modulus: $3.5-11 \mathrm{GPa})$; however, low glass transition temperature $\left(T_{g}: \approx 100{ }^{\circ} \mathrm{C}\right)$ is not suitable for high temperature fabrication. PI film show good thermal stability $\left(T_{g}: \approx 300^{\circ} \mathrm{C}\right)$ due to strong imide bonding, so high temperature fabrication can be possible. Also, PI has good flexibility as well as PET (flexural modulus: 3.9-19 GPa, Young's modulus: 3.7-20 GPa). Basic PI film has yellowish-brown color. However, transparent and colorless PI films have been developed for use in transparent devices and wearable electronic in recent years. In addition, clothing type sensors were fabricated using fabric-type of PET substrate to demonstrate wearable sensors [30].

Stretchable and wearable sensors essentially require stretchable substrates. Silicon-based elastomers such as polydimethylsiloxane (PDMS) and Ecoflex are selected as stretchable substrates in numerous researches of wearable sensors, which are formed by the polymerization of siloxane monomers with platinum catalysts [3,31-34]. PDMS shows 4.8 MPa of Young's modulus and 420\% of elongation limit. Ecoflex shows $900 \%$ of elongation limit. These elastomers polymer chain entanglements with low intermolecular force, thus they show good stretchability. Besides the silicon-based elastomers, parylene is also used for the substrate of thin-film wearable sensors because of its strength and intermediate flexibility (Young's modulus $\approx 4 \mathrm{GPa}$ ). In addition, parylene is known to be biocompatible in many reports [35].

Electrode parts are also important parts of wearable sensors. Substrate parts mostly use polymer-based materials, but in the case of electrodes, metal-based electrodes are used because high-conductivity is important. Thin-metal is used to form flexible interconnects or serpentine-structure metal to increase stretchablility [3,36-38]. As alternative approaches to achieving the stretchable interconnect, nanowire-based random network [12,18,31,32] and liquid metal. Liquid metal exhibits metal-like conductivity at room temperature, but due to the nature of the liquid, the failure does not occur under strain, and thus highly stretchable interconnects can be achieved.

Various materials can be used as the active material of the wearable sensor according to the type and purpose of the sensor. Strain or pressure sensor use a strain sensitive resistor or piezoelectric material that changes resistance according to strain or pressure. Chemical sensors also use various 
active materials, mostly carbon nanotube (CNT), or graphene are used as an active material [31-33,39,40]. Because $\mathrm{CNT}$ and graphene surfaces can be easily tuned by using various functional groups to produce variety wearable sensors. Polymer containing conjugated group which can easily conjugate with CNT and graphene such as pyrene can be coated on CNT and graphene surface to demonstrate various sensors such as ion, polymer, and gas sensors.

Based on these various materials, wearable sensors have been rapidly developed. Table 1 summarizes materials and properties of wearable sensors which were introduced in this review.

These smart sensors monitor health conditions in real time, and the diagnostic results are transmitted to control and processing units. To accomplish this, both wired and wireless systems are used extensively to transmit health-related data for subsequent diagnosis. Wireless systems are preferred because wired systems impair the user's mobility and comfort and increase the risk of the occurrence of a transmission failure [32,41]. Another advantage of the wireless systems is that they also can realize the telemedicine to a doctor such as continuous diagnosis and scheduling an appointment.

In this paper, various smart sensors and wireless systems are reviewed, the current state of research related to such systems is reported, and their detection mechanisms are compared. Our focus was limited to wearable and attachable sensors, so we did not address implantable sensors, such as those implanted in the skin, tissue, or brain. Section 1 presents the various smart sensors divided into two major categories, i.e., physical sensors for detecting temperature, pressure, and strain and chemical sensors for detecting gases, ions, and biomolecules. In Section 2, we describe multiplexed sensors that can monitor several physiological signals simultaneously. Section 3 provides a discussion about short-range wireless systems including bluetooth, near field communication (NFC), and resonance antenna systems for wearable electronic devices. Our conclusions are presented in Section 4.

\section{Individual Sensors}

\subsection{Physical Sensors}

Physical sensors are capable of sensing physical factors, such as temperature, pressure, and strain. Recently, wearable physical sensors have been developed that have sufficient flexibility and stretchability to resist being deformed by human activities $[3,42,43]$. The physical factors measured by wearable sensors indicate a person's condition, including body and skin temperature, blood pressure, pulse rate, and skin strain. All of these factors are important indicators of a person's health status. Since physical sensors can measure these types of physical factors, they can be used for electronic monitoring of the person's skin, the human-machine interface, the person's activities, and personal healthcare applications $[3,6,39,44,45]$.

\subsubsection{Temperature Sensors}

Body temperature is one of the most fundamental factors associated with human health and physical activity. For example, changes in the temperature can be indicative of pathological symptoms, such as infection, inflammation, hyperthermia, and hypothermia. In addition, real-time monitoring of body temperature is crucial for recognizing sudden adverse occurrences, such as heart attacks. Furthermore, temperature monitoring is important for a soldier and an athlete, where physical activity is directly concerned with their accomplishment.

As they are closely related to the environment and human life, temperature sensors have been studied extensively in various applications. Several methods can be used to fabricate temperature sensors, and they can be divided into several different types, such as pyroelectric temperature detectors, resistive temperature detectors, and thermistors. In addition to the studies related to temperature sensors, other related research has been conducted. One example is the development of thermocouples based on the principle of the Seebeck effect [46] in which a thermal detector that uses thermochromic materials that change colors when the temperature changes $[47,48]$. In order to utilize these temperature sensors for monitoring people's health and activities, they must be flexible and stretchable so that they 
can be attached successfully on the person to be monitored. In recent years, flexibility and stretchability have been achieved by using polymers as the active material and by reconfiguring the structure. The advances in the mechanical properties of these devices have made wearable temperature sensors a reality.

Pyroelectric temperature detectors are fabricated to take advantage of the pyroelectric effect, which is the generation of an electric field by the spontaneous polarization of the material due to changes in the temperature. Lithium tantalate $\left(\mathrm{LiTaO}_{3}\right)$ and barium titanate $\left(\mathrm{BaTiO}_{3}\right)$ are typical pyroelectric materials in which the crystal lattice group of the unit cell has intrinsic polarity. Because these pyroelectric materials are rigid crystals, it is difficult to apply them to flexible, stretchable electronics. To overcome this problem, polymer-based pyroelectric materials, such as polyvinylidene fluoride (PVDF) and its copolymers, have been investigated and used as wearable temperature sensors [49-51]. Cosseddu et al. demonstrated a temperature transducer based on an organic thin-film transistor (OTFT) by detecting the pyroelectric effect of PVDF [52]. Because of the pyroelectric properties of the material, a charge separation is produced across the PVDF film when the temperature varies, which is inducing the current variation in the OTFT. Since PVDF and its copolymer, poly(vinylidenefluoride-trifluoroethylene) (P(VDF-TrFE)), have piezoelectric properties as well as pyroelectric properties, they can detect both pressure and temperature as target sensing parameters. Tien et al. demonstrated a flexible, bimodal sensor array to detect both temperature and pressure simultaneously by using a mixture of $\mathrm{P}(\mathrm{VDF}-\mathrm{TrFE})$ and $\mathrm{BaTiO}_{3}$ nanoparticles as a gate dielectric material [53]. By applying alternating current (AC) gate bias to the field-effect transistor (FET), effective remnant polarization of the piezo-pyroelectric gate dielectric layer has been measured based on the amplitude and offset values of the modulated drain current.

Resistive temperature detectors (RTDs) are one of the most widely used types of temperature sensors. Typically, a pure metal, usually platinum or copper, is used as the resistive material. The resistance of the metal increases linearly as the temperature increases according to the temperature coefficient of resistance [42,54-59]; therefore, the metal-based resistive temperature sensors can detect the changes in the temperature according to the following equation, $R=R_{0}\left[1+\alpha\left(T-T_{0}\right)\right]$, where $R$ is resistance of the sensor at temperature " $T$ ", $R_{0}$ is resistance of the sensor at reference temperature, usually $20^{\circ} \mathrm{C}, \alpha$ is the temperature coefficient of resistance, $T$ is the temperature of the sensor, and $T_{0}$ is reference temperature. Kim et al. demonstrated surgical suture strips that had platinum temperature sensors with Si diodes for a diagnostic system [54]. Serpentine-structured platinum has a linear resistance change of $2.7 \Omega /{ }^{\circ} \mathrm{C}$ as the temperature changes. In particular, an in vivo animal experiment was performed to demonstrate scalability and biocompatibility, and four temperature sensors in the sutures demonstrated stable measurements of the local temperature. Webb et al. fabricated ultrathin conformal devices with gold serpentine-structured temperature sensor arrays (Figure 1a) [42]. Four-by-four arrays of the temperature coefficient of resistance (TCR) can be used as both temperature sensors and local microscale heaters since the electrode can be Joule heated. Subtle variations of the temperature of human skin, which can occur due to physical stimuli, mental activity, vasoconstriction, and dilation, can be determined by TCR array devices in real time (Figure 1b,c).

However, metal-based RTDs have low temperature resolution for wearable applications, which are used to monitor temperatures in the range of $30-40{ }^{\circ} \mathrm{C}$. Unlike metal-based RTDs, the resistance of thermistor-type temperature sensors changes nonlinearly according to the temperature according to the following equation, $R=R_{0} \exp (B / T)$, where $R$ is the resistance at temperature $T, R_{0}$ is the resistance at $T=\infty, B$ is the thermal index, $T$ is the temperature of the sensor. This feature makes it possible for these sensors to measure temperature much more precisely than RTDs, but the temperature range is limited. The resistance of thermistor-type temperature sensors changes nonlinearly according to the temperature, which makes it possible for these sensors to measure temperature much more precisely than RTDs, but the temperature range is limited. In addition, they have a significant advantage in bio-applications because they have high sensitivity and low cost [31,60-64]. Yu et al. fabricated a stretchable temperature sensor by transferring the elastically-buckled, thin-film thermistors to 
elastomeric materials [61]. The thermistors were fabricated on silicon-on-insulator and transferred to a pre-strained polydimethylsiloxane (PDMS) substrate to form a buckled structure, and they had negligible resistance changes under the $30 \%$ of strain. Yan et al. demonstrated a stretchable graphene thermistor with a graphene thermal channel and silver nanowires (AgNWs) electrode (Figure 1d-f) [31]. The graphene thermal channel shows negative temperature coefficient like a semiconductor. The graphene thermistor embedded in the PDMS not only can be stretched up to $50 \%$ but also can be $360^{\circ}$ twisted, where the twist is one of the most important properties of wearable electronic devices. Although the offset resistance of the graphene thermal channel changes depending on the applied strain up to $50 \%$, it can be modified by tuning the thermal index.
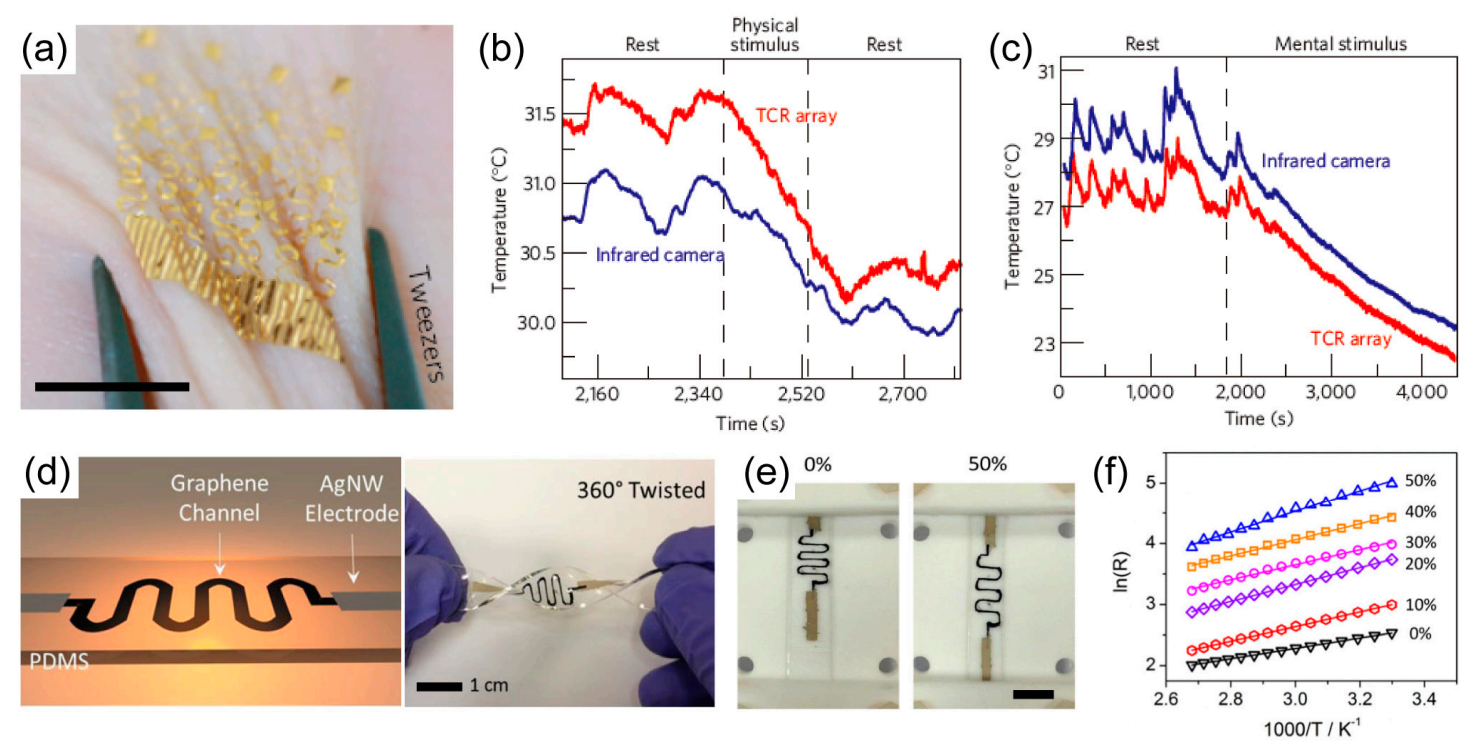

Figure 1. Wearable temperature sensors. (a) Image of a $4 \times 4$ temperature coefficient of resistance (TCR) sensor array after application to the skin deformed by pinching the skin in a twisting motion (scale bar $8 \mathrm{~mm}$ ). (b) Temperature of the palm measured with an infrared camera (blue) and a sensor array (red, offset for clarity) during mental and (c) physical stimulus tests. Reprinted with permission from Ref. [42]. Copyright 2016, Nature Publishing Group. (d) Schematic diagram and representative image of the stretchable graphene thermistors at twisted states (scale bar $1 \mathrm{~cm}$ ). (e) Images of the stretchable graphene thermistor at $0 \%$ and $50 \%$ strains (scale bar $1 \mathrm{~cm}$ ). (f) Resistance variation with temperature (30 to $100{ }^{\circ} \mathrm{C}$ ) within $0 \%$ to $50 \%$ strains (step 10\%). Reprinted with permission from Ref. [31]. Copyright 2015, American Chemical Society.

\subsubsection{Pressure Sensors}

The pressure ranges are very different depending on the body part or purpose. The pressure ranges of the wearable pressure sensors are divided into three categories, i.e., low-pressure range $(<10 \mathrm{kPa})$, medium-pressure range $(10$ to $100 \mathrm{kPa})$, and high-pressure range $(>100 \mathrm{kPa})$ [65]. The low-pressure range $(<10 \mathrm{kPa})$, which corresponds to both the intraocular and intracranial pressures, is an important range because it encompasses the intra-body pressure [6,32]. The type of body pressure that corresponds to the medium-pressure range (10 to $100 \mathrm{kPa}$ ) includes blood pressure, heart rate, the radial artery wave, phonation vibration, and skin modulus [66-68]. The high-pressure range $(>100 \mathrm{kPa})$ includes the weight of a person or atmospheric pressure at high altitudes [69]. By measuring these various types of pressure, we can monitor eye disease, heart disease, damaged vocal cords, and exercise. Thus, wearable pressure sensors have been studied extensively for applications in healthcare and medical diagnosis devices. Various sensing mechanisms, including piezoelectric, piezoresistive, and capacitance mechanisms turn physical stimuli into electrical signals. 
The principle of piezoelectric-based pressure is based on piezoelectric effects that are electrical charges that occur in certain types of solid materials under pressure. The electricity induced by pressure can be expressed by the following equations: $D_{i}=\varepsilon_{0} \varepsilon_{i j}{ }^{\sigma} E_{i}+d_{i j} \sigma_{J}$, and $\delta_{I}=S_{I J} E_{\sigma_{J}}+d_{I i} E_{i} . D, E$, $\sigma, \delta, \varepsilon_{0}, d, \varepsilon^{\sigma}$, and $S^{E}$ represent the electric displacement, the electric field, the stress by pressure, the strain by pressure, the free-space electric permittivity, the piezoelectric coefficient, the electric relative permittivity, and the mechanical compliance matrix. $I, J, i$, and $j$ are indices. The $d_{31}$ and $d_{33}$ is known as the transverse and longitudinal coefficient, respectively. Therefore, the piezoelectric effect means that the dipole forms a polarization when pressure is applied to the materials, and this polarization is proportional to the applied pressure. Due to their fast response time and low power consumption, piezoelectric pressure sensors are used extensively in the detection of dynamic pressures, such as the vibrations of sound. Typical materials used for piezoelectric pressure sensors are lead titanate $\left(\mathrm{PbTiO}_{3}\right), \mathrm{BaTiO}$, PVDF and $\mathrm{P}(\mathrm{VDF}-\mathrm{TrFE})$. Particularly, a film type sensor is used extensively for manufacturing a wearable pressure sensor, and a representative material is $P(V D F-\operatorname{TrFE})$ [51,70-72]. Persano et al. introduced a large-area, flexible pressure sensor through the free-standing aligned array of $\mathrm{P}(\mathrm{VDF}-\mathrm{TrFE})$ nanofibers [72]. The sensor demonstrated ultra-high sensitivity to pressure changes, even very small changes, e.g., $0.1 \mathrm{~Pa}$. Recently, a pressure sensor was combined with a transistor to improve the performances of the devices [3,67]. Dagdeviren et al. reported a stretchable, ultrathin pressure sensor based on $\mathrm{PbZr}_{0.52} \mathrm{Ti}_{0.48} \mathrm{O}_{3}$ (PZT) that conforms nicely to the skin. The ultrathin and high-quality PZT sheet is used as a component of a capacitor that was connected to the gate electrodes of a FET (Figure 2a) [3]. FETs amplify the piezoelectric response of the PZT and convert it to an output current. The device is very thin $(25 \mu \mathrm{m})$ and lightweight $(2 \mathrm{mg})$, and it has high sensitivity $(\sim 0.005 \mathrm{~Pa})$ and fast response time $(0.1 \mathrm{~ms})$. For monitoring blood pressure, the device can be softly laminated on the wrist, neck, or throat (Figure 2b).
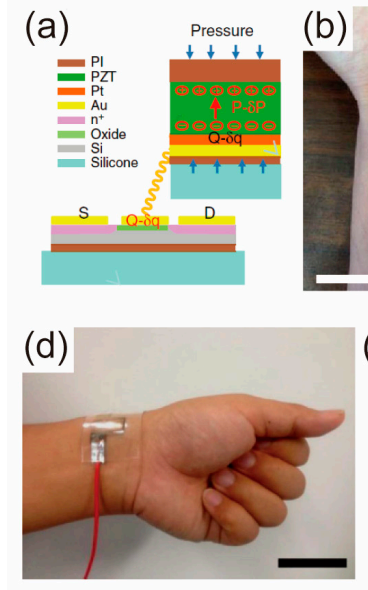

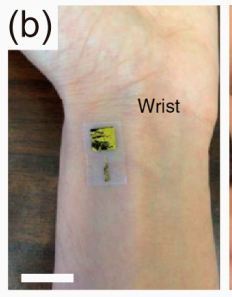

$(\mathrm{e})^{0}$
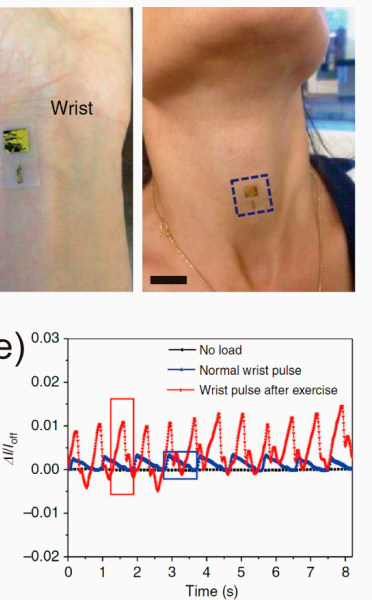

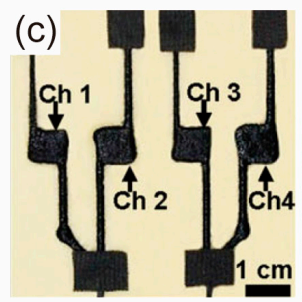

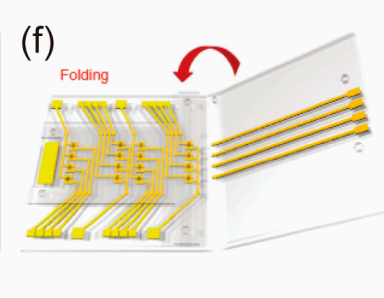
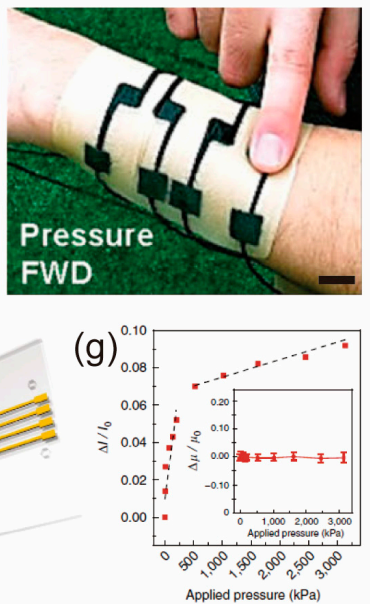

Figure 2. Wearable pressure sensors. (a) Cross-sectional schematic illustration of the pressure sensor and its connections to an associated transistor. (b) Photograph of the pressure sensor placed on a wrist and neck for measuring fast transients in the blood pressure (scale bars $1 \mathrm{~cm}$ and $2 \mathrm{~cm}$ ). Reprinted with permission from Ref. [3]. Copyright 2014, Nature Publishing Group. (c) Images of pressure sensor printed on the commercial elastomeric patch. The sensor array is composed of four channels of pressure sensors (scale bars $1 \mathrm{~cm}$ ). Reprinted with permission from Ref. [39]. Copyright 2014, John Wiley and Sons. (d) Photograph showing the skin-attachable sensor directly above the artery of the wrist (scale bar $3 \mathrm{~cm}$ ). (e) Measurement of the physical force of a heartbeat under normal and exercise conditions. Reprinted with permission from Ref. [36]. Copyright 2014, Nature Publishing Group. (f) Schematic image of pressure-sensitive graphene FETs with air-dielectric layers. (g) Plot of normalized drain current changes versus applied pressure. (inset indicates relative change in the field effect mobility under applied pressure). Reprinted with permission from Ref. [33]. Copyright 2017, Nature Publishing Group. 
The piezo-resistive pressure sensor is based on the fact that the resistance of the material changes with the applied pressure. The resistance change of the material can be expressed by the equation $\Delta R / R=(1+2 v) \varepsilon+(\Delta \rho / \rho)$, where $(1+2 v), \varepsilon$, and $(\Delta \rho / \rho)$ are geometric effect term, strain by pressure, and resistivity effect term, respectively. That is, the change in resistance originates from a change in dimension by pressure. The pressure sensor using this mechanism is very simple to manufacture, and it has been studied extensively because it can detect a wide range of pressures. Usually, conductive fillers (reduced graphene oxides (rGO), carbon nanotubes (CNTs), or metal particles) are added to the elastomer to produce materials with piezoresistive properties, but these sensors have low sensitivity. To solve this problem, studies have been conducted to increase the sensitivity using a microstructure or a porous structure. Park et al. introduced stretchable pressure sensors using the unique geometry of interlocked microdome structures [45,73]. These pressure sensors can be attached to the skin and distinguish a variety of mechanical stimuli. However, the fabrication method requires the use of an Si mold, which is complicated, expensive, and has poor reproducibility. Therefore, Jung et al. developed a wearable piezoresistive pressure sensor by creating pores in a conventional pressure-sensitive rubber (PSR) [39]. Sensors based on these methods have greater sensitivity than conventional PSR-based sensors. This wearable porous PSR pressure sensor successfully conforms to the skin for various applications, such as human-machine interfaces, healthcare monitoring, and radio control of robots (Figure 2c). In addition to the aforementioned pressure sensors based on the microstructure and porous structures, piezoresistive pressure sensors based on other materials also have been developed [36,74]. Gong et al. reported a flexible pressure sensor with high sensitivity by interposing the gold nanowires (AuNWs) between two PDMS films [36]. The AuNW-based pressure sensors provide real-time monitoring of blood pressure with high sensitivity and flexibility, as shown in Figure 2d,e.

Capacitive pressure sensors use capacitors, and their capacitance values vary with the thickness of dielectric materials. The capacitance $C$ is given by the equation $C=\varepsilon_{0} \varepsilon_{r}(A / d)$, where $\varepsilon_{0}$ is the electric constant, $\varepsilon_{r}$ is the relative static permittivity of the dielectric, $A$ is the area of the overlap of the two plates, and $\mathrm{d}$ is the thickness of the dielectric. When the thickness is reduced by pressure, the capacitance increases. In order to change the thickness depending on the pressure, materials with small modulus values, such as PDMS, ecoflex, and polyurethane (PU), usually are used. Sun et al. developed a pressure sensor that includes a transparent, stretchable dielectric that is sandwiched between two flexible ion conductors [75]. This sensor can be used for wearable or implantable electronic applications due its transparency, stretchability, and biocompatibility. In addition, Park et al. developed a flexible, capacitive pressure sensor with very high sensitivity by constructing an air gap between a porous PDMS film and a single-wall carbon nanotube (SWCNT) film [76]. However, capacitive-type pressure sensors have limitations, such as low sensitivity and slow response time, because of the small modulus of elastomer. The sensitivity can be improved through the use of an air dielectric layer. Therefore, Zang et al. demonstrated a flexible pressure sensor based on the suspended gate electrode of the FET [77]. The sensor has very high sensitivity to low pressures and can be attached to the wrist to monitor pulse waves. The abovementioned pressure sensors are sensitive and can detect specific pressure ranges. However, there is a need for a pressure sensor that can sense a wide range of pressures for a variety of applications. Recently, Shin et al. reported an unconventional approach to fabricating a pressure sensor array with an air dielectric layer formed by folding panels (Figure 2f) [33]. The sensor can be used for a wide range of tactile sensing, as shown in Figure 2g. These results demonstrated that pressure sensing devices are the essential element for monitoring human activity and personal healthcare. 


\subsubsection{Strain Sensors}

Small and large deformations can occur when the person is moving. In wearable electronics, the strain sensor has the significant role of monitoring the motion of the person's body, ranging from the vibration of the vocal cords to the movements of joints. Thus, strain sensors have been designed and developed to be flexible, stretchable materials, quite different from the previously-studied, silicon-based strain sensors [78]. The requirements for wearable strain sensors include stretchability, sensitivity (gauge factor), mechanical reliability, hysteresis, and a linear output signal [79]. Wearable strain sensors can be specified according to the principles that use for sensing, e.g., there are piezoresistive, capacitive, and piezoelectric strain sensors.

Piezoresistive strain sensors detect deformations mainly by changes in the resistivity. The factors associated with the change in the resistance of materials used in piezoresistive strain sensors can be explained by the simple equation, $R=\rho(l / A)$, where $\rho$ is resistivity, $l$ is length, and $A$ is the cross-sectional area of the material. Both $l$ and $A$ are geometrical factors, and changes in $\rho$ are induced by the piezoresistivity of the materials themselves. During the deformation of metals and semiconductors, the bandgap changes because of the change in the interatomic spacing [80]. Consequently, $\Delta R / R$ becomes gauge factor of strain sensors. Semiconductors have a high gauge factor due to their large changes in resistivity, so many semiconducting materials are used for piezoresistive strain sensing materials, such as zinc oxide $(\mathrm{ZnO})$, carbon black, and CNT [34,81-83]. Roh et al. fabricated strain sensors by embedding single-wall carbon nanotubes in a conductive elastomer polyurethane-poly(3,4-ethylenedioxythiophene) polystyrenesulfonate (PU-PEDOT:PSS), as shown in Figure $3 \mathrm{a}$. This sensor has the stretchability of $100 \%$ strain, $62 \%$ transmittance in the visible range, and a gauge factor of 62. (Figure 3b) [34]. In addition, changes in the resistance are possible due to disconnections in the network geometry or cracks that may occur during deformation. In the case of conductive nanomaterial networks, such as metal nanowires (mNWs), graphene flakes or films, and CNTs, sliding can occur within the network during stretching or bending, and it results in significant changes in the resistance [84-89]. For example, graphene woven fabric (GWF) was made and used as a strain sensor (Figure $3 c, d$ ), and the sensor had gauge factors of $10^{3}$ at strains of $2-6 \%$ and $10^{6}$ at higher strains $(>7 \%)$ because of the high-density cracks that were generated in the network during stretching [86].

Capacitive strain sensors detect strain based on changes in the capacitance that occur due to the geometrical effect. Capacitive strain sensors usually have two electrode pads separated by an elastomeric dielectric layer. The capacitance of strain sensor can be expressed with the equation $C_{0}=\varepsilon_{0} \varepsilon_{r} l_{0} w_{0} / d_{0}, \varepsilon_{0}$ and $\varepsilon_{r}$ is the dielectric constants and $l_{0}, w_{0}, d_{0}$ are length, width, thickness of the active area of the sensor, respectively. When the sensor is stretched with the strain $\varepsilon$, the length becomes $l=(1+\varepsilon) l_{0}$ but the width and thickness decrease up to the poisson's ratio $v, w=(1-v) w_{0}$ and $d=(1-v) d_{0}$ thus capacitive increases to $C=(1+\varepsilon) C_{0}$. To ensure stretchability in wearable applications, stretchable transparent electrodes usually are used, such as mNWs or CNTs [69,90-94]. Lipomi et al. demonstrated a stretchable and transparent strain sensor using CNTs and silicon elastomer (Figure 3e,f) [69]. Frutiger et al. fabricated a fiber-shaped, capacitive strain sensor for wearable electronics using silicon elastomer and ionic conductive fluid (Figure 3g,h). The gauge factor was 0.348 , and the sensor had $700 \%$ stretchability [92].

The piezoelectric effect of certain materials has been applied for sensing strain. Piezoelectric strain sensors have been developed using various oxides, such as $\mathrm{ZnO}$ and zinc stannate $\left(\mathrm{ZnSnO}_{3}\right)$ or piezoelectric polymers, such as PVDF and P(VDF-TrFE) [95-98]. Wu et al. demonstrated $\mathrm{ZnSnO}_{3}$ nano/microwire-based piezoelectric sensors that were flexible and had a gauge factor of 3740 at $0.35 \%$ strain [95]. Piezoelectric strain sensors usually are self-powered, thus they do not require an additional battery or power supply. However, the mechanical properties of piezoelectric materials limit the application of such sensors in wearable electronics, which require stretchability, so there are still challenges to be overcome [98]. 

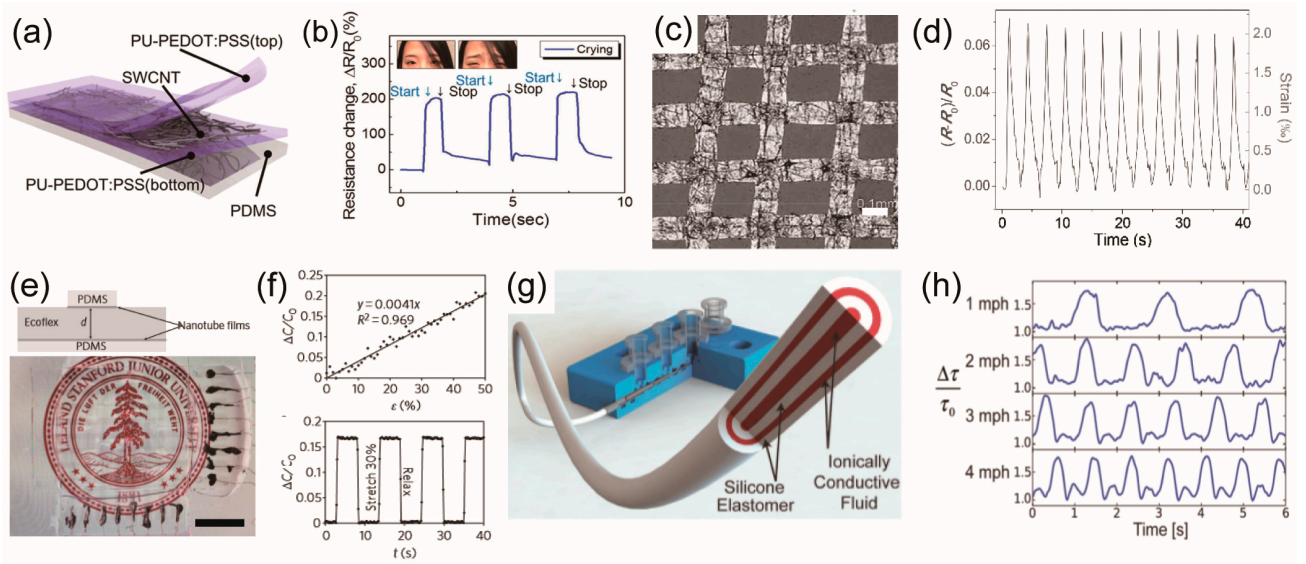

Figure 3. Wearable strain sensors. (a) Schematic illustration of the cross-section of the strain sensor consisting of the three-layer stacked nano hybrid structure of polyurethane-poly(3,4ethylenedioxythiophene) polystyrenesulfonate (PU-PEDOT:PSS)/single-wall carbon nanotube (SWCNT)/PU-PEDOT:PSS on a polydimethylsiloxane (PDMS) substrate. (b) Time-dependent $\Delta R / R_{0}$ responses of the sensor attached to the forehead when the subject was crying. Reprinted with permission from Ref. [34]. Copyright 2015, American Chemical Society. (c) Optical micrograph of a graphene woven fabrics (GWFs)-PDMS-tape composite film (scale bar $0.1 \mathrm{~mm}$ ). (d) Relative change of resistance between $0 \%$ and $0.2 \%$ strain. Reprinted with permission from Ref. [86]. Copyright 2014, John Wiley and Sons. (e) Schematic illustration of stretchable capacitor with transparent electrode (top) and photograph of the same device reversibly adhered to a backlit liquid-crystal display (bottom) (scale bar $1 \mathrm{~cm}$ ). (f) Change in capacitance $\Delta C / C_{0}$ versus strain $\varepsilon$ (top) and $\Delta C / C_{0}$ versus time tover four cycles of stretching (bottom). Reprinted with permission from Ref. [69]. Copyright 2011, Nature Publishing Group. (g) Schematic image of multicore-shell printing process for fiber-type capacitive strain sensor. (h) Normalized decay time output of the sensor for different walking speeds up to $4 \mathrm{mph}$. Reprinted with permission from Ref. [92]. Copyright 2015, John Wiley and Sons.

\subsection{Chemical Sensors}

Recently, wearable sensors that are capable of detecting of various signals have attracted substantial research interest because of their potential application in healthcare $[32,38,99]$ and environmental monitoring $[18,21]$. The chemical signals from environmental pollutants, chemical and biological warfare agents, and clinically-relevant biomarkers are related closely to the chemical signals from the human body [100-102], and, as a result, there is significant expectation that chemical sensors will eventually have a large share of the market for wearable sensors. Currently, the available commercial medical devices used to extract bodily fluids from patients, such as blood, urine, saliva, or tears cause pain and inconvenience for the patients [103]. Also, 24-h monitoring is required for certain diseases, so the patients' daily activities are restricted. Thus, research on chemical sensors that can be worn or attached to the body is a high priority in the healthcare field because it offers hope for minimizing the inconvenience of that user's experience, and it will enable 24-h monitoring of the status of patients.

\subsubsection{Gas Sensors}

With the increase in the problems associated with environmental pollution and threat of the use of biochemical weapons, it is highly desirable to have sensors that can detect the molecules of various gases, which would enhance our ability to protect people by providing information concerning the presence of hazardous gases at specific places and sounding alarm signals to protect the public [104,105]. To develop such a system, it is necessary to study wearable gas sensors that are light, inexpensive, and effective in providing timely warnings. This could be done by attaching gas sensors to arbitrary surfaces 
such as human skin, portable devices, live plants, and insects. There are many sensing mechanisms for detecting gas molecules, such as resistive mechanisms [106], piezoelectric devices [107], surface acoustic waves [108], electrochemical processes [109], and colorimetric methods [110]. Among the various sensing methods, wearable resistive, electrochemical, and colorimetric types of gas sensors have been studied extensively.

A resistive-type gas sensor operates based on the difference in the electrical resistance of various materials, such as metal oxides, conducting polymers, and graphene. Recently, graphene has been used extensively in wearable gas sensors due to its outstanding flexibility and high surface-to-volume ratio and its electrical response to adsorbed gas molecules on $\mathrm{sp}^{2}$-bonded carbon networks $[18,111-113]$. However, gas phase detection with graphene sensors is generally irreversible because this system relies on the adsorption of gas molecules on the graphene, and complete desorption of the adsorbed gas molecules is very challenging. In an attempt to solve this problem, Choi et al. reported centimetre-scale transparent graphene sensors for nitrogen dioxide $\left(\mathrm{NO}_{2}\right)$ gas that had laterally-integrated or vertically-integrated graphene heaters on a polyethersulfone (PES) substrate [37]. Figure 4a shows a photograph of a transparent, flexible single-layer graphene (SLG) gas sensor with built-in, bilayer graphene (BLG) heaters. Figure $4 \mathrm{~b}$ shows that the temperature of the SLG sensor can reach $165^{\circ} \mathrm{C}$ when the BLG heater temperature is $250{ }^{\circ} \mathrm{C}$. Figure $4 \mathrm{c}$ shows the recovery time constant $\left(\tau_{r}\right)$ after using the heaters to apply different temperatures. The $\tau_{r}$ can be extracted from the equation as $\Delta R / R_{0}(t)=\Delta R / R_{0}\left(t_{0}\right) \exp \left[-\left(t-t_{0}\right) / \tau\right]$, where $\Delta R / R_{0}$ is the change in the relative resistance, and $t_{0}$ is the time required to change the curvature of $\Delta R / R_{0}$. When the BLG heater was operated to increase the temperature $(T)$ of the SLG sensor, the $\tau_{r}$ was drastically shorter than that of room temperature $\left(T<100{ }^{\circ} \mathrm{C}, \tau_{r}>100 \mathrm{~s}\right.$, but for $T<250{ }^{\circ} \mathrm{C}, \tau_{r} \approx 11 \mathrm{~s}$ ). This combined sensor-heater device can detect concentrations of $\mathrm{NO}_{2}$ gas in the range of 0.5 to $40 \mathrm{ppm}$ (Figure $4 \mathrm{~d}$ ). In addition to graphene based gas sensors, Lui et al. demonstrated colloidal quantum dots (CQDs) based resistive type gas sensors for $\mathrm{NO}_{2}$ gas detection [114]. Because CQDs are nanocrystals of a few nanometers, they have an extremely large surface-to-volume ratio capable of active interaction with target gas molecules [115]. Lead sulfide $(\mathrm{PbS}) \mathrm{CQDs}$ were spin-coated on the gold electrodes patterned paper substrates for highly flexible gas sensors. Moreover, to improve the gas sensing performances, oleate ligands on the surface of PbS CQD was removed by sodium nitrite $\left(\mathrm{NaNO}_{2}\right)$ treatment, which contributed to enhancing the accessibility of CQD surfaces to gas molecules. Figure $4 \mathrm{e}$ shows the dynamic response of the gas sensors upon $\mathrm{NO}_{2}$ exposure/removal cycles with $\mathrm{NO}_{2}$ concentration of $0.5,2,5,10,30$, and $50 \mathrm{ppm}$, respectively. As shown in the inset of Figure $4 \mathrm{e}$, the sensor exhibited a sensitivity of $0.41 \mathrm{ppm}^{-1}$. Figure $4 \mathrm{f}, \mathrm{g}$ show the bending and fatigue properties of gas sensors. As shown in Figure $4 \mathrm{f}$, the response and reversibility of the sensor were fully retained at the bending angles of $50^{\circ}$ and $70^{\circ}$. Also, the gas sensor exhibits excellent reliability under repeated bending cycles of 5000 (bending angles of $50^{\circ}$ ).

An electrochemical gas sensor operates by reacting with gas molecules and creating an electrical signal. This sensor consists of a sensing electrode and a counter electrode that are separated by an electrolyte. When the target gas diffuses into the sensors, through the porous membrane to the working electrodes where it is oxidized or reduced. This electrochemical reaction generates an electric current flow between the sensing and counter electrodes. Electrochemical gas sensors are among the most promising approaches for wearable devices due to their low power consumption, low cost, high sensitivity, and high selectivity. Also, they can be operated easily by using a single microelectronics chip [116]. However, conventional electrochemical sensors have limited lifetimes because they use volatile electrolytes. To overcome this limitation, many researchers have replaced the volatile electrolytes with room temperature ionic liquids (RTILs). Unlike conventional electrolytes, RTILs are non-volatile, and they have negligible vapor pressure and high thermal stability. Mu et al. demonstrated a flexible electrochemical oxygen $\left(\mathrm{O}_{2}\right)$ gas sensor using an RTIL as the electrolyte with a porous polytetrafluoroethylene (PTFE) substrate [117]. The porous structure of the PTFE substrate is suitable for an electrochemical gas sensor membrane due to its outstanding chemical resistance, flexibility, and gas permeability. Figure 4e shows a micro-fabricated, flexible, RTIL-based gas sensor. 
$\mathrm{An}_{2}$ gas sensor can respond linearly to $\mathrm{O}_{2}$ gas concentrations ranging from 0 to $21 \%$, and Figure $4 \mathrm{f}$ shows that the sensor recovered fully from these responses when the $\mathrm{O}_{2}$ gas was removed.

In addition to the sensing mechanism mentioned above, colorimetric gas sensors are capable of producing a visually-recognizable signal, and they do not have some of the disadvantages associated with conventional gas sensors due to electrical issues with power sources, displays, and electronic circuits. Recently, Wang et al. reported a flexible, transparent, colorimetric $N, N$-dimethylformamide (DMF) gas sensor using a hierarchical polydiacetylene/molybdenum disulfide (PDA/MoS $)$ nanocomposite film [110]. PDA, as a typical conjugated polymer for colorimetric sensors, has novel properties of color and changes in fluorescence in response to external stimuli, e.g., temperature, $\mathrm{pH}$, and chemical stress. $\mathrm{MoS}_{2}$, with its nanoflake form, acts as a supporter for PDA films, thereby enhancing the surface-to-volume ratio. Figure $4 \mathrm{~g}$ shows the fabrication process of PDA/ $\mathrm{MoS}_{2}$ composite film and the sensor upon exposure to DMF gas. When the PDA/ $\mathrm{MoS}_{2}$ composite was exposed to $0.1 \% \mathrm{DMF}$ vapor, the peak intensity of optical adsorption at $\sim 640 \mathrm{~nm}$ (blue) decreased, and another peak appeared at $\sim 550 \mathrm{~nm}$ (red) (Figure 4h). A quantitative measure for the blue to red transition was given by the colorimetric response (CR), which was defined as $B_{i}=A_{\text {blue }} /\left(A_{\text {blue }}+A_{\text {red }}\right)$, where $A_{\text {blue }}$ was the absorbance at $\sim 640 \mathrm{~nm}$ and $A_{\text {red }}$ was the absorbance at $\sim 550 \mathrm{~nm}$. The $B_{i}$ of the PDA/MoS 2 composite film in the absence and presence of an DMF gas was recorded to calculate the vapor-induced $C R$. $\mathrm{CR}=\left(B_{0}-B_{1}\right) / B_{0} \times 100 \%$, where $B_{0}$ and $B_{1}$ were the percent of blue before and after DMF gas exposure, respectively. As the concentration of the DMF vapor increased, the absorption peak at $\sim 640$ $\mathrm{nm}$ gradually was weakened, and this was accompanied by increased intensity of the adsorption peak at $\sim 550 \mathrm{~nm}$, indicating that the PDA/ $\mathrm{MoS}_{2}$ has outstanding sensitivity to DMF vapor in the concentration range of $0.01 \%$ to $4 \%$ (Figure $4 \mathrm{i}$ ). Figure $4 \mathrm{j}$ shows the performance of sensors upon exposure to various vapors, including of methanol, chloroform, tetrahydrofuran, and DMF. The colour of the PDA $/ \mathrm{MoS}_{2}$ composite film changed to red in DMF vapor, but no changes in colour were observed in other vapors. As shown in Figure 4k, wearable wrist-strap DMF gas sensors based on the PDA/ $\mathrm{MoS}_{2}$ composite were demonstrated with high transparency, vivid colour changes, and outstanding flexibility and reliability, all of which suggests this composite has great potential for smart wearable devices. Although colorimetric gas sensors have provided a promising strategy for producing wearable gas sensors, there are still substantial challenges to their practical application, such as limits on the quantitative display of gas concentrations and the recovery of the sensors after removing target gases.
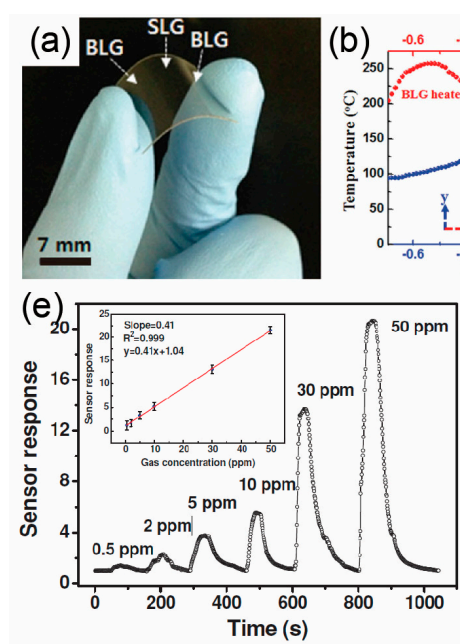
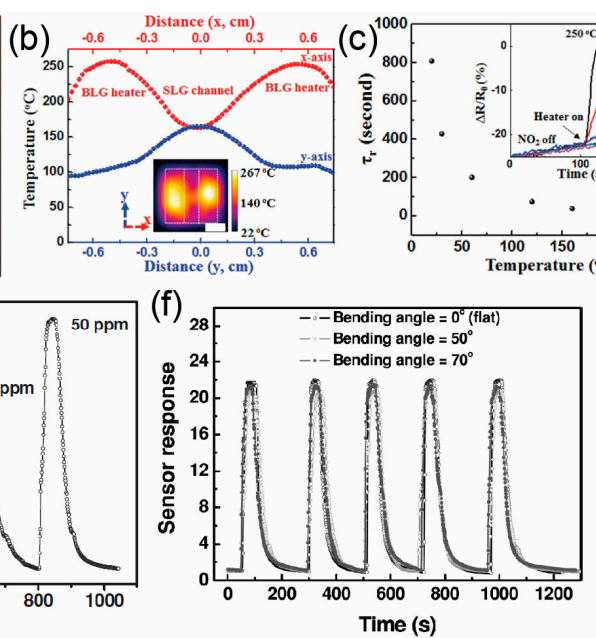
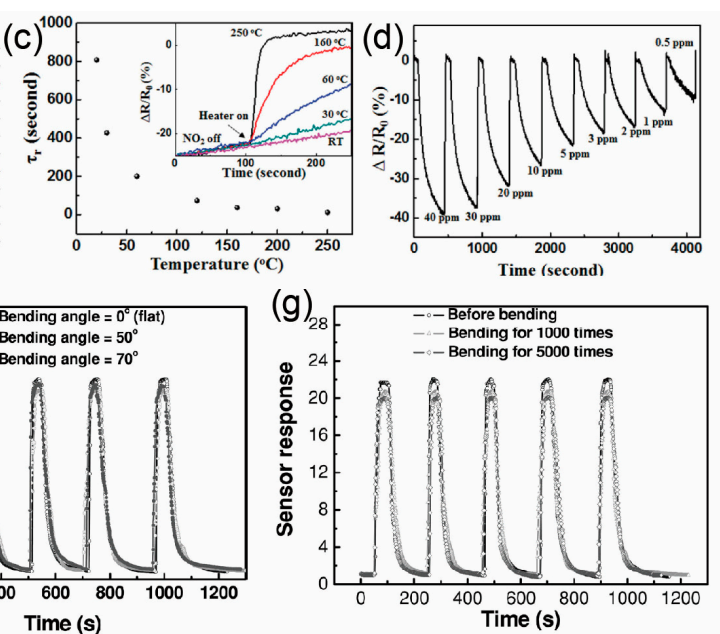

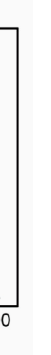

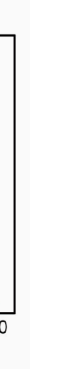

Figure 4. Cont. 

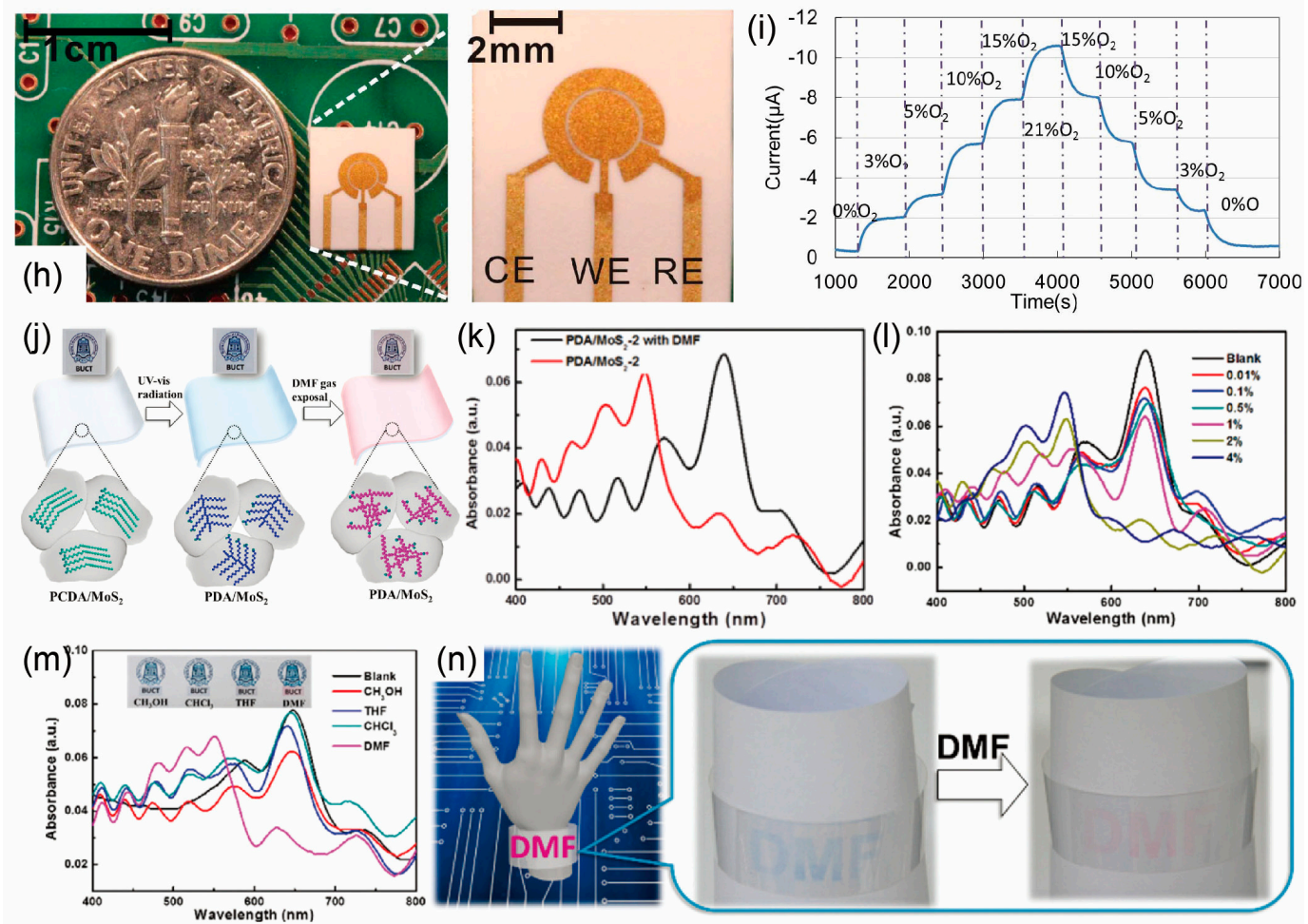

Figure 4. Wearable gas sensors and its integrated systems. (a) Photograph of transparent and flexible single-layer graphene (SLG) sensor channel-bilayer graphene (BLG) heater on a polyethersulfone (PES) substrate (scale bar $7 \mathrm{~mm}$ ). (b)Temperature distribution along transverse (x-axis) and longitudinal (y-axis) direction of sensor-heater device structured as laterally intercalated SLG sensor channel (6 mm width) between BLG heaters ( $7 \mathrm{~mm}$ width) with applied $1.7 \mathrm{~W}$ of electric power. Here the red dot and blue dot are temperature profiles of thermal image in inset along $x$-axis and y-axis with origin at center on channel, respectively. Inset: Spatial temperature distribution of graphene heaters (7 mm width) which intercalate $6 \mathrm{~mm}$ width graphene sensor with applied $1.7 \mathrm{~W}$. Here three broken squares indicate center channel and side heaters area, respectively (scale bar $7 \mathrm{~mm}$ ). (c) Recovering time constant $\tau_{r}$ as a function of heater temperature. Inset: the recovering curves of the $\Delta R / R_{0}$ as a function of time under different temperature range from room temperature to $250{ }^{\circ} \mathrm{C}$. (d) The relative resistance variation $\Delta R / R_{0}$ of SLG channels as a function of time including recovery step with 100 to $165^{\circ} \mathrm{C}$ heating under different $\mathrm{NO}_{2}$ gas concentration from 40 to $0.5 \mathrm{ppm}$. Reprinted with permission from Ref. [37] Copyright 2014, John Wiley and Sons. (e) Response curves of the sensor to $\mathrm{NO}_{2}$ of different concentrations. Inset: The sensor response depends linearly on $\mathrm{NO}_{2}$ concentration. (f) Response curves of the sensor to $50 \mathrm{ppm}$ of $\mathrm{NO}_{2}$ when tested under different bending angles. (g) Response curves of the sensor tested before and after bending 1000 and 5000 times (bending angle $=50^{\circ}$ ). Reprinted with permission from Ref. [114] Copyright 2014, John Wiley and Sons. (h) Photograph of microfabricated flexible room temperature ionic liquid (RTIL) based gas sensor (scale bars $1 \mathrm{~cm}$ and 2 $\mathrm{mm}$, respectively). (i) Current versus time curve at various oxygen concentrations when the potential is held at $-1.4 \mathrm{~V}$ vs. Au. Nitrogen is the background gas. Oxygen concentration steps up from $0 \%$ to $21 \%$ and steps down from $21 \%$ to $0 \%$. Reprinted with permission from Ref. [117] Copyright 2013, IEEE. (j) Schematic illustration of the preparation of the $\mathrm{PDA} / \mathrm{MoS}_{2}$ film and the sensor upon exposure to DMF vapor. (k) UV-vis spectra of polydiacetylene (PDA) $/ \mathrm{MoS}_{2}$ composites with an increased ratio of $\mathrm{MoS}_{2}$ to PDA in the absence and presence of $0.1 \%$ DMF vapor. (1) UV-vis spectra of PDA/MoS films exposed to $\mathrm{N}, \mathrm{N}$-dimethylformamide (DMF) vapor with different concentrations. (m) UV-vis spectra of the PDA/ $\mathrm{MoS}_{2}$ film upon exposure to different (5\%) vapors, in comparison with $2 \%$ DMF vapor. (n) Flexible transparent wrist strap with DMF sensing ability. Reprinted with permission from Ref. [110] Copyright 2017, Royal Society of Chemistry. 


\subsubsection{Ion Sensors}

In recent years, personalized healthcare systems have been emphasized substantially and explored extensively by many researchers, targeting people who desire to monitor their physiological status continuously and wish to detect any pathologies as early as possible. Electrolyte imbalances can be indicative of potential health problems, such as hyperkalemia, cystic fibrosis, physical stress, osteoporosis, and mineral loss in bones [118]. Thus, monitoring the core electrolytes, e.g., $\mathrm{H}^{+}, \mathrm{Na}^{+}, \mathrm{K}^{+}$, $\mathrm{Na}^{+}, \mathrm{Ca}^{2+}, \mathrm{Fe}^{3+}$, and $\mathrm{NH}_{4}{ }^{+}$, in biological fluids is very important in the diagnosis of latent diseases. Therefore, a wide variety of wearable devices have been developed to date, including skin patches, wrist watches, and chest bands $[119,120]$.

The most common analytes for wearable electrochemical sensors are $\mathrm{pH}$ and ions occupying 33\% of whole wearable electrochemical sensors [121]. In addition, healthcare and medical applications account for $46 \%$ of the total market. As a result, the development of a wearable device for sensing ions is essential in meeting current social needs. Electrochemical sensors generally utilize one of three representative analytical methods, i.e., potentiometric, amperometric, and voltammetric sensors. Each type of wearable electrochemical ion sensor, classified by the analytical method it uses, is discussed below.

Potentiometric sensors are the most used among the three types of sensors, and this is due to their simplicity, people's familiarity with them, and their comparatively low cost. One electrode is the working electrode, and its potential is determined by its environment. The second electrode is a reference electrode, and its potential is fixed by a solution that contains the ion of interest. Since the reference electrode has a constant potential, the value of the potential difference (cell potential) can be related to the concentration of the dissolved ions. Parrilla et al. fabricated highly-stretchable, textile-based potentiometric multi-ion $\left(\mathrm{K}^{+}\right.$and $\left.\mathrm{Na}^{+}\right)$sensors using polyurethane (PU)-based ion-selective membranes and inks with a serpentine sensor pattern [122] (Figure 5a). Instead of the common polyvinyl chloride (PVC) matrix, they used a PU membrane to achieve excellent biocompatibility [123] and additional resistance to mechanical stress, while providing exceptional analytical performance when the potentiometric technique was used [124]. For selective penetration of target ions, they fabricated sodium-selective membrane $\left(\mathrm{Na}^{+} \mathrm{SM}\right)$ and potassium-selective membrane $\left(\mathrm{K}^{+} \mathrm{SM}\right)$. The membranes were prepared by dissolving the mixture in THF $(1 \mathrm{~mL})$. Figure $5 \mathrm{~b}$ shows that the results from both the $\mathrm{K}^{+}$and $\mathrm{Na}^{+}$sensor arrays exhibited dynamic ranges that fully covered the physiological sodium and potassium levels in the subjects' sweat before, during, and after prolonged exercise. All of the sensors performed favorably within the linear range from $10^{-3}$ to $10^{-1} \mathrm{M}$, yielding a near-Nernstian response of the sensor. In addition, for sensing sweat, the sensor can be printed on various textile products that are commonly worn, such armbands, bandages, and underwear. In experiments to determine the resilience of the sensors, excellent mechanical stability was observed when the sensors were stretched, bent, crumpled, and washed in a beaker of water with vigorous agitation (1250 rpm). Overall, the wearable textile potentiometric array provides an attractive analytical performance before and after exposures to severe mechanical stress. As another application of the potentiometric ion sensor, Gao et al. presented wearable, flexible, integrated sensing arrays for simultaneous and selective screening of sodium ions and potassium ions, as well as other sweat metabolites and body temperature [38]. The measurement of $\mathrm{Na}^{+}$and $\mathrm{K}^{+}$levels is facilitated by the use of ion-selective electrodes (ISEs), coupled with a polyvinyl butyral (PVB)-coated reference electrode maintaining a stable potential in solutions with different ionic strengths. Figure $5 c$ shows the integrated wearable sensor system, which is smart wristwatch for real-time monitoring of perspiration. Also, Figure $5 \mathrm{~d}$,e indicate that the $\mathrm{Na}^{+}$and $\mathrm{K}^{+}$sensors had almost the same sensitivities, i.e., 62.5 and $59.5 \mathrm{mV}$ per decade of concentration, respectively, in ambient conditions. 
Amperometric measurements are made by recording the current flow in the cell at a given applied potential. However, voltammetric measurements exploit the potential difference across an electrochemical cell. When the potential is swept from one set value to another, the current in the cell is plotted as a function of the applied potential. In both cases, the electron transfer is the essential operational mechanism of the devices. Kwan et al. constructed an amperometric ion sensor for the analysis of phosphates in human saliva by immobilizing pyruvate oxidase on a screen-printed electrode [125]. Hydrogen peroxide $\left(\mathrm{H}_{2} \mathrm{O}_{2}\right)$ is generated by the enzyme reaction, depending on the concentration of phosphate in the human saliva. The sensor responds within $2 \mathrm{~s}$ after the addition of a sample of a standard solution sample, and it has a short recovery time ( $2 \mathrm{~min}$ ). This means that the time the sensor requires for each measurement is much shorter than the time required by a commercial kit for testing for phosphates, i.e., 2 and $10 \mathrm{~min}$, respectively. As an example of voltammetric methods, Park et al. presented a flexible and semi-transparent monolithic graphene-graphite field-effect transistor (FET) array for real-time sensing of $\mathrm{pH}$ [126]. The FET arrays we fabricated were composed of four blocks, each of which had nine individual FETs. The real-time, multiplexed, $\mathrm{pH}$-sensing outputs from each of the nine FET sensors describe complementary sensing mechanisms caused by the change in conductance, which depended on the concentration of the solution, and the sensors exhibited inverted responses in the p-type regime (water-gate voltage, $\left.V_{W G}=-0.1 \mathrm{~V}\right)$ and in the n-type regime $\left(V_{W G}=0.3 \mathrm{~V}\right)$. These inverted responses in each region expand the possibility for reducing electrical cross-talk or false-positive signals. While sweeping the silver $(\mathrm{Ag})$ / silver chloride $(\mathrm{AgCl})$ water-gate voltage at different $\mathrm{pH}$ levels, the point of charge neutrality shifted positively with increasing $\mathrm{pH}$, and its sensitivity was $\sim 17 \mathrm{mV} / \mathrm{pH}$ (Figure $5 \mathrm{f}$ ). Also, this flexible monolithic device can be integrated with various nonplanar surfaces, such as cylindrical glass tubes, contact lens, glove fingers, coins, and the epidermis of an insect, providing the versatility of flexible, wearable electronics, as shown in Figure $5 \mathrm{~g}$.

For another application of voltammetric measurements, Nyein et al. demonstrated a wearable electrochemical sensor for the continuous monitoring of ionized calcium and the $\mathrm{pH}$ of body fluids [127]. Measurement of calcium ions is known to be difficult because of the strict experimental procedure and its dependence on the $\mathrm{pH}$ value. Actually, ionized calcium binds to negatively charged sites on protein molecules, competing with hydrogen ions for the same binding sites [128]. This mechanism is $\mathrm{pH}$-dependent, and it alters the level of ionized calcium in the blood. Therefore, Nyein et al. fabricated a wearable, electrochemical-sensing platform to detect in a non-invasive and continuous manner the actual $\mathrm{Ca}^{2+}$ concentration in body fluids and the $\mathrm{pH}$ of these fluids, such as sweat, urine, and tears. Figure $5 \mathrm{~h}$ shows a fully-integrated, wearable, multiplexed sensing system that is composed of flexible sensor arrays and a flexible printed circuit board. The device is attached directly to human skin so that immediate analysis after the secretion of fluids is possible, and the lack of a time delay minimizes cross-contamination. In this study, the $\mathrm{Ca}^{2+}$ sensing electrode consists of a thin organic membrane containing electrically neutral carrier calcium ionophore II (ETH 129) and an ion-electron transducer (PEDOT:PSS), and the $\mathrm{pH}$ sensing electrode detects $\mathrm{H}^{+}$by deprotonation at the surface of polyaniline (PANI). The general performances of both $\mathrm{Ca}^{2+}$-based and polyaniline (PANI)-based $\mathrm{pH}$ sensors were evaluated by in-situ and ex-situ analyses. The sensitivity of an electrochemical $\mathrm{Ca}^{2+}$ sensor shows a near-Nernstian response with an average of $32.7 \mathrm{mV} /$ decade, and the sensitivity of the $\mathrm{pH}$ sensor exhibited an average slope of $62.5 \mathrm{mV} /$ decade with good selectivity (Figure $5 \mathrm{i}, \mathrm{j}$ ). 


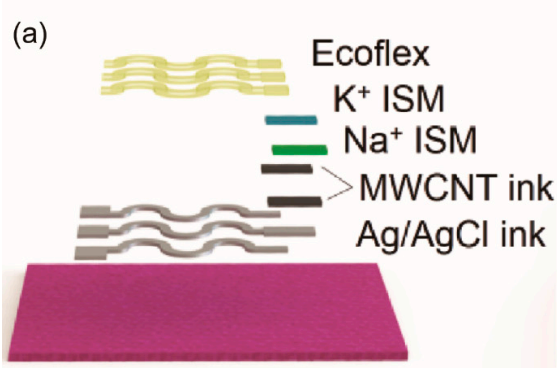

Textile
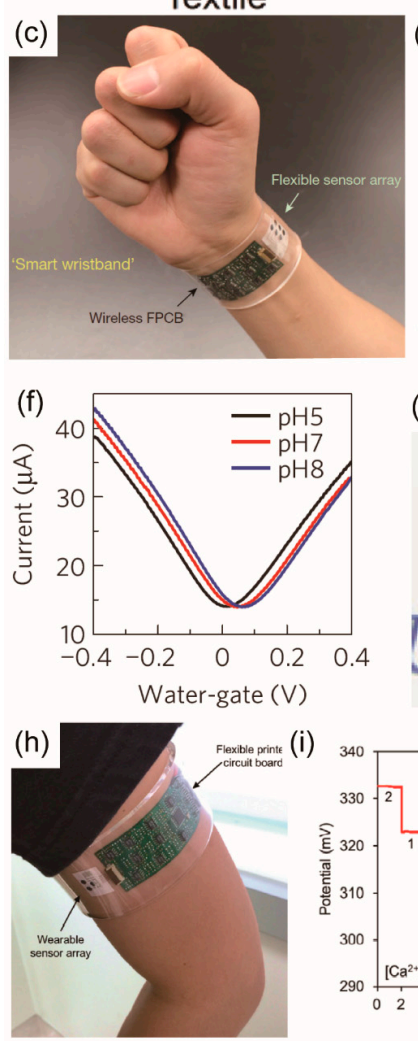

(d)

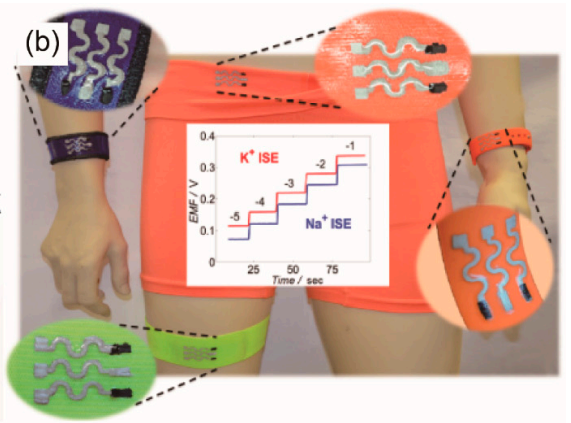

(e)
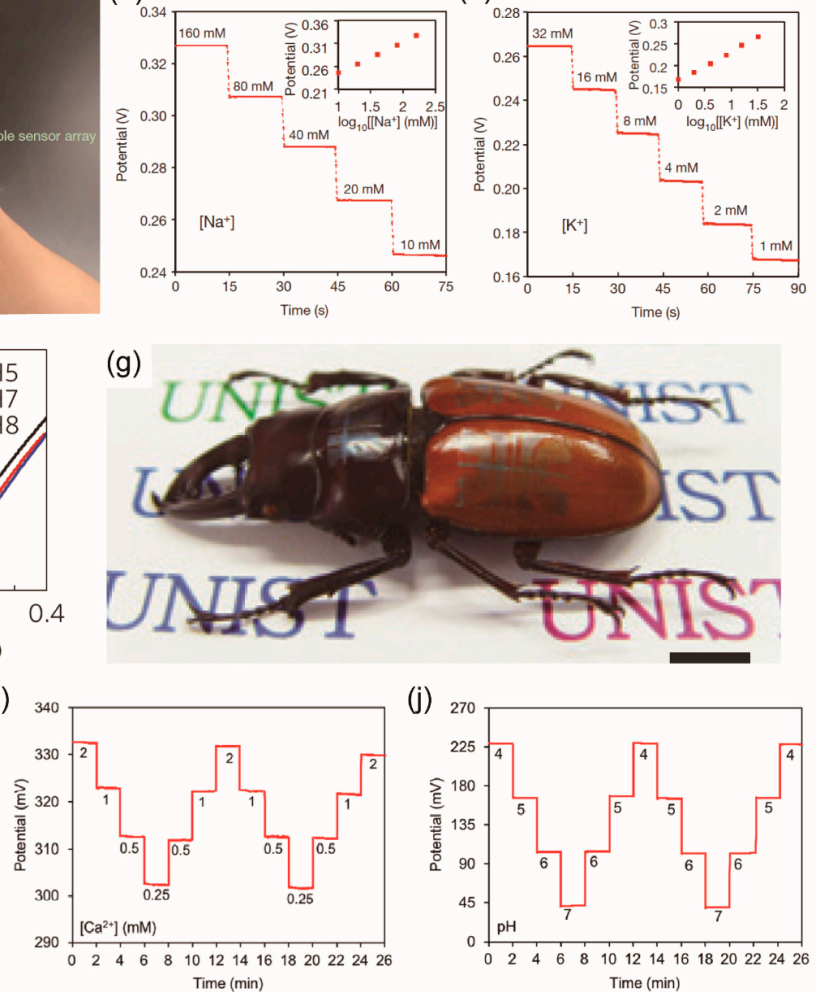

Figure 5. Wearable electrochemical ion sensors and its integrated systems. (a) Schematic representation of the tailor-made stretchable materials and manufacturing process. (b) Photograph of the printed sensors on different common textiles and typical time trace plots for potassium and sodium. Reprinted with permission from Ref. [122]. Copyright 2016, John Wiley and Sons. (c) Photograph of a wearable flexible integrated sensing array and the open circuit potential responses of $\mathrm{Na}^{+}(\mathbf{d})$ and $\mathrm{K}^{+}(\mathbf{e})$ sensor, respectively. Reprinted with permission from Ref. [38]. Copyright 2016, Nature Publishing Group. (f) Water-gate characterization at different $\mathrm{pH}$ levels. (g) Photograph of monolithic device structures transferred onto the epidermis of an insect. (scale bar $5 \mathrm{~mm}$ ). Reprinted with permission from Ref. [126]. Copyright 2012, Nature Publishing Group. (h) A fully integrated wearable sensing system on a subject's arm and general performance of $\mathrm{Ca}^{2+}(\mathbf{i})$ and $\mathrm{pH}$ (j) sensors. Reprinted with permission from Ref. [127]. Copyright 2016, American Chemical Society.

\subsubsection{Biosensors}

Biosensors are analytical devices that are used to detect biological analytes, such as glucose, lactate, DNA, and antibodies, by using physiochemical measurements. Since biological analytes reflect health problems, biosensors are being used in treating patients and providing healthcare. In addition, by making biosensors wearable, they can perform continuous and non-invasive monitoring of the biological analytes. Biosensors use various sensing methods, and wearable biosensors are being 
developed that use the electrochemical method, the FET-based electrochemical method, and the optical method $[129,130]$.

Electrochemical biosensors are conventional devices that are used to determine the concentration of biological analytes by directly converting a biological event into an electronic signal. These sensors consist of electrodes, which are the electrochemical transducers, and biorecognition materials. The interaction between the biorecognition materials on the electrodes of the sensor and the biological analyte produce changes in the values of the current and the potential, and these changes are measured [131-133]. Many fabrication methods have been studied for applying these sensors to wearable devices [119,134-136]. Windmiller et al. developed an electrochemical biosensor consisting of electrodes that were transferred onto non-planar surfaces by using stamp [135]. The screen printing approaches, which were published before their work, largely were confined to flat surfaces, which may restrict the potential utility of the method in the fields of electrochemical sensors and biosensors $[133,137]$. However, they have been used to transfer various conducting and insulating inks used as electrode materials to irregular surfaces, such as human skin, by using an elastomeric stamp that contained the electrode pattern. The biosensor formed on the skin can detect the concentration of uric acid.

Biosensors that can be attached to the skin in the form of tattoos also have been developed [119]. Jia et al. developed a flexible, printed, temporary-transfer tattoo electrochemical biosensor that conforms to the wearer's skin [136]. They described the first example of real-time, non-invasive, sensing of lactate in human sweat during exercise (Figure 6a). Such direct epidermal monitoring of lactate was conducted using tattoo sensors functionalized with lactate oxidase. Figure $6 \mathrm{~b}$ shows the resulting calibration curve that indicates the correlation between the current that is measured during evaluation of the epidermis and the absolute lactate concentration. This sensitive sensor exhibited a low noise level even at the $1 \mathrm{mM}$ concentration of lactate.

In recent years, electrochemical biosensors based on FET have been proven to be suitable for detecting biomolecules, because exposed regions of the semiconductor channel can be modified chemically with high-sensitivity functional groups or receptors. The working principle of these biosensors is similar to that of an electrochemical sensor, except that these biosensors use a different recognition layer in which the bio-material is immobilized and used as a transducer $[138,139]$. The interactions between receptor groups and their targets alter local electric fields, which causes variations in channel conductance, even at low target concentrations. Rim et al. created wearable and highly-sensitive glucose sensors by combining ultra-thin indium oxide $\left(\operatorname{In}_{2} \mathrm{O}_{3}\right)$ semiconductor-based FETs on the ultra-thin films. [40]. Ultra-thin $\mathrm{In}_{2} \mathrm{O}_{3}$ films, i.e., films that are only $3.5 \mathrm{~nm}$ thick, can avoid the intrinsic effects of strain, such as physical strain and peeling from substrates. Figure $6 \mathrm{c}$ shows conformal contacted devices on an artificial eye and on human skin with good adhesion, irrespective of the relaxation and tensing of the hand. Conformal contact occurred because the $1.7 \mu \mathrm{m}$ thickness of the device was less than $1.77 \mu \mathrm{m}$, the critical thickness of the device (Figure 6d). Glucose sensing was based on the oxidation of D-glucose by the enzyme glucose oxidase. Figure 6e shows the responses of $\mathrm{In}_{2} \mathrm{O}_{3}$ thin-film FET biosensors upon addition of different glucose concentrations. As the concentration of D-glucose was increased, changes in current responses were detected. Responses showed linear behavior. Also, these $\mathrm{In}_{2} \mathrm{O}_{3}$-based FET biosensors can be used for sensing over the wide range represented by the very low glucose level in tears and the comparatively high glucose level in blood (Figure 6e).

You et al. fabricated a graphene-based FET enzymatic glucose biosensor [140]. This biosensor detected glucose levels by measuring the differential drain-source current and the Dirac point shift of the graphene transistor. Glucose immobilized on the silk film on the graphene FET was oxidized by glucose oxidase, a biorecognition material. When silk is used as the substrate, flexible and biocompatible forms of biosensors can be used in wearable devices. The average sensitivity of the sensor was $2.5 \mu \mathrm{A} / \mathrm{mM}$ measured at $V_{d s}=100 \mathrm{mV}$ and $V_{g}=0 \mathrm{~V}$. These organic field-effect 
transistors (OFETs) possess beneficial properties, such as mechanical flexibility, printability, and low manufacturing cost, making them applicable in wearable sensors [141].

In addition to the types mentioned above, there are also optical biosensors that are based on measuring the changes in the intensity of light and converting light signals into electrical signals that can be recorded in the form of currents or potentials [142-144]. Badugu et al. used a colorimetry method to develop a glucose-sensing contact lens [143]. They doped boronic acid-containing fluorophores in the contact lens. Spectral changes in the contact lens occurred due to the interaction between sugar and the fluorophores. However, this sensor required a hand-held device that was used to flash light for non-UV excitation into the eye and measure the intensity of the emissions, making it difficult to provide continuous sensing information.
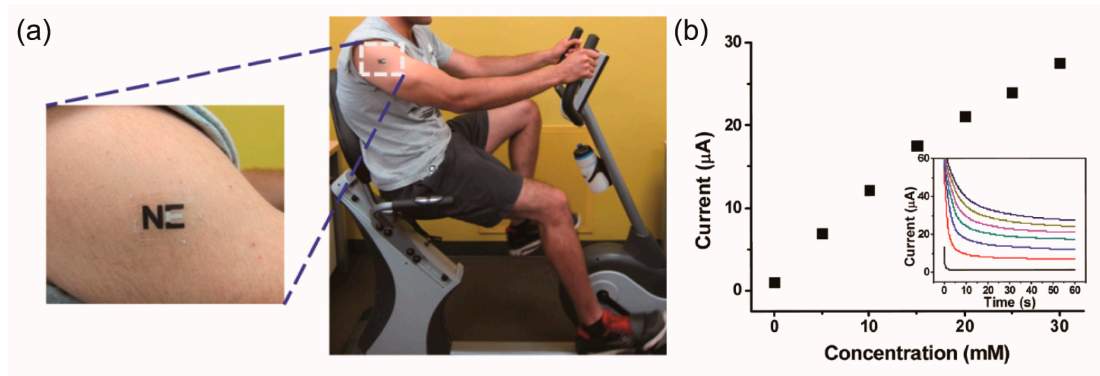

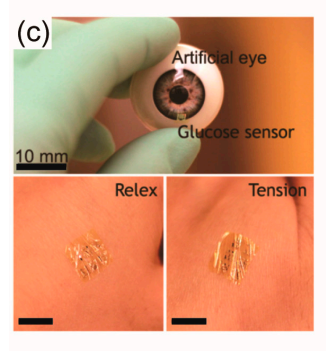

(f)
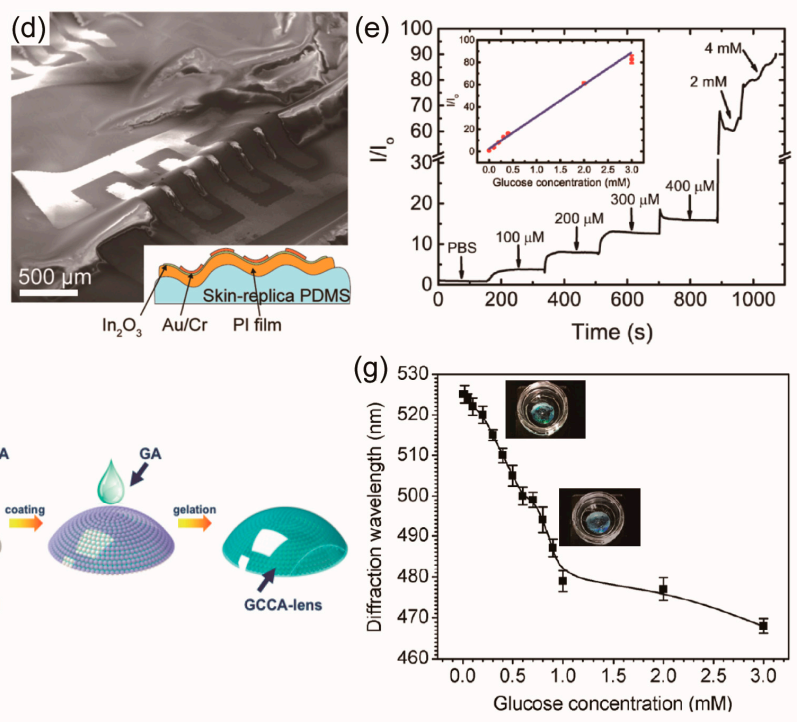

Figure 6. Wearable biosensors (a) The images of the temporary transfer-tattoo biosensor attached on deltoid. (b) Amperometric response as a function of lactate concentration for the sensor at $37^{\circ} \mathrm{C}$. Inset: profiles of current at different lactate concentrations. Reprinted with permission from [136]. Copyright 2013, American Chemical Society. (c) Conceptual images of conformally contacted devices on an artificial eye for glucose sensing in tears are shown. Thin-film sensors remained in contact with skin even during tension and relaxation (scale bars $10 \mathrm{~mm}$ ). (d) Scanning electron microscope image of a representative device (thickness of $1.7 \mu \mathrm{m}$ ) on an artificial PDMS skin replica indicating conformal contact between the device and the substrate (scale bar $500 \mu \mathrm{m}$ ). (e) Representative responses of In2O3 sensors to physiologically relevant D-glucose concentrations found in human diabetic tears (lower range) and blood (upper range). Inset: data from five devices. Error bars represent standard deviations of the means. Reprinted with permission from Ref. [40]. Copyright 2013, American Chemical Society. (f) The preparation route of the 4-boronobenzaldehyde (4-BBA)-modified poly(vinyl alcohol) (PVA) gelated colloidal crystal array (GCCA)-lens. (g) The diffraction response at low glucose concentration. Insert: the photograph of the GCCA-lens sample. Reprinted with permission from Ref. [144]. Copyright 2017, MDPI AG. 
Ruan et al. fabricated a gelated colloidal crystal array (GCCA)-lens that provided rapid visual detection of analytes through colorimetric determinations of concentrations without additional instruments [144]. These sensor materials were attached to a gas permeable contact lens by gelating a crystalline colloidal array (CCA) embedded in a hydrogel matrix (Figure 6f). This physical gelation method enabled the construction of a hydrogel-based CCA on the irregular surface. When the diols and borate ions in the hydrogel combined with glucose, the volume of the hydrogel was changed, leading to a shift in the diffraction wavelength, which appears as a lens color offset. The change in volume, which is directly proportional to the change in thickness, can explain the shifts in diffracted wavelength by Bragg's law: $\lambda=2 n d \sin \theta$, where $d$ is thickness of a given layer in this case, $\lambda$ is wavelength, $n$ is refractive index, and $\theta$ is the Bragg angle (during measurements, $\theta=90^{\circ}$ ). Figure $6 \mathrm{~g}$ shows the diffraction wavelength shift at a relatively lower glucose concentration before the turning point. GCCA-lens' response the color changes between green and blue within the tear glucose concentration region (0 to $1 \mathrm{mM})$.

\section{Multiplexed Sensors}

With the development of wearable sensors with excellent flexibility and stretchability, it has become possible to detect various signals, such as temperature, strain, and the presence of ions, and research applications are being expanded. As a result of the additional research, multiplexed sensors have been reported that are capable of simultaneously acquiring and analyzing more information and signals from the natural environment using various single sensors.

Gao et al. developed a wearable, wrist-band sensor that combined a flexible multiplexed sensor and a flexible, printed circuit board (FPCB) [38]. Figure 7a shows a wearable flexible integrated sensing array (FISA) that can simultaneously measure skin temperature during both indoor and outdoor long-term physical activity as well as metabolites and electrolyte panels for human sweat at the same time. By fabricating the flexible sensor on a polyethylene terephthalate (PET) substrate, a stable sensor-skin contact is formed and the FPCB technology uses an easily available integrated circuit to form a component (Figure $7 \mathrm{~b}$ ). This multiplexed sensor can sense a variety of signals through the human skin. For example, exorbitant loss of sodium and potassium in sweat could cause hyponatremia, muscle cramps, hypokalemia, and dehydration [145]; glucose in sweat has been reported to be metabolically related to serum glucose [146]; lactate in sweat can potentially serve as a sensitive marker of pressure ischemia [147], and the temperature of the skin is clinically informative concerning a variety of diseases and skin injuries, such as pressure ulcers [42,148]. In addition, skin temperature measurement is required to compensate and remove the effect of temperature change on readings of chemical sensors through the built-in signal processing device. The performance of each sensor was monitored separately from other analytical solutions. All five sensors are integrated in FISA, and simultaneous system level measurements maintain excellent selectivity when the concentration of each analyte is varied as shown in Figure 7c. The multiplexed sensor was attached to human wrist.

Lee et al. implemented a stretchable multiplexed sensor using a serpentine Au electrode on a cellular substrate with a honeycomb structure. It was confirmed that even though the completed sensor were stretched up to $30 \%$ by the Au serpentine electrode and hexagonal honeycomb structure without deformation, as shown in Figure $7 \mathrm{~d}$ [149]. In addition, $\mathrm{Ca}^{+}, \mathrm{K}^{+}$, and $\mathrm{H}^{+}$ions can be detected in the device. 


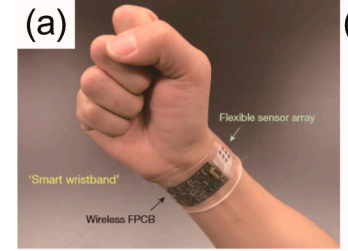

(e)
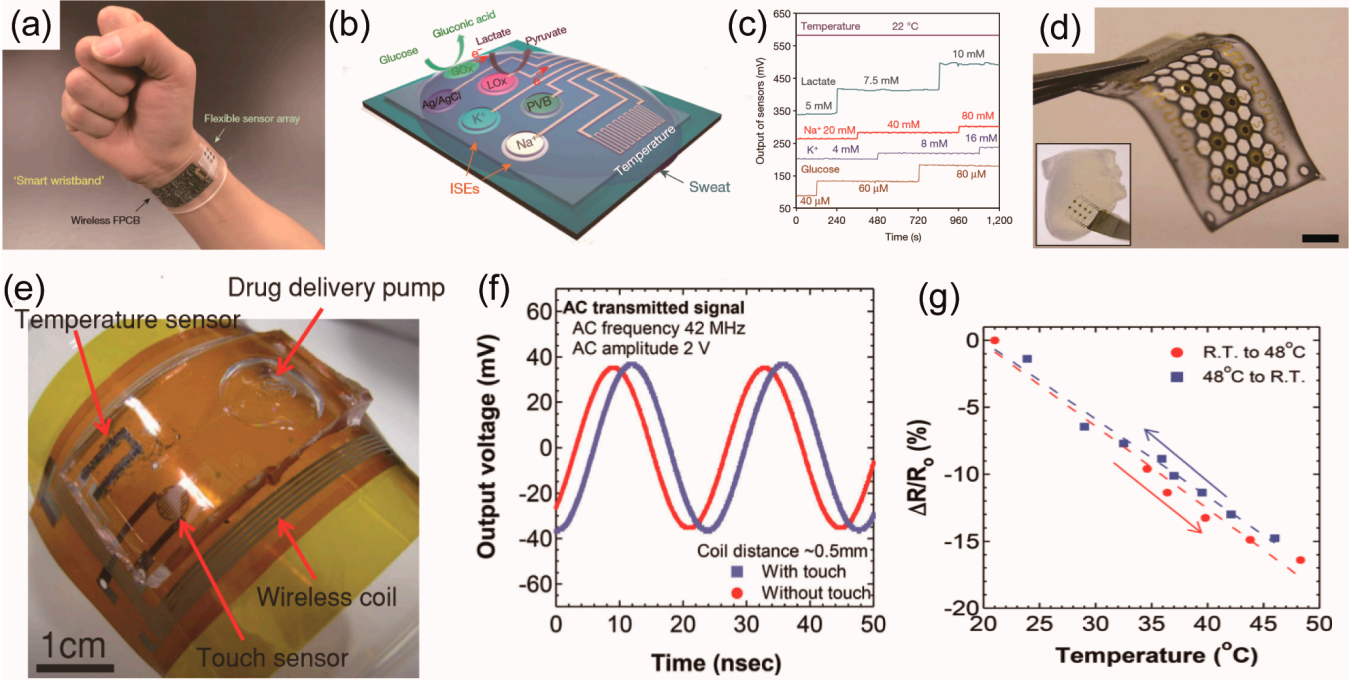

(g)
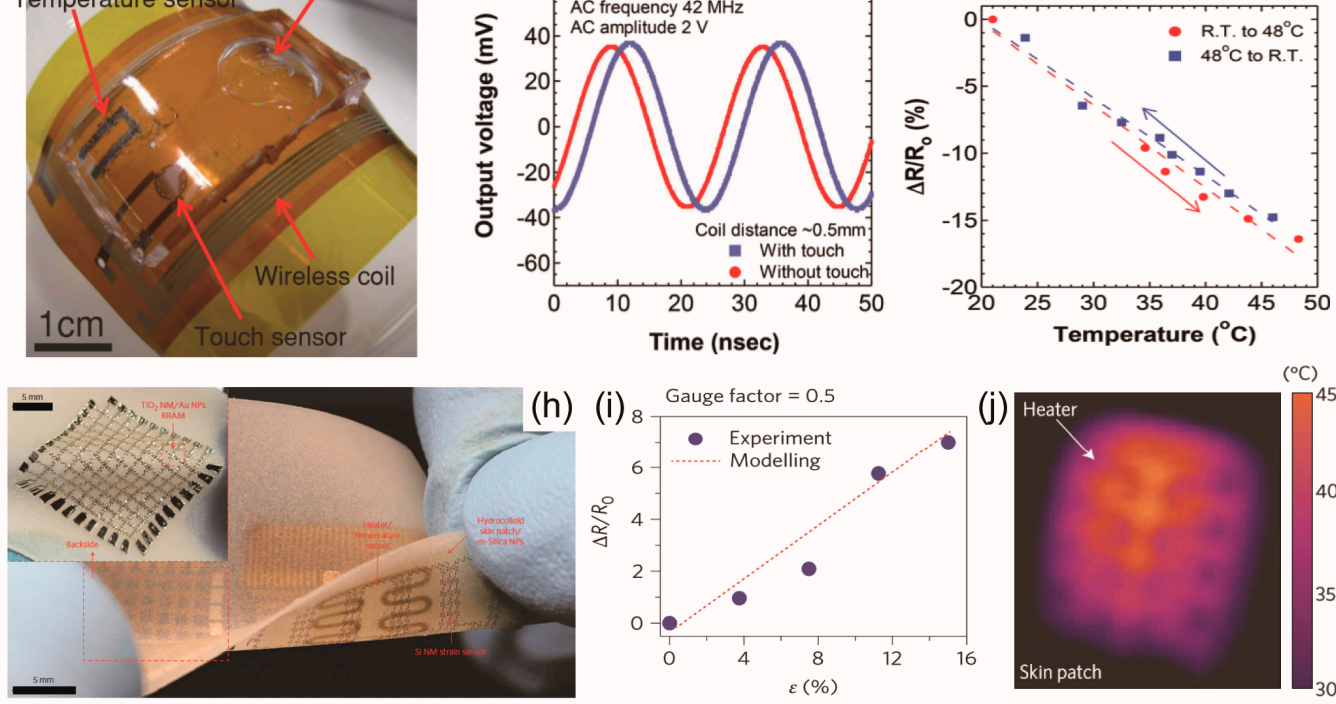

(h)
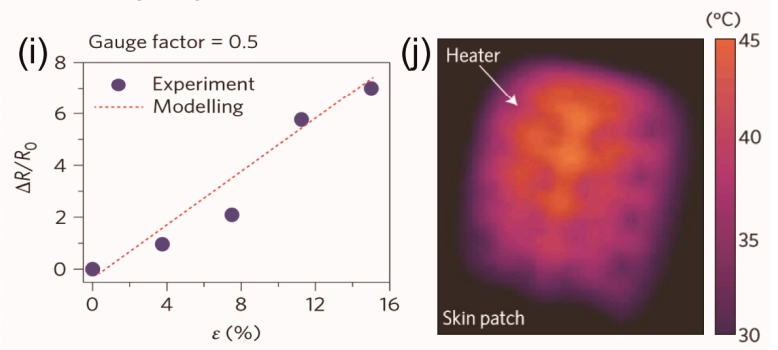

Figure 7. Wearable multiplexed sensors. (a) Photograph of a wearable flexible integrated sensing array (FISA) on a subject's wrist, integrating the multiplexed sweat sensor array and the wireless flexible, printed circuit board (FPCB). (b) Schematic of the sensor array (including glucose, lactate, sodium, potassium and temperature sensors) for multiplexed perspiration analysis. GOx and LOx, glucose oxidase and lactate oxidase. (c) System-level interference studies of the sensor array. Reprinted with permission from Ref. [38]. Copyright 2014, Nature Publishing Group. (d) Optical image of the fabricated ion sensor on a cellular substrate. Ion sensor mounted on a rabbit heart model constructed from agarose gel (inset). (scale bar $2 \mathrm{~mm}$ ) Reprinted with permission from Ref. [149]. Copyright 2014, John Wiley and Sons. (e) Photograph of the fabricated smart band. (f) Output AC signal with and without touching. (g) Normalized resistance change as a function of temperature. Reprinted with permission from Ref. [62]. Copyright 2014, John Wiley and Sons. (h) Photographs of the wearable bio-integrated system. Inset: Wearable $10 \times 10$ RRAM array on the hydrocolloid side of the patch (scale bars $5 \mathrm{~mm}$ ). (i) Plot of percentage change in resistance versus strain for calculation of the gauge factor (j) Temperature distribution measurement of the heater on the skin patch using an infrared camera. Reprinted with permission from Ref. [99]. Copyright 2014, Nature Publishing Group.

Another development direction of multiplexed sensors, i.e., a multiplexed sensor for medical purposes, was developed by combining various sensors and drug-delivery devices. These wearable devices are capable of measuring vital signals in real time, and they have the merit of providing more stable and detailed treatment by injecting the appropriate amounts of drugs every hour.

Honda et al. developed an initial type of multiplexed sensor for therapy [62]. A capacitance-type touch sensor and temperature sensor were fabricated on a polyimide (PI) substrate to produce a flexible, multiplexed sensor, as shown in Figure $7 \mathrm{e}$. There is a $1.6 \mathrm{mV}$ amplitude difference and a $44^{\circ}$ phase shift with the touch sensor, confirming that the device can successfully detect a touch wirelessly (Figure 7f). Also, the temperature change was measured with a resistor using PEDOT:PSS and CNT (Figure 7g). In addition, a drug chamber using PDMS was fabricated to develop a device capable of putting the drug into the skin using the pressure applied to the chamber. 
Son et al. demonstrated wearable bio-integrated systems with optimized performance of data storage, diagnostics, and drug delivery functionality in stretchable formats; their systems were enabled by the integration of bottom-up nanoparticles and top-down nanomembranes (Figure 7h) [99]. In treating Parkinson's disease, medication is needed to relieve seizures. It is also important to sense the cramps before they become severe so that small amounts of the drug can be infused continuously rather than injecting large amounts at once. In the case of the multiplexed sensor that was developed, a silicon nanowire (SiNW)-based strain sensor measures muscle spasms, puts the results into a memory device, analyzes the results, and heats the heater to inject the drug into the skin at the silica nanoparticle layer, as shown in Figure 7i,j. This system has the advantage of making it possible to perform more stable care by injecting a small amount of drug at that time instead of about drug injection at a time.

In addition, sensors for various purposes have been developed by combining various sensors to sense the surrounding environment and synthesizing the results.

\section{Wireless Sensors}

Wearable sensor technology is essential for monitoring the status of people's health in an industrial environment $[78,79]$. Wireless systems on wearable sensors have been studied to wirelessly operate the devices as well as to deliver sensing signals to the external detectors, which leads to continuous monitoring of the internal physiological parameters of the human body [150-153]. For wireless operation, sensors have been developed that incorporate resonant antennas into resistor, inductor, and capacitor(RLC) circuits, which consist of a resistor $(R)$, an inductor $(L)$, and a capacitor (C) [6]. The resonant antenna is a radiative element in the circuits, and it is used in most real applications. Because the resonance frequency $\left(f_{r}=1 / 2 \pi \sqrt{L \times C}\right)$ enables the capacitive and inductive reactance to be canceled each other out and wirelessly delivers the maximum amount of energy. The physical properties of capacitance and inductance determine the frequency of the antenna, so that changes in resonance frequency of the antenna coil exhibit the changes of the passive components in the circuits. These concepts enable the electronics to be miniaturized designing wearable sensors that do not require batteries, which makes wireless, skin-mounted devices possible.

In addition, wearable health-monitoring systems integrated with the wireless communication modules can transfer data wirelessly to a distant server in a healthcare facility. In order to do this, the physiological signals measured by the sensors require a two-step communication to deliver the data to the server [154]. The first step is short-range communication. In this step, the sensor transmits the signals to nearby gateway nodes, such as a smartphone, a computer, or a personal digital assistant (PDA). In the second step, the information gathered on the gateway nodes is transmitted to the remote health server through the Internet or a telecommunication system. During the first step, the wearable sensors transmit the data to the gateway nodes over a prolonged period of time through a wired or wireless medium. However, the wired connection may limit the user's mobility or lead to a failed connection with the devices. Thus, the integration of wearable sensor with wireless technology is preferred, and data-transfer modules, such as Bluetooth, ZigBee, and near-field communication (NFC), have been combined with wearable sensors [155-157]. Recently, the remarkable improvements in the designs of flexible and stretchable devices and of packaging technologies have enabled skin-mounted or implantable devices to be integrated with Bluetooth or NFC modules, and this leads to the possibility of accessing remote healthcare via mobile electronic devices.

\subsection{Resonance Antenna Integrated Sensors}

A resonance antenna integrated sensor is based on the electrical RLC resonant circuit, so the sensing results can be monitored by the change in the impedance according to the change in resistance $(R)$ or capacitance $(C)$. Using this concept, wireless sensors can be demonstrated by the integration of resonance antenna and electronic sensors or capacitive sensors $[18,32,158,159]$. In the wireless sensors 
based on electronic sensors, the change in resistance of coils induces the modulation of reflection value (S11) by following the Equation (1),

$$
\mathrm{S} 11=\frac{\omega^{2} M_{12}^{2}}{2 Z_{1} Z_{2}+\frac{2 \omega^{2} M_{23}^{2} Z_{1}}{Z_{3}}+\omega^{2} M_{12}^{2}}
$$

where $M_{x y}$ and $Z_{x}$ are the coupling coefficient and resistance of reader coil (1), resonate coil (2), and load coil (3), respectively. Their resonance frequency is constant due to no change in capacitance. Furthermore, in the wireless sensors based on capacitive sensors, the detection is realized by the shift of resonance frequency due to the change of capacitance [32,160]. Also, in the case of resonance antennas, it is possible to fabricate antennas with in-plane structures that do not require additional or bulky device chips and energy storage devices [18,32,38,158,159,161]. Therefore, unlike other communication systems, such antennas are fairly easy to miniaturize. In addition, the replacement of antenna electrode materials and the modification of antenna designs make it possible to easily implement wearable and wireless electronics. For these reasons, many groups have conducted extensive studies of wearable and wireless sensors based on resonance antennas, and such sensors have been used in many applications [18,32,158-160,162].

Wearable and wireless sensor platforms based on resonance antennas can be utilized as advanced wearable biosensors $[12,160,162]$. The wearable biosensors have been studied extensively because they can rapidly detect various biomarkers that represent the status of the human body. Mannoor et al. fabricated wearable and wireless sensors to detect bacterial cells (such as Escherichia coli (E. coli), Staphylococcus aureus (S. aureus), and Helicobacter pylori (H. pylori)) on a silk substrate, as shown in Figure 8a [159]. The sensors are very thin $(\sim 50 \mu \mathrm{m})$, so they can be attached to objects with rough surfaces, such as enamel. Figure $8 \mathrm{~b}$ shows a sensor that was fabricated to exhibit high sensitivity with a low detection limit of $\sim 100$ bacterial cells. In addition, Kim et al. explored stretchable, transparent, and wireless sensors based on AgNW-graphene hybrid conductors to detect protein (Concanavalin $\mathrm{A}(\mathrm{Con} \mathrm{A})$ ), as depicted in Figure 8c [12]. In this platform, the graphene acts as a sensing channel layer to detect Con A, and its resistance is changed by the detection of Con A. As a result, the impedance in the RLC circuit and the reflection coefficient at the resonance frequency are modulated (Figure 8d). Furthermore, the investigated sensors could be stretched up to $20 \%$ strain due to the intrinsic stretchability of the AgNW-graphene hybrid structures, so they could be operated wirelessly and stably even on human skin.

Resonance antenna-integrated wearable sensors also have been studied for environmental monitoring [18]. Jun et al. fabricated a wireless and flexible gas sensor based on the carboxyl group functionalized polypyrrole (C-PPy) to detect volatile organic compounds (ammonia and acetic acid), as shown in Figure 8e [163]. By integrating the resonance antenna, the wireless sensors can measure 0.1 part per million (ppm) of ammonia vapor through the difference in the reflection coefficient at the resonance frequency (Figure 8f). In addition, their performances were acceptable during deformations (rolling or twisting) because the devices are so thin. Park et al. explored stretchable and transparent gas sensors based on AgNW-graphene hybrid electrodes [18]. Due to their superior stretchability (stable up to $20 \%$ strain), the gas sensors could be mounted onto various objects with large roughness, such as a leaf of a live plant (Figure 8g), and they can monitor dimethyl methylphosphonate (DMMP) vapor at concentrations as low as $5 \mathrm{ppm}$ (Figure $8 \mathrm{~h}$ ). These results offer promising strategies for their use in wireless and wearable electronics, which also is represented to the Internet of Things (IoT). 

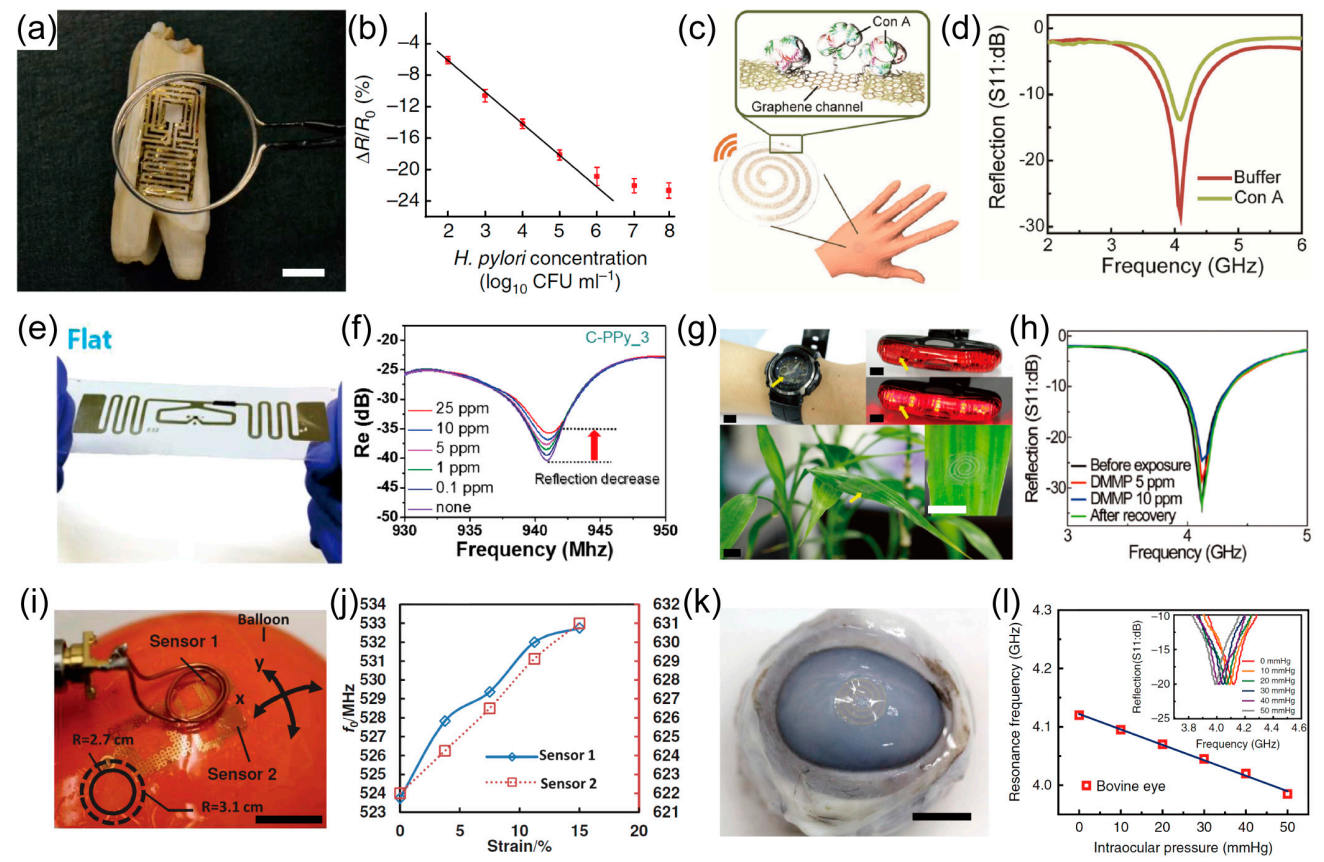

Figure 8. Wearable sensors integrated with resonance antenna. (a) Optical image of the graphene-based wireless sensor transferred onto the surface of a tooth (scale bar: $1 \mathrm{~cm}$ ). (b) graphene resistance change versus concentration of H. (a,b) Reproduced with permission from Ref. [159]. Copyright 2012, Nature Publishing Group; (c) Schematic of the biosensor attached to the skin on the back of a human hand; (d) Frequency response of the reflection coefficient of the antenna on the plastic substrates after buffer and Con A treatment. (c,d) Reproduced with permission from Ref. [12]. Copyright 2015, John Wiley and Sons; (e) Photographs of the RFID tag sensor; (f) Change in the reflectance properties. (e,f) Reproduced with permission from Ref. [163] Copyright 2016, American Chemical Society. (g) Optical photos of wearable gas sensors integrated with resonance antenna transferred onto various substrates (wristwatch, light of bicycle, and a leaf of live plant) (scale bars: $1 \mathrm{~cm}$ ). (h) change in reflection coefficient (S11) of the wireless sensor on the leaf at varied DMMP vapor concentrations (before exposure, 5 ppm of DMMP, 10 ppm of DMMP, and after recovery). (g,h) Reproduced with permission from Ref. [18]. Copyright 2016, Royal Society of Chemistry. (i) Image of a wireless epidermal sensor attached onto the surface of a balloon to simulate measurement of lymphedema. Scale bar, $1 \mathrm{~cm}$. (j) Change in resonance frequencies of strain sensors under the expansion of the balloon. $(\mathbf{i}, \mathbf{j})$ Reproduced with permission from Ref. [160]. Copyright 2014, John Wiley and Sons. (k) Photograph of the sensor transferred onto the contact lens worn by a bovine eyeball. Scale bar, $1 \mathrm{~cm}$. (l) Frequency response of the intraocular pressure sensor on the bovine eye from $5 \mathrm{mmHg}$ to $50 \mathrm{mmHg}$ (Inset: the corresponding reflection coefficients of the sensor). (k,1) Reproduced with permission from Ref. [32]. Copyright 2017, Nature Publishing Group.

Wearable sensors integrated with resonance antennas also can measure physical parameters, such as strain and pressure $[32,151,160,164,165]$. The advanced sensor platforms possess both wearability and wireless communication capability, so they easily can monitor the physical parameters of the human body by merely mounting them on the human body (e.g., skin or tissue) [160]. Huang et al. studied wirelessly operable strain sensors for monitoring health/wellness (e.g., lymphedema or edema), as shown in Figure 8i [160]. They produced wearable and wireless strain sensors by using electrodes and antennas that had serpentine structures. Figure $8 \mathbf{j}$ shows the perpendicularly oriented strain sensors on the surface of an expandable balloon that wirelessly measured the biaxial strain of $15 \%$ by the shift of their resonance frequency. As shown in Figure 8k, Kim et al. recently presented wearable, transparent, and wireless sensors for detecting intraocular pressure to diagnose glaucoma [32]. The sensors for intraocular pressure require both high stretchability and high transparency, because 
they must be mounted directly on the eyeball in order to acquire the desired measurements. Thus, the sensors were demonstrated by using the stretchable and transparent AgNW-graphene hybrid structures. In these sensors, the intraocular pressure can be detected by the shift in the resonance frequency since an increase in the intraocular pressure results in a decrease in thickness of the elastomer that is placed between two inductive coils. Subsequently, the decrease in thickness of elastomer causes a change in the capacitance and a shift in the resonance frequency. Based on this sensing principle, the sensors can detect the physiologically relevant range of intraocular pressure, i.e., from 5 to $50 \mathrm{mmHg}$ (Figure 81).

Based on the results that have been mentioned, diverse wearable sensors integrated with resonance antenna can be miniaturized quite easily. However, these systems have several limitations, including undesired shifts in the resonance frequency or other properties due to the deformation and the short transmitting distance $[6,160,166]$. Also, the sensor platforms that use resonance antennas require bulky devices for the measurements, so they have limited portability $[160,164,165]$. Thus, it is essential to demonstrate wearable and wireless sensor platforms that use portable measuring devices (e.g., smartphones).

\subsection{Bluetooth Integrated Sensors}

Since wearable sensor technologies have enhanced people's quality of life it has become important to exchange information about their physiological condition and motion activities in real time through mutual transfers of information between the devices and monitoring systems [154]. The exchange of information through mutual transfers is measured by the sensors connected in various wireless systems, such as Zigbee [156,167], Bluetooth [168-170], Infrared Data Association (IrDA), Wireless Local Area Network (WLAN) [171], and NFC [172]. Among the various wireless transmission technologies, Bluetooth uses a frequency range from 2.4 to $2.485 \mathrm{GHz}$, which is industrial scientific and medical (ISM) frequency band, and it uses one of the 79 designed channels. It can avoid interference between the systems by using a frequency-hopping method that uses multiple frequencies alternately instead of one frequency. The reasons Bluetooth is getting attention in the field of wireless wearable sensors are (1) it can be used at low cost and low power; (2) the transmission of data can be divided over multiple frequencies because Bluetooth divides the frequency band; and (3) Bluetooth signals, unlike infrared rays, can be transmitted through obstacles, such as walls, so there is no need to visually check the status of the wiring and connections. In addition, it is an indispensable part of the wearable wireless sensor field because many countries around the world use the same technology to comply with Bluetooth standards. Bluetooth is a short-range, RF-based industry standard for the inter-operation of smart devices. It is used extensively for wearable devices at low power and low cost, and it can transmit a maximum distance of $100 \mathrm{~m}$ at a maximum data transmission rate of $24 \mathrm{MB} / \mathrm{s}$. Previously, the mutual transfer performance of the Bluetooth was insufficient, and there were many restrictions due to the size of the Bluetooth module for wearable devices. However, due to the recent development of flexible electronic materials, extensive research has been conducted using flexible devices in which wireless communication modules are integrated using a flexible substrate and electrodes. Wearable devices with an integrated Bluetooth module have been studied in recent years because of the miniaturization of the Bluetooth module and the improvement of mutual transfer performance.

As described by Gao. et al., a wearable, multi-sensor, which enables the detection of electrolytes, such as sodium and potassium ions, glucose, and lactate, can be integrated with the Bluetooth module to wirelessly monitor the physiological information contained in people's sweat [38]. This wireless sensor enables users to check an individual's health condition in real time through a smartphone. In addition, it is capable of storing sensing data through mutual transfer between mobile devices and the Bluetooth module. As shown in Figure 9a, this sensor can be used to measure people's sweat in real time while a subject is wearing a 'smart headband' and a 'smart wristband' during stationary cycling. This sensor is fabricated to detect a human sweat to extract the complex information from sweat. It is also a fully integrated multiplex detection system, which is sensed by the potential difference of the 
electrolyte through mechanisms such as biomarker partitioning and passive or active partitioning [173]. These real-time sensing results of the sodium and glucose sensor measured on the body are comparable to the ex situ results (Figure 9b). To measure the uric acid in people's saliva(SUA), Kim et al. fabricated a wirelessly-operable mouth-guard biosensor in which both the sensor array (red box) and the module (green box) were loaded, as shown in the Figure 9c [29]. To use the device inserted in the body for a long term, they used Bluetooth Low Energy (BLE) technology, which enable them to reduce the power consumption [170,174]. Choi et al. fabricated a wearable gas sensor with the capability of Bluetooth communication. The sensor was fabricated on a polyimide film by using graphene oxide, and it detected chemical substances, including $\mathrm{H}_{2} \mathrm{~S}, \mathrm{C}_{2} \mathrm{H}_{5} \mathrm{OH}$, and $\mathrm{H}_{2}$ [175]. The integration of the Bluetooth module with the sensor can be used for wirelessly monitoring the individual's environment and status. Lee et al. fabricated a flexible textile strain sensor by using carbon hybrid materials (carbon nanotube/reduced graphene oxide) as electrodes and $\mathrm{ZnO}$ nanowires as the active channel layer. The sensor was integrated with a Bluetooth module for real-time detection of the strain variation due to the subject's movements (Figure 9d). Figure 9e shows that the sensor was attached to the subject's clothes, and the sensing results were displayed on a smartphone when the subject bends an arm. These wearable strain sensors integrated with Bluetooth modules are expected to be used in the healthcare field as well as in the sportswear, automotive, aeronautic, medical applications, industrial safety, and other fields [83].
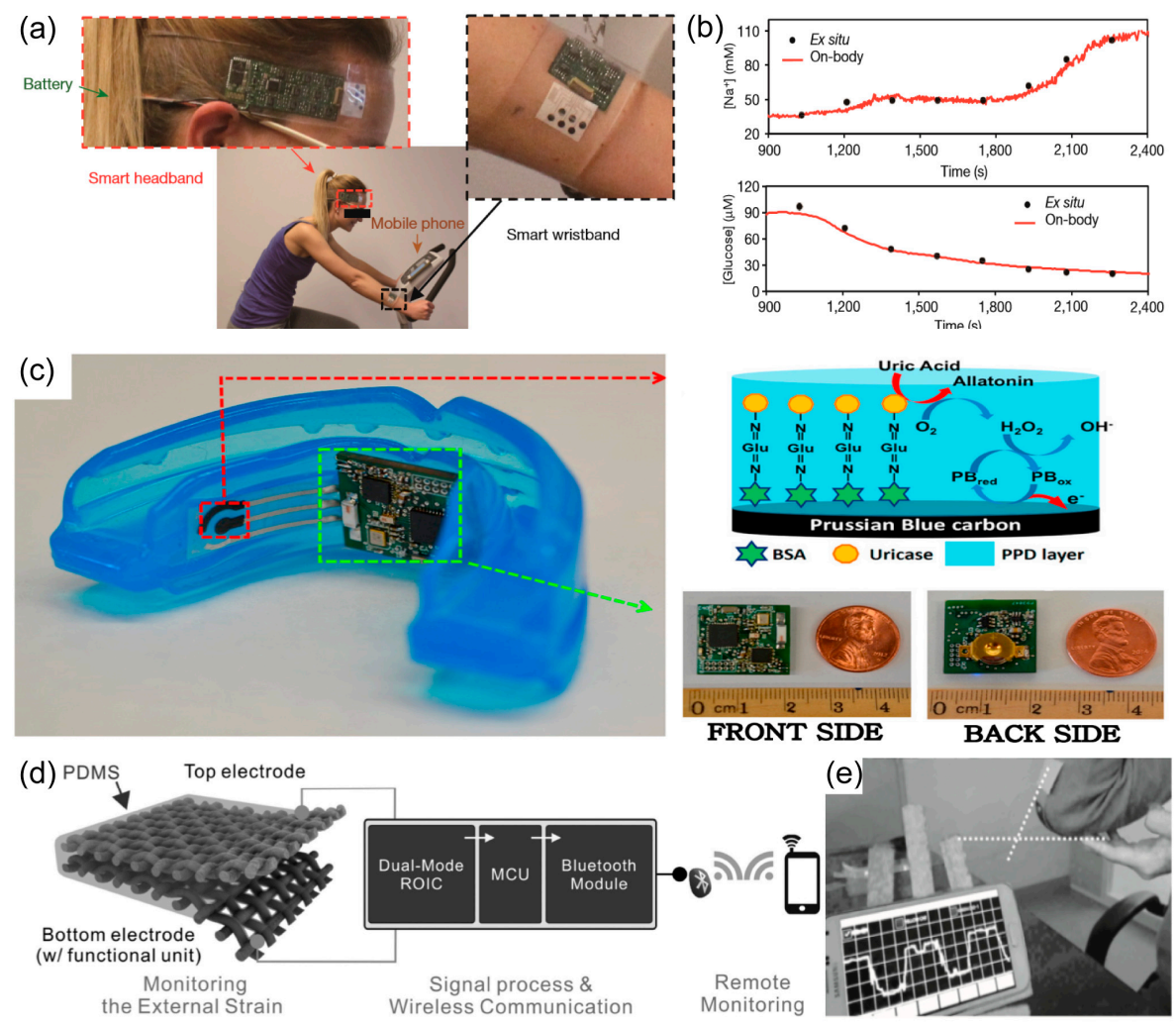

BACK SIDE

Figure 9. Bluetooth integrated wearable sensors. (a) Photographs of wearing a wearable sensor in band types during a stationary cycling; (b) Real-time reading data of the sodium and glucose measured with wearable sensors; (a,b) Reproduced with permission from Ref. [38]. Copyright 2016, Nature Publishing Group; (c) Photographs of the wireless SUA biosensor module with Bluetooth and the operation principles of mouthguard biosensor; (c) Reproduced with permission from Ref. [29]. Copyright 2015, Elsevier; (d) Schematic illustration of a flexible textile-based strain sensor with wireless monitoring system; (e) Photographs of the flexible textile-based strain sensor with Bluetooth module and real-time operation via wireless communication with mobile phone. (d,e) Reproduced with permission from Ref. [83]. Copyright 2016, John Wiley and Sons. 


\subsection{Near Field Communication (NFC) Integrated Sensors}

NFC is a non-contact, near field wireless communication (operation distance of $\sim 20 \mathrm{~cm}$ ), and it facilitates the simultaneous transfer of both power and data. It is a next-generation communication technology for wearable electronics because of its (1) compatibility with mobile electronic devices; (2) relatively high security due to its short operational range; (3) possibility of miniaturization of the chip to just a few millimeters; and (4) operation in the passive mode without a battery [154]. The NFC connected with wearable sensors operates in reader/writer mode. In this operational mode, a smartphone initiates the communication as an active device and can both read and write to an NFC tag, which consists of a chip, a sensor, an antenna, and other components. Recently, the advances of stretchable packaging technology have resulted in the production of NFC-enabled sensors in a wearable and skin-attachable form by enhancing the mechanical softness of the entire system [157,176-178]. When mounted on a person's body, these sensors enable the continuous monitoring of the physiological signals and simultaneously digitize the detection results in mobile electronics.

The power supply has been an issue in the development of body-integrated electronics. Even though many researchers have reported impressive results in the fields of energy generation and storage, the limitation of the soft mechanical properties has hindered the practical use of devices attached to the human body. Lee et al. reported the integration of an NFC chip with a stretchable energy storage system composed of a photovoltaic solar cell and rechargeable lithium-ion batteries as shown in Figure 10a,b [176]. The components of the device were interconnected with the fractal-designed electrodes, and the entire system was encapsulated by using a low-modulus elastomer, i.e., the moduli of the core and the shell were $\sim 3$ and $\sim 60 \mathrm{kPa}$, respectively, in order to provide stretchabiltiy and environmental protection. For example, both the solar cell and the battery can endure $\sim 55 \%$ and $\sim 45 \%$ elongation, which is almost twice as elastic as human skin. In addition to the battery system, the device can be operated wirelessly by using an NFC chip. The NFC device with built-in temperature sensor can be integrated with a power supply in the stretchable system, and this skin-attachable, wireless sensor can deliver sensing data through the NFC to the smartphone for use in analyzing skin thermography of the human body (Figure 10c,d). Even though it may be possible to fabricate a wireless sensor that can work interactively with a smartphone, there is a limitation to the applicability of various sensors. For example, they only use the built-in sensor in the NFC chip. In addition, the use of an external battery results in enlarging the size of the device.

To operate the external sensor without the external power supply, Kim et al. reported a battery-free, wireless optoelectronic system [157]. The NFC technology allows power to be delivered to the devices by using a magnetic inductive coupling, and the sensing results are extracted and displayed on a smartphone. As a demonstration, they fabricated a photodetector to measure the optical properties of the human skin and used multi-colored light-emitting diodes (LEDs) to present the sensing results (Figure 10e). The devices were connected externally to the NFC chip and integrated with the fractal designed interconnection in the elastomer for the conformal contact on the skin. The multi-colored LEDs (Figure 10f) were designed to emit different wavelengths wirelessly, depending on the reflectance of the targeted color. Figure $10 \mathrm{~g}$ shows the different skin colors of the three subjects, and the NFC-enabled photo detectors wirelessly measured the differences in the colors (Figure 10h). Figure 10i shows that the LEDs emitted yellow, orange, and red colors, corresponding to subjects 1,2 , and 3 , respectively. 
(a)

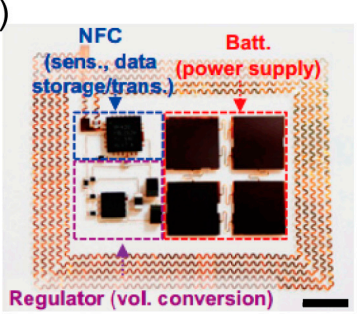

(b)

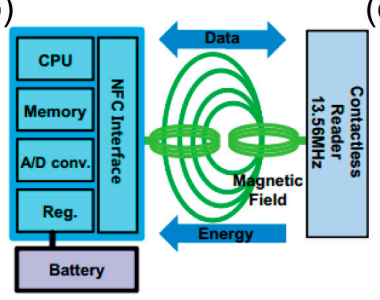

(c)

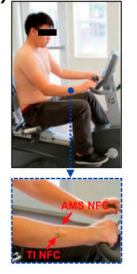

(d)

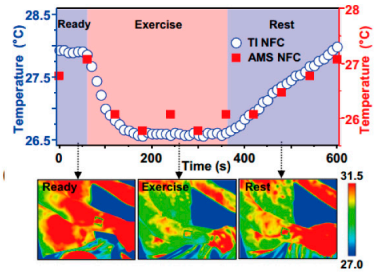

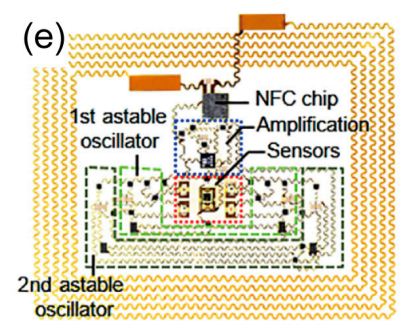
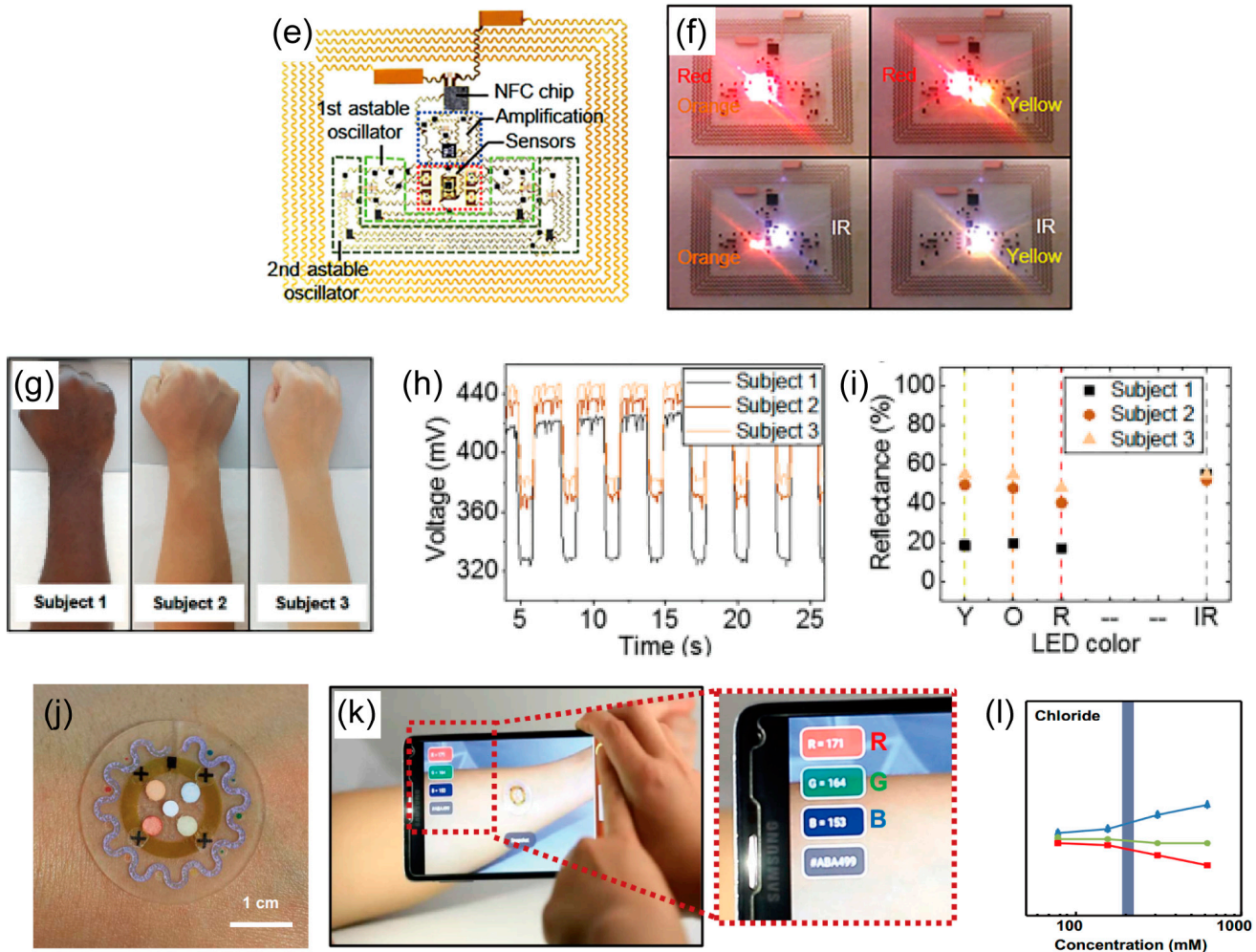

Figure 10. Near field communication (NFC)-enabled wearable sensor. (a) Image of the NFC-enabled wearable sensor system composed of the NFC devices, batteries, and a power regulator. Scale bar, $5 \mathrm{~mm}$; (b) Schematic illustration of the entire operation system; (c) Photo images of the NFC-enabled wearable sensor attached onto the human skin during exercise; (d) Temperature data and IR images at the stage of the before, during, and after exercise (which correspond to the "ready", "exercise", "rest") recorded by using NFC-enabled wearable sensor with a battery module (AMS NFC, red squares) and with the battery-integrated system (TI NFC, open circle). (a-d) Reproduced with permission from Ref. [176]. Copyright 2016, National Academy of Sciences; (e) Image of a NFC-enabled wearable sensor system including four pulsed LEDs (red, IR, orange, and yellow), two oscillators, amplifier and sensors; (f) Photo images of the NFC-enabled wearable sensor system during operation; (g) Images of subjects with different skin colors; $(\mathbf{h}, \mathbf{i})$ Wirelessly measured data and calculated reflectance value of the different skin colors. (e-i) Reproduced with permission from Ref. [157]. Copyright 2016, American Association for the Advancement of Science; (j) Optical image of a fabricated device mounted on the forearm; (k) Pictures demonstrating NFC between a sweat monitoring device and a smartphone to launch software for image capture and analysis; (1) Standard calibration curves between normalized $\%$ RGB value and concentration of markers for quantitative analysis (error bars show s.d. $(N=3)$ ). (j-1) Reproduced with permission from Ref. [177]. Copyright 2016, American Association for the Advancement of Science. 
Koh et al. reported an NFC-operable sweat sensor that could detect the concentrations of chloride, lactate, and glucose, as well as $\mathrm{pH}$, as shown in Figure 10j [177]. In order to harvest the sweat from the human skin in a microfluidic system, they used an artificial pore system that included a perforated PI membrane to mimic sweat glands. When the sweat entered the microfluidic channel, the enzyme changed the hydration status of the analytes, and the dyes in the water changed their colors. For example, the anhydrous cobalt chloride chelated with water was converted to hexahydrate cobalt chloride, and the color changed from deep blue $\left(\lambda_{\max }=657 \mathrm{~nm}\right)$ to pale purple $\left(\lambda_{\max }=511 \mathrm{~nm}\right)$. In addition, to detect the concentration of the glucose, they used glucose oxidase for enzymatic reaction which is capable of oxidation of glucose and reduction of oxygen. This reaction produced hydrogen peroxide, and it enables the iodide to oxidize to iodine, which makes color change from yellow to brown. The concentration of the target materials can be analyzed quantitatively by ultraviolet (UV)-visible spectroscopy. After fabrication of the microfluidic sensor that indicated the detection results as colorimetric responses, the sensor was integrated with the NFC chips to record color changes and to convert the colors into the exact red, green, and blue (RGB) colors of the smartphone display. Figure 10k shows the devices mounted on the human skin and operating stably while displaying RGB values. After wirelessly recording the images, the RGB colors, which can be exported as percentages in the RGB format, can be expressed as analyte concentrations, as shown in Figure 101. This wireless sweat sensor can detect changes of $0.5 \mathrm{pH}$ units and $0.2,0.3$ and $0.1 \mathrm{mM}$ chloride, and lactate and glucose concentration, respectively, and they correspond to a 1\% change in R channel of RGB images. Similarly, Akira et al. reported NFC-operable UV dosimeters that included photo-activators (PPDP-TF) and two types of color changeable dyes (CVL and Congo red, which respond to UV-A and UV-B, respectively) [178]. After absorption of the UV photons, the photosensitive activator generates radical species, which enables colorless dyes to become brightly colored. After exposure to the UV radiation, the smartphone enables the analysis of the RGB color from the UV dosimeters. These colorimetric sensing approaches are compatible with the NFC-enabled smartphone, and they also are applicable other types of environmental constituents, such as pollution or toxic gases. 
Table 1. Summary of the wearable sensors.

\begin{tabular}{|c|c|c|c|c|c|c|c|c|c|c|c|}
\hline Sensor Type & $\begin{array}{l}\text { Sensing } \\
\text { Element }\end{array}$ & Substrate & Electrode & Active Material & $\begin{array}{l}\text { Working } \\
\text { Voltage }\end{array}$ & $\begin{array}{l}\text { Sensing } \\
\text { Range }\end{array}$ & Sensitivity & Flexibility & Stretchability & Reliability & Reference \\
\hline Temperature & $\begin{array}{l}\text { Human hand } \\
\text { temperature }\end{array}$ & PDMS or thin PVA & $\mathrm{Au}$ & $\mathrm{Au}$ & $0.6 \mathrm{~V}$ & $20 \sim 150^{\circ} \mathrm{C}$ & $1.9 \mathrm{Ohm} \mathrm{K}^{-1}$ & - & $100 \%$ & - & [42] \\
\hline Temperature & Temperature & PDMS & $\mathrm{AgNW}$ & Graphene & $10 \mathrm{~V}$ & $30 \sim 100^{\circ} \mathrm{C}$ & $\begin{array}{l}\text { Nonlinear resistance } \\
\text { response }\end{array}$ & - & $50 \%$ & 100 & [31] \\
\hline Temperature & Endothelial layer & $\begin{array}{c}\text { Polyester fabric strip } \\
\text { coated with PDMS }\end{array}$ & $\mathrm{Au}$ & Platinum $(\mathrm{Pt})$ & $0.8 \mathrm{~V}$ & $0 \sim 120^{\circ} \mathrm{C}$ & $2.7 \mathrm{Ohm} \mathrm{K}^{-1}$ & $0.01 \%$ & - & - & [54] \\
\hline pressure & $\begin{array}{l}\text { Intraocular } \\
\text { pressure (IOP) }\end{array}$ & Parylene & graphene-AgNW & ecoflex (capacitive-type) & - & $\begin{array}{c}5 \sim 150 \\
\mathrm{mmHg}\end{array}$ & - & $\begin{array}{l}\text { Bending radius: } \\
3.1 \mu \mathrm{m}\end{array}$ & $25 \%$ & $\begin{array}{c}10,000 \text { cycles with } \\
25 \% \text { strain }\end{array}$ & [32] \\
\hline Pressure & $\begin{array}{l}\text { Cutaneous } \\
\text { pressure }\end{array}$ & Ecoflex & $\mathrm{Au}$ & $\begin{array}{c}\text { Lead zirconate titanate } \\
\text { (PbZr0.52Ti0.48O3, PZT) }\end{array}$ & $\begin{array}{l}\text { VG: } 3.5 \mathrm{~V} \text { VD: } \\
0.1 \mathrm{~V}\end{array}$ & $\begin{array}{c}0.005 \sim 10 \\
\mathrm{~Pa}\end{array}$ & $1.36 \mu \mathrm{A} \mathrm{Pa}^{-1}$ & $\begin{array}{l}14.8 \text { mm bending } \\
\text { radius }\end{array}$ & $30 \%$ & 1000 & [3] \\
\hline Pressure & Touch & PET or Polyurethane & $\begin{array}{l}\text { Conductive carbon } \\
\text { fabric }\end{array}$ & CNT/PDMS porous & $0.1 \mathrm{~V}$ & $\begin{array}{c}0.25 \sim 100 \\
\mathrm{kPa}\end{array}$ & - & $\begin{array}{c}30 \text { mm bending } \\
\text { radius }\end{array}$ & $30 \%$ & 10 & [39] \\
\hline Pressure & $\begin{array}{l}\text { Artery wrist } \\
\text { pulse or acoustic } \\
\text { vibrations }\end{array}$ & PDMS & $\mathrm{Au}$ & Au NWs & $1.5 \mathrm{~V}$ & $\begin{array}{l}13 \mathrm{~Pa} \sim 50 \\
\mathrm{kPa}\end{array}$ & $1.14 \mathrm{kPa}^{-1}$ & $\begin{array}{c}30 \text { mm bending } \\
\text { radius }\end{array}$ & $25 \%$ & 50,000 & [36] \\
\hline Pressure & Pressure & $\begin{array}{l}\text { PDMS and Epoxy } \\
\text { (SU8) }\end{array}$ & $\begin{array}{c}\text { Au or } \\
\text { AgNW/graphene }\end{array}$ & Graphene & $\begin{array}{l}\text { VG: } 25 \mathrm{~V} \text { VD: } \\
0.1 \mathrm{~V}\end{array}$ & $\begin{array}{l}250 \mathrm{~Pa} \\
\sim 3 \mathrm{Mpa}\end{array}$ & $\begin{array}{l}2.05 \times 10^{-4} \mathrm{kPa}^{-1} \\
\left(\text { below } 500 \mathrm{kPa}^{-9}, 9.43\right. \\
\times 10^{-6} \mathrm{kPa}^{-1} \\
(\text { above } 500 \mathrm{kPa})\end{array}$ & - & - & 1000 & [33] \\
\hline Strain & $\begin{array}{c}\begin{array}{c}\text { Facial } \\
\text { expressions }\end{array}\end{array}$ & PDMS & $\begin{array}{l}\text { Polyurethane- } \\
\text { PEDOT:PSS }\end{array}$ & $\begin{array}{l}\text { Single-walled carbon } \\
\text { nanotubes }\end{array}$ & $1 \mathrm{~V}$ & $\begin{array}{l}1.6 \sim 3.6 \%, \\
10 \sim 100 \%\end{array}$ & $62(\Delta R / R) / \varepsilon$ & $3.60 \%$ & $100 \%$ & $\begin{array}{l}\text { Minimum } 50 \text { cycles } \\
\text { for bending, } 1000 \\
\text { cycles for stretching }\end{array}$ & [34] \\
\hline Strain & Heartbeats & PDMS & $\begin{array}{l}\text { Graphene woven } \\
\text { fabrics }\end{array}$ & Graphene woven fabrics & $1 \mathrm{~V}$ & $\begin{array}{l}\text { under } \\
0.2 \sim 30 \%\end{array}$ & $1000(\Delta R / R) / \varepsilon$ & - & $30 \%$ & - & [86] \\
\hline Strain & $\begin{array}{l}\text { Stretch and } \\
\text { pressure }\end{array}$ & PDMS & $\begin{array}{l}\text { Eutectic Gallium } \\
\text { Indium }\end{array}$ & $\begin{array}{l}\text { Single-walled carbon } \\
\text { nanotubes-Ecoflex }\end{array}$ & - & $\sim 150 \%$ & $0.004(\Delta C / C) / \varepsilon$ & - & $150 \%$ & - & [69] \\
\hline Strain & $\begin{array}{l}\text { Joint movement } \\
\text { (bending) }\end{array}$ & $\begin{array}{l}\text { Silicon elastomer } \\
\text { (Dragonskin } 10+ \\
\text { Thi-Vex silicon } \\
\text { thickener + Slo-jo } \\
\text { platinum silicon } \\
\text { cure retarder) }\end{array}$ & Silver wire & $\begin{array}{l}\text { Ionic fluid - silicon } \\
\text { elastomer }\end{array}$ & $\begin{array}{l}\text { AC } 5 \mathrm{~V}, \\
50 \sim 200 \mathrm{~Hz}\end{array}$ & $\sim 700 \%$ & $0.348(\Delta C / C) / \varepsilon$ & - & $700 \%$ & $\begin{array}{l}\text { minimum } 20 \text { cycles } \\
\text { for stretching }\end{array}$ & [92] \\
\hline Strain & Bending & $\begin{array}{l}\text { PDMS coated } \\
\text { Polystyrene }\end{array}$ & Silver paste & $\mathrm{ZnSnO}_{3}$ nanowires & $1.2 \mathrm{~V}$ & $\sim 0.33 \%$ & $3740(\Delta I / I) / \varepsilon$ & $0.33 \%$ & $\begin{array}{c}\text { No } \\
\text { stretchability }\end{array}$ & - & [95] \\
\hline Strain & Lymphedema & $\begin{array}{l}\begin{array}{l}\text { Silicon rubber } \\
\text { (Solaris) }\end{array} \\
\text { (S) }\end{array}$ & $\mathrm{Cu}$ & Cu-PI (capacitive-type) & - & $0 \sim 30 \%$ & - & - & $30 \%$ & - & [160] \\
\hline Strain & Strain & PET textile & $\begin{array}{c}\text { Carbon } \\
\text { nanotube/reduced } \\
\text { Graphene oxide }\end{array}$ & $\mathrm{ZnO}$ Nanowire & - & $\begin{array}{c}\text { Sensor } \\
\text { limits of } \\
\text { bacterium } / \mu \mathrm{L}\end{array}$ & - & $3 \sim 5 \%$ & - & 100 bending cycles & [83] \\
\hline Gas & $\mathrm{O}_{2}$ (oxygen) & $\begin{array}{l}\text { Porous PTFE } \\
\text { (porous } \\
\text { polytetrafluoroethylene) }\end{array}$ & $\mathrm{Au}$ & $\begin{array}{c}\text { High-purity } \\
\text { 1-butyl-1-methylpyrrolidinium } \\
\text { bis } \\
\text { (trifluoro-methylsulfonyl)imide }\end{array}$ & $-1.4 \mathrm{~V}$ & $0 \sim 21 \%$ & $0.48 \mathrm{uA} / \%$ & $\begin{array}{l}\text { Can be bent either } \\
\text { convex or concave }\end{array}$ & - & - & [117] \\
\hline
\end{tabular}


Table 1. Cont

\begin{tabular}{|c|c|c|c|c|c|c|c|c|c|c|c|}
\hline Sensor Type & $\begin{array}{l}\text { Sensing } \\
\text { Element }\end{array}$ & Substrate & Electrode & Active Material & $\begin{array}{l}\text { Working } \\
\text { Voltage }\end{array}$ & $\begin{array}{l}\text { Sensing } \\
\text { Range }\end{array}$ & Sensitivity & Flexibility & Stretchability & Reliability & Reference \\
\hline Gas & $\begin{array}{l}\mathrm{NO}_{2} \text { (nitrogen } \\
\text { dioxide) }\end{array}$ & $\begin{array}{c}\text { PES } \\
\text { (polyethersulfone) }\end{array}$ & $\mathrm{Cr} / \mathrm{Au}$ & Graphene & $30 \mathrm{~V}$ & $\begin{array}{c}0.5 \text { to } \\
40 \mathrm{ppm}\end{array}$ & $\begin{array}{c}\Delta R / R_{0}=-40 \% \text { (at } \\
40 \mathrm{ppm} \mathrm{N2})\end{array}$ & $\begin{array}{c}\Delta R / R_{0}=5 \% \text { under a } \\
\text { bending strain } \\
\text { of } 1.4 \%\end{array}$ & - & - & [37] \\
\hline Gas & $\begin{array}{l}\mathrm{NO}_{2} \text { (nitrogen } \\
\text { dioxide) }\end{array}$ & Paper & $\mathrm{Au}$ & $\mathrm{NaNO} 2$ treated $\mathrm{PbS} C Q D$ & $4.1 \mathrm{~V}$ & $\begin{array}{l}0.5 \text { to } 50 \\
\text { ppm }\end{array}$ & $0.41 / \mathrm{ppm}$ & Bending angle of $70^{\circ}$ & - & $\begin{array}{l}7 \% \text { decrease in } \\
\text { response under } 5000 \\
\text { cyclic bending tests } \\
\text { (Bending angle of } 50^{\circ} \text { ) }\end{array}$ & [114] \\
\hline Gas & $\begin{array}{c}\text { Volatile } \\
\text { compouds } \\
\text { (ammonia, acetic } \\
\text { acid) }\end{array}$ & Plastic substrate & $\mathrm{Cr} / \mathrm{Au}$ & $\begin{array}{l}\text { Polypyrrole (Ppy) } \\
\text { (functionalized by } \\
\text { carboxyl group) }\end{array}$ & $-0.1 \sim 0.1 \mathrm{~V}$ & $\begin{array}{c}0.1 \sim 100 \\
\text { ppm }\end{array}$ & - & Bending angle: $15^{\circ}$ & - & - & [163] \\
\hline Gas & $\begin{array}{l}\text { Dimethyl } \\
\text { methylphosphonate } \\
\text { (DMMP) }\end{array}$ & $\begin{array}{l}\text { PI or PDMS or } \\
\text { parylene }\end{array}$ & Graphene-AgNW & $\begin{array}{l}\text { Graphene (functionalized } \\
\text { by polypyrrole (Ppy)) }\end{array}$ & $0.1 \mathrm{~V}$ & $5 \sim 25 \mathrm{ppm}$ & - & - & $20 \%$ & $\begin{array}{l}1000 \text { cycles with } \\
5 \% \text { strain }\end{array}$ & [18] \\
\hline Gas & $\begin{array}{c}\mathrm{H}_{2} \mathrm{~S}, \mathrm{C}_{2} \mathrm{H}_{5} \mathrm{OH} \\
\mathrm{H}_{2}\end{array}$ & PI & $\mathrm{Ti} / \mathrm{Au}$ & Graphene oxide & - & $\begin{array}{l}\text { Graphene } \\
\text { limits of } \\
\text { bacterium } / \mu \mathrm{L}\end{array}$ & $\begin{array}{l}\text { Toluene, Acetone, } \\
\text { CO Ethanol at } \\
20 \text { PPM, Acetone at } \\
20 \text { ppm, H2S, } \\
\text { H2 at } 5-20 \text { ppm }\end{array}$ & A $30^{\circ}$ bending angle & - & 104 bending cycles & [175] \\
\hline Bio & $\begin{array}{c}\text { Protein } \\
\text { (Concanavalin A, } \\
\text { Con A) }\end{array}$ & $\begin{array}{l}\text { PET or PDMS or } \\
\text { parylene }\end{array}$ & Graphene-AgNW & $\begin{array}{l}\text { Graphene (functionalized } \\
\text { by mannosyl-pyrene) }\end{array}$ & $0.1 \mathrm{~V}$ & $1 \mathrm{mg} / \mathrm{mL}$ & - & $\begin{array}{l}\text { Bending radius: } \\
27 \mu \mathrm{m} \text { (bending } \\
\text { strain: } 2.59 \% \text { ) }\end{array}$ & $20 \%$ & - & [12] \\
\hline Bio & $\begin{array}{l}\text { Bacteria (E. coli, } \\
\text { S. aureus, } \\
\text { H. pylori) }\end{array}$ & Silk fibroin film & $\mathrm{Cr} / \mathrm{Au}$ & $\begin{array}{l}\text { graphene (functionalized by } \\
\text { antimicrobial peptides } \\
\text { (AMPs)) }\end{array}$ & - & $\begin{array}{l}\text { Detection } \\
\text { limits of } \\
\text { bacterium } / \mu \mathrm{L}\end{array}$ & $100 \sim 10^{8} \mathrm{CFU} / \mathrm{mL}$ & - & - & - & [159] \\
\hline Bio & Lactate & $\begin{array}{l}\text { Temporary transfer } \\
\text { tatto paper, } \\
\text { GORETEX }\end{array}$ & $\begin{array}{c}\mathrm{Ag} / \mathrm{AgCl} \text {, } \\
\text { conductive carbon }\end{array}$ & lactate oxidase $\left(\mathrm{LO}_{\mathrm{x}}\right)$ & $0.05 \mathrm{~V}$ & $\underset{\mathrm{mM}}{1 \mathrm{mM} \text { to } 25}$ & $\begin{array}{c}644.2 \mathrm{nA} / \mathrm{mM} \text { at RT, } \\
0.916 \mu \mathrm{A} / \mathrm{mM} \text { at } \\
37^{\circ} \mathrm{C}\end{array}$ & Bending angle of $90^{\circ}$ & $\begin{array}{l}\text { stretched at } \\
\sim 10 \%\end{array}$ & $\begin{array}{l}\text { The bending/ } \\
\text { stretching test: } \\
10 \text { times }\end{array}$ & [136] \\
\hline Bio & D-glucose & $\begin{array}{l}\text { Polyimide film } \\
(2 \mu \mathrm{m})\end{array}$ & $\mathrm{Cr} / \mathrm{Au}$ & $\mathrm{In}_{2} \mathrm{O}_{3}$, glucose oxidase & $0.2 \sim 0.8 \mathrm{~V}$ & $\begin{array}{c}100 \mu \mathrm{M} \text { to } \\
4 \mathrm{mM}\end{array}$ & - & $\begin{array}{l}\text { Bending radius of } \\
837(0.078 \sim 0.082 \%)\end{array}$ & - & - & [40] \\
\hline Bio & Glucose & $\begin{array}{l}\text { PDMS, Polyimide, } \\
\text { Parylene }\end{array}$ & Graphene/AgNW & Graphene, glucose oxidase & $0.1 \mathrm{~V}$ & $\underset{\mathrm{mM}}{1 \mu \mathrm{M} \sim 10}$ & - & - & $\begin{array}{c}\Delta \mathrm{R}<6 \% \text { at } \\
25 \% \text { tensile } \\
\text { strain } \\
\text { (5000 cycles) }\end{array}$ & $\begin{array}{l}\Delta \mathrm{R} \sim 20 \% \text { at } 10,000 \\
\text { cycles of stretching }\end{array}$ & [32] \\
\hline Bio & Glucose, Lactate & PDMS & - & $\begin{array}{c}\text { Enzyme and } \\
\text { chromogenic reagent }\end{array}$ & - & $\begin{array}{l}\text { Glucose: } \\
0 \sim 25 \mathrm{mM} \\
\text { Lactage: } \\
0 \sim 100 \mathrm{mM}\end{array}$ & - & $5 \mathrm{~cm}$ bending radius & Strain $30 \%$ & - & [177] \\
\hline Bio & $\begin{array}{l}\text { Salivary Uric } \\
\text { acid }\end{array}$ & PET & $\mathrm{Ag} / \mathrm{AgCl}$ & Prussian-blue-graphite & - & $\begin{array}{l}\text { Mouthguard } \\
\text { limits of } \\
\text { bacterium } / \mu \mathrm{L}\end{array}$ & $2.45 \mu \mathrm{A} / \mathrm{mM}$ & - & - & - & [29] \\
\hline Ion & Chloride, $\mathrm{H}^{+}$ & PDMS & - & $\begin{array}{l}\text { Enzyme and } \\
\text { chromogenic reagent }\end{array}$ & - & $\begin{array}{r}\text { Chloride: } \\
0 \sim 625 \mu \mathrm{M} \\
\mathrm{pH}: 5.0 \sim 8.5 \\
\end{array}$ & - & $5 \mathrm{~cm}$ bending radius & Strain $30 \%$ & - & [177] \\
\hline
\end{tabular}


Table 1. Cont.

\begin{tabular}{|c|c|c|c|c|c|c|c|c|c|c|c|}
\hline Sensor Type & $\begin{array}{l}\text { Sensing } \\
\text { Element }\end{array}$ & Substrate & Electrode & Active Material & $\begin{array}{l}\text { Working } \\
\text { Voltage }\end{array}$ & $\begin{array}{c}\text { Sensing } \\
\text { Range }\end{array}$ & Sensitivity & Flexibility & Stretchability & Reliability & Reference \\
\hline Ion & $\mathrm{Na}^{+}, \mathrm{K}^{+}$ & Textile & $\begin{array}{l}\text { Ecoflex-containing } \\
\text { Ag/AgCl ink, } \\
\text { MWCNT }\end{array}$ & $\begin{array}{l}\text { Multi-walled carbon } \\
\text { nanotubes (functionalized } \\
\text { by carboxylic acid) }\end{array}$ & - & 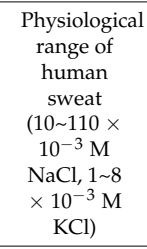 & $\begin{array}{c} \\
54.1 \pm 1.5 \mathrm{mV} / \log \\
{\left[\mathrm{Na}^{+}\right], 56.9 \pm 1.6} \\
\mathrm{mV} / \log \left[\mathrm{K}^{+}\right]\end{array}$ & $\begin{array}{l}\text { Bending angle } \\
\text { of } 180^{\circ}\end{array}$ & $\begin{array}{c}100 \% \\
\text { (uniaxial } \\
\text { stretching) }\end{array}$ & $\begin{array}{c}\text { No sensitivity } \\
\text { degradation at linear } \\
\text { strain of } 75 \% \text { during } \\
60 \mathrm{~min} \text { at a speed of } \\
1 \mathrm{~mm} / \mathrm{s}\end{array}$ & [122] \\
\hline Ion & $\mathrm{Na}^{+}, \mathrm{K}^{+}$ & $\begin{array}{l}\text { PET (polyethylene } \\
\text { terephthalate) }\end{array}$ & $\mathrm{Cr} / \mathrm{Au}, \mathrm{Ag} / \mathrm{AgCl}$ & $\begin{array}{l}\text { Multi-walled carbon } \\
\text { nanotubes }\end{array}$ & $3.7 \mathrm{~V}$ & $\begin{array}{c}1 \mathrm{mM} \mathrm{KCl} \\
\text { and } 10 \mathrm{mM} \\
\mathrm{NaCl} \\
\text { (working } \\
\text { condition) }\end{array}$ & $\begin{array}{c}62.5 \mathrm{mV} / \log \left[\mathrm{Na}^{+}\right] \\
59.5 \mathrm{mV} / \log \left[\mathrm{K}^{+}\right]\end{array}$ & $\begin{array}{c}\text { Radius of curvature } \\
1.5 \mathrm{~cm}\end{array}$ & - & $\begin{array}{c}\text { No sensitivity } \\
\text { degradation by } \\
\text { bending radius of } \\
1.5 \mathrm{~cm} \text { over } 60 \text { cycles }\end{array}$ & [38] \\
\hline Ion & $\mathrm{H}^{+}$ & $\begin{array}{c}\text { Poly } \\
\text { (methylmethacrylate) }\end{array}$ & Graphite & Graphene & $-0.4 \sim 0.4 \mathrm{~V}$ & pH $5 \sim 8$ & $17 \mathrm{mV} / \mathrm{pH}$ & $\begin{array}{c}\text { Radius of curvature: } \\
1.2 \mathrm{~cm}\end{array}$ & 0.04 & $\begin{array}{l}\text { No significant change } \\
\text { in the electrical } \\
\text { response (mobility } \\
\text { values remained } \\
\text { constant) as a result of } \\
\text { bending to radii of } \\
\text { curvature as small as } \\
0.7 \mathrm{~cm} \text { (estimated } \\
\text { bending-induced } \\
\text { strain: } 0.6 \% \text { ) }\end{array}$ & [126] \\
\hline Ion & $\mathrm{Ca}^{2+}, \mathrm{H}^{+}$ & $\begin{array}{l}\text { PET (polyethylene } \\
\text { terephthalate) }\end{array}$ & $\begin{array}{c}\mathrm{Ag} / \mathrm{AgCl} \\
\text { reference electrode }\end{array}$ & Polyaniline (PANI) & - & $\begin{array}{c}\text { Typical } \\
\text { physiological } \\
{\left[\mathrm{Ca}^{2+}\right]} \\
\text { variations } \\
\text { (e.g., } 1 \mathrm{mM} \\
\text { to } 0.5 \mathrm{mM}) \\
\text { pH } 4 \sim 7\end{array}$ & $\begin{array}{c}32.7 \mathrm{mV} / \log \left[\mathrm{Ca}^{2+}\right] \\
62.5 \mathrm{mV} / \mathrm{pH}\end{array}$ & - & - & - & [127] \\
\hline
\end{tabular}




\section{Conclusions}

In this review, we summarized recent advances in wearable electronic devices, including smart sensors and wireless systems, for real-life applications in monitoring people's activities and their personal healthcare. Smart sensors that have various configurations, such as piezo-resistive, piezo-electric, and capacitive types, can monitor various human physiological signals. The recently developed smart sensors are flexible and stretchable so that they can resist external deformation generated by human activities. These smart sensors can be classified into individual sensors that measure only one signal and multiplexed sensors that measure two or more signals, depending on the number of physiological signals being measured. Also, the individual sensors can be classified as physical sensors, which are those that measure temperature, pressure, and strain, chemical sensors, which are those that measure gases and ions, and biosensors, depending on the type of physiological signals being measured. Currently, the research efforts are focused more on the development of multiplexed sensors, which enable multiple detections, such as temperature, pressure, and strain, for precise monitoring of healthcare. Using smart sensors, the condition of a person's health can be monitored in real time, and the diagnostic results can be transported to control and processing units. Most of the recently reported studies related to wearable electronic devices used wireless systems to transmit the diagnostic data because wires can hinder the user's mobility, make the device feel uncomfortable on the body, and increase the risk of system failure. As mentioned earlier, these wireless systems can be classified into Bluetooth, NFC, and resonance antenna systems, according to the driving principle. Someday, these wearable electronic devices will allow us to monitor people's health status in real time with a smartphone and make telemedicine a reality, including injecting medications and scheduling appointments wirelessly.

Despite the progress described above, many challenges still remain before the implementation of wearable electronic devices in practical applications. For example, high performance sensors are affected by the external noisy signals generated by the human motion. To weaken the disturbance from these external noisy signals, cost-effective packaging and manufacturing methods should be accompanied with the fabrication of wearable electronic devices. Micro Electro Mechanical Systems (MEMS) technology is widely used for manufacturing, but it needs expensive production equipment. Recently, new technologies, such as 3D-printing technology [179-181], are capable of reducing the fabrication costs and enabling mass production contrast to the traditional step-by-step manufacturing technology. Moreover, conformal attachment of strain and pressure sensors on the human body is also essential for more accurate measurements of the human motion. For this purpose, the intermediate adhesive layers $[4,5,86,182]$ such as microhair adhesive structures [183-186] can be integrated with the strain and pressure sensors for enhanced contact efficiency. Also, designing low power consuming wearable electronic devices has always been an exciting but challenging issue. To provide the required operating power of wearable electronic devices, sensing devices that are self-powered have been introduced [187-189], although there still are challenging issues regarding the extended sustainability of the flexible power source. We believe that these challenges will be gradually solved, leading to such wearable electronic devices, which allow us to monitor our health status in real-time with a smart phone, and doctors to practice telemedicine simply from scheduling an appointment even to wireless drug injections.

Acknowledgments: This work was supported by the Ministry of Science, ICT \& Future Planning and the Ministry of Trade, Industry and Energy (MOTIE) of Korea through the National Research Foundation (2016R1A2B3013592 and 2016R1A5A1009926), the Nano Material Technology Development Program (2015M3A7B4050308 and 2016M3A7B4910635), the Convergence Technology Development Program for Bionic Arm (NRF-2014M3C1B2048198), and the Pioneer Research Center Program (NRF-2014M3C1A3001208). Also, the authors thank financial support by the Development Program of Manufacturing Technology for Flexible Electronics with High Performance (SC0970) funded by the Korea Institute of Machinery and Materials, and by the Development Program of Internet of Nature System (1.150090.01) funded by UNIST. 
Author Contributions: Byeong Wan An and Jung Hwal Shin contributed equally to this work. Byeong Wan An, Jung Hwal Shin, So-Yun Kim, Joohee Kim, Sangyoon Ji, Jihun Park, Youngjin Lee, Jiuk Jang, Young-Geun Park, Eunjin Cho, and Subin Jo wrote the paper. Jang-Ung Park oversaw all research phases. All authors discussed and commented on the manuscript.

Conflicts of Interest: The authors declare no conflict of interest.

\section{References}

1. Bonato, P. Wearable sensors/systems and their impact on biomedical engineering. IEEE Eng. Med. Biol. Mag. 2003, 22, 18-20. [CrossRef] [PubMed]

2. Wang, X.; Gu, Y.; Xiong, Z.; Cui, Z.; Zhang, T. Electronic Skin: Silk-Molded Flexible, Ultrasensitive, and Highly Stable Electronic Skin for Monitoring Human Physiological Signals (Adv. Mater. 9/2014). Adv. Mater. 2014, 26, 1309. [CrossRef]

3. Dagdeviren, C.; Su, Y.; Joe, P.; Yona, R.; Liu, Y.; Kim, Y.-S.; Huang, Y.; Damadoran, A.R.; Xia, J.; Martin, L.W.; et al. Conformable amplified lead zirconate titanate sensors with enhanced piezoelectric response for cutaneous pressure monitoring. Nat. Commun. 2014, 5, 4496. [CrossRef] [PubMed]

4. Pang, C.; Koo, J.H.; Nguyen, A.; Caves, J.M.; Kim, M.-G.; Chortos, A.; Kim, K.; Wang, P.J.; Tok, J.B.-H.; Bao, Z. Highly skin-conformal microhairy sensor for pulse signal amplification. Adv. Mater. 2015, 27, 634-640. [CrossRef] [PubMed]

5. Pang, C.; Lee, C.; Suh, K.-Y. Recent advances in flexible sensors for wearable and implantable devices. J. Appl. Polym. Sci. 2013, 130, 1429-1441. [CrossRef]

6. Chen, L.Y.; Tee, B.C.-K.; Chortos, A.L.; Schwartz, G.; Tse, V.; Lipomi, D.J.; Wong, H.-S.P.; McConnell, M.V.; Bao, Z. Continuous wireless pressure monitoring and mapping with ultra-small passive sensors for health monitoring and critical care. Nat. Commun. 2014, 5, 5028. [CrossRef] [PubMed]

7. Takei, K.; Honda, W.; Harada, S.; Arie, T.; Akita, S. Toward Flexible and Wearable Human-Interactive Health-Monitoring Devices. Adv. Healthc. Mater. 2015, 4, 487-500. [CrossRef] [PubMed]

8. Zang, Y.; Zhang, F.; Di, C.; Zhu, D. Advances of flexible pressure sensors toward artificial intelligence and health care applications. Mater. Horiz. 2015, 2, 140-156. [CrossRef]

9. Chortos, A.; Bao, Z. Skin-inspired electronic devices. Mater. Today 2014, 17, 321-331. [CrossRef]

10. Dagdeviren, C.; Joe, P.; Tuzman, O.L.; Park, K.-I.; Lee, K.J.; Shi, Y.; Huang, Y.; Rogers, J.A. Recent progress in flexible and stretchable piezoelectric devices for mechanical energy harvesting, sensing and actuation. Extrem. Mech. Lett. 2016, 9, 269-281. [CrossRef]

11. Dagdeviren, C.; Li, Z.; Wang, Z.L. Energy harvesting from the animal/human body for self-powered electronics. Annu. Rev. Biomed. Eng. 2017, 19, 85-108. [CrossRef] [PubMed]

12. Kim, J.; Lee, M.-S.; Jeon, S.; Kim, M.; Kim, S.; Kim, K.; Bien, F.; Hong, S.Y.; Park, J.-U. Highly Transparent and Stretchable Field-Effect Transistor Sensors Using Graphene-Nanowire Hybrid Nanostructures. Adv. Mater. 2015, 27, 3292-3297. [CrossRef] [PubMed]

13. An, B.W.; Hyun, B.G.; Kim, S.-Y.; Kim, M.; Lee, M.-S.; Lee, K.; Koo, J.B.; Chu, H.Y.; Bae, B.-S.; Park, J.-U. Stretchable and Transparent Electrodes using Hybrid Structures of Graphene-Metal Nanotrough Networks with High Performances and Ultimate Uniformity. Nano Lett. 2014, 14, 6322-6328. [CrossRef] [PubMed]

14. Lee, M.-S.; Lee, K.; Kim, S.-Y.; Lee, H.; Park, J.; Choi, K.-H.; Kim, H.-K.; Kim, D.-G.; Lee, D.-Y.; Nam, S.; et al. High-Performance, Transparent, and Stretchable Electrodes Using Graphene-Metal Nanowire Hybrid Structures. Nano Lett. 2013, 13, 2814-2821. [CrossRef] [PubMed]

15. Ji, S.; Jang, J.; Cho, E.; Kim, S.-H.; Kang, E.-S.; Kim, J.; Kim, H.-K.; Kong, H.; Kim, S.-K.; Kim, J.-Y.; et al. High Dielectric Performances of Flexible and Transparent Cellulose Hybrid Films Controlled by Multidimensional Metal Nanostructures. Adv. Mater. 2017, 29, 1700538. [CrossRef] [PubMed]

16. Jo, Y.; Kim, J.Y.; Kim, S.-Y.; Seo, Y.-H.; Jang, K.-S.; Lee, S.Y.; Jung, S.; Ryu, B.-H.; Kim, H.-S.; Park, J.-U.; et al. 3D-printable, highly conductive hybrid composites employing chemically-reinforced, complex dimensional fillers and thermoplastic triblock copolymers. Nanoscale 2017, 9, 5072-5084. [CrossRef] [PubMed]

17. Ji, S.; Hyun, B.G.; Kim, K.; Lee, S.Y.; Kim, S.-H.; Kim, J.-Y.; Song, M.H.; Park, J.-U. Photo-patternable and transparent films using cellulose nanofibers for stretchable origami electronics. NPG Asia Mater. 2016, 8, e299. [CrossRef] 
18. Park, J.; Kim, J.; Kim, K.; Kim, S.-Y.; Hyung Cheong, W.; Park, K.; Hyeb Song, J.; Namgoong, G.; Joon Kim, J.; Heo, J.; et al. Wearable, wireless gas sensors using highly stretchable and transparent structures of nanowires and graphene. Nanoscale 2016, 8, 10591-10597. [CrossRef] [PubMed]

19. Jung, E.D.; Nam, Y.S.; Seo, H.; Lee, B.R.; Yu, J.C.; Lee, S.Y.; Kim, J.-Y.; Park, J.-U.; Song, M.H. Highly efficient flexible optoelectronic devices using metal nanowire-conducting polymer composite transparent electrode. Electron. Mater. Lett. 2015, 11, 906-914. [CrossRef]

20. Lee, M.-S.; Kim, J.; Park, J.; Park, J.-U. Studies on the mechanical stretchability of transparent conductive film based on graphene-metal nanowire structures. Nanoscale Res. Lett. 2015, 10, 1-9. [CrossRef] [PubMed]

21. Lee, K.; Park, J.; Lee, M.-S.; Kim, J.; Hyun, B.G.; Kang, D.J.; Na, K.; Lee, C.Y.; Bien, F.; Park, J.-U. In-situ Synthesis of Carbon Nanotube-Graphite Electronic Devices and Their Integrations onto Surfaces of Live Plants and Insects. Nano Lett. 2014, 14, 2647-2654. [CrossRef] [PubMed]

22. Kang, D.J.; Park, G.U.; Lee, H.H.; Park, H.Y.; Park, J.-U. Photopatternable and refractive-index-tunable sol-Gel-derived silica-Titania nanohybrid materials. Curr. Appl. Lett. 2013, 13, 1732-1737. [CrossRef]

23. Hyun, B.G.; Son, H.J.; Ji, S.; Jang, J.; Hur, S.-H.; Park, J.-U. Multi-dimensional carbon nanofibers for supercapacitor electrodes. J. Electroceram. 2017, 38, 43-50. [CrossRef]

24. Kim, K.; Hyun, B.G.; Jang, J.; Cho, E.; Park, Y.-G.; Park, J.-U. Nanomaterial-based stretchable and transparent electrodes. J. Inf. Disp. 2016, 17, 131-141. [CrossRef]

25. Kim, S.-Y.; Kim, K.; Hwang, Y.H.; Park, J.; Jang, J.; Nam, Y.; Kang, Y.; Kim, M.; Park, H.J.; Lee, Z.; et al. High-resolution electrohydrodynamic inkjet printing of stretchable metal oxide semiconductor transistors with high performance. Nanoscale 2016, 8, 17113-17121. [CrossRef] [PubMed]

26. Kim, K.; Kim, G.; Lee, B.R.; Ji, S.; Kim, S.-Y.; An, B.W.; Song, M.H.; Park, J.-U. High-resolution electrohydrodynamic jet printing of small-molecule organic light-emitting diodes. Nanoscale 2015, 7, 13410-13415. [CrossRef] [PubMed]

27. An, B.W.; Kim, K.; Lee, H.; Kim, S.-Y.; Shim, Y.; Lee, D.-Y.; Song, J.Y.; Park, J.-U. High-Resolution Printing of 3D Structures Using an Electrohydrodynamic Inkjet with Multiple Functional Inks. Adv. Mater. 2015, 27, 4322-4328. [CrossRef] [PubMed]

28. An, B.W.; Kim, K.; Kim, M.; Kim, S.-Y.; Hur, S.-H.; Park, J.-U. Direct Printing of Reduced Graphene Oxide on Planar or Highly Curved Surfaces with High Resolutions Using Electrohydrodynamics. Small 2015, 11, 2263-2268. [CrossRef] [PubMed]

29. Kim, J.; Imani, S.; de Araujo, W.R.; Warchall, J.; Valdés-Ramírez, G.; Paixão, T.R.L.C.; Mercier, P.P.; Wang, J. Wearable salivary uric acid mouthguard biosensor with integrated wireless electronics. Biosens. Bioelectron. 2015, 74, 1061-1068. [CrossRef] [PubMed]

30. Cochrane, C.; Koncar, V.; Lewandowski, M.; Dufour, C. Design and Development of a Flexible Strain Sensor for Textile Structures Based on a Conductive Polymer Composite. Sensors (Basel) 2007, 7, 473-492. [CrossRef]

31. Yan, C.; Wang, J.; Lee, P.S. Stretchable Graphene Thermistor with Tunable Thermal Index. ACS Nano 2015, 9, 2130-2137. [CrossRef] [PubMed]

32. Kim, J.; Kim, M.; Lee, M.-S.; Kim, K.; Ji, S.; Kim, Y.-T.; Park, J.; Na, K.; Bae, K.-H.; Kim, H.K.; et al. Wearable smart sensor systems integrated on soft contact lenses for wireless ocular diagnostics. Nat. Commun. 2017, 8, 14997. [CrossRef] [PubMed]

33. Shin, S.-H.; Ji, S.; Choi, S.; Pyo, K.-H.; An, B.W.; Park, J.; Kim, J.; Kim, J.-Y.; Lee, K.-S.; Kwon, S.-Y.; et al. Integrated arrays of air-dielectric graphene transistors as transparent active-matrix pressure sensors for wide pressure ranges. Nat. Commun. 2017, 8, 14950. [CrossRef] [PubMed]

34. Roh, E.; Hwang, B.-U.; Kim, D.; Kim, B.-Y.; Lee, N.-E. Stretchable, Transparent, Ultrasensitive, and Patchable Strain Sensor for Human-Machine Interfaces Comprising a Nanohybrid of Carbon Nanotubes and Conductive Elastomers. ACS Nano 2015, 9, 6252-6261. [CrossRef] [PubMed]

35. Rodger, D.C.; Weiland, J.D.; Humayun, M.S.; Tai, Y.-C. Scalable high lead-count parylene package for retinal prostheses. Sens. Actuators B Chem. 2006, 117, 107-114. [CrossRef]

36. Gong, S.; Schwalb, W.; Wang, Y.; Chen, Y.; Tang, Y.; Si, J.; Shirinzadeh, B.; Cheng, W. A wearable and highly sensitive pressure sensor with ultrathin gold nanowires. Nat. Commun. 2014, 5, 3132. [CrossRef] [PubMed]

37. Choi, H.; Choi, J.S.; Kim, J.-S.; Choe, J.-H.; Chung, K.H.; Shin, J.-W.; Kim, J.T.; Youn, D.-H.; Kim, K.-C.; Lee, J.-I.; et al. Flexible and transparent gas molecule sensor integrated with sensing and heating graphene layers. Small 2014, 10, 3685-3691. [CrossRef] [PubMed] 
38. Gao, W.; Emaminejad, S.; Nyein, H.Y.Y.; Challa, S.; Chen, K.; Peck, A.; Fahad, H.M.; Ota, H.; Shiraki, H.; Kiriya, D.; et al. Fully integrated wearable sensor arrays for multiplexed in situ perspiration analysis. Nature 2016, 529, 509-514. [CrossRef] [PubMed]

39. Jung, S.; Kim, J.H.; Kim, J.; Choi, S.; Lee, J.; Park, I.; Hyeon, T.; Kim, D.-H. Reverse-Micelle-Induced Porous Pressure-Sensitive Rubber for Wearable Human-Machine Interfaces. Adv. Mater. 2014, 26, 4825-4830. [CrossRef] [PubMed]

40. Rim, Y.S.; Bae, S.-H.; Chen, H.; Yang, J.L.; Kim, J.; Andrews, A.M.; Weiss, P.S.; Yang, Y.; Tseng, H.-R. Printable Ultrathin Metal Oxide Semiconductor-Based Conformal Biosensors. ACS Nano 2015, 9, 12174-12181. [CrossRef] [PubMed]

41. Na, K.; Ma, H.; Park, J.; Yeo, J.; Park, J.-U.; Bien, F. Graphene-Based Wireless Environmental Gas Sensor on PET Substrate. IEEE Sens. J. 2016, 16, 5003-5009. [CrossRef]

42. Webb, R.C.; Bonifas, A.P.; Behnaz, A.; Zhang, Y.; Yu, K.J.; Cheng, H.; Shi, M.; Bian, Z.; Liu, Z.; Kim, Y.-S.; et al. Ultrathin conformal devices for precise and continuous thermal characterization of human skin. Nat. Mater. 2013, 12, 938-944. [CrossRef] [PubMed]

43. Kaltenbrunner, M.; Sekitani, T.; Reeder, J.; Yokota, T.; Kuribara, K.; Tokuhara, T.; Drack, M.; Schwödiauer, R.; Graz, I.; Bauer-Gogonea, S.; et al. An ultra-lightweight design for imperceptible plastic electronics. Nature 2013, 499, 458-463. [CrossRef] [PubMed]

44. Yeo, W.-H.; Kim, Y.-S.; Lee, J.; Ameen, A.; Shi, L.; Li, M.; Wang, S.; Ma, R.; Jin, S.H.; Kang, Z.; et al. Multifunctional Epidermal Electronics Printed Directly Onto the Skin. Adv. Mater. 2013, 25, 2773-2778. [CrossRef] [PubMed]

45. Park, J.; Lee, Y.; Hong, J.; Lee, Y.; Ha, M.; Jung, Y.; Lim, H.; Kim, S.Y.; Ko, H. Tactile-Direction-Sensitive and Stretchable Electronic Skins Based on Human-Skin-Inspired Interlocked Microstructures. ACS Nano 2014, 8 , 12020-12029. [CrossRef] [PubMed]

46. Park, H.; Kim, Y.; Jung, E.S.; Kwon, S. Implantable hybrid chrome silicide temperature sensor for power MEMS devices. IET Micro Nano Lett. 2011, 6, 895-899. [CrossRef]

47. Brenci, M.; Contorti, G.; Falciai, R.; Mignani, A.G.; Scheggi, A.M. Thermochromic Transducer Optical Fiber Temperature Sensor. In Proceedings of the 2nd International Conference on Optical Fiber Sensors, Stuttgart, Germany, 5-7 September 1984; Volume 0514, pp. 155-160.

48. Gao, L.; Zhang, Y.; Malyarchuk, V.; Jia, L.; Jang, K.-I.; Webb, R.C.; Fu, H.; Shi, Y.; Zhou, G.; Shi, L.; et al. Epidermal photonic devices for quantitative imaging of temperature and thermal transport characteristics of the skin. Nat. Commun. 2014, 5, 4938. [CrossRef] [PubMed]

49. Ploss, B.; Domig, A. Static and dynamic pyroelectric properties of PVDF. Ferroelectrics 1994, 159, $263-268$. [CrossRef]

50. Broadhurst, M.G.; Davis, G.T.; McKinney, J.E.; Collins, R.E. Piezoelectricity and pyroelectricity in polyvinylidene fluoride-A model. J. Appl. Phys. 1978, 49, 4992-4997. [CrossRef]

51. Park, J.; Kim, M.; Lee, Y.; Lee, H.S.; Ko, H. Fingertip skin-Inspired microstructured ferroelectric skins discriminate static/dynamic pressure and temperature stimuli. Sci. Adv. 2015, 1, e1500661. [CrossRef] [PubMed]

52. Cosseddu, P.; Viola, F.; Lai, S.; Raffo, L.; Bonfiglio, A. A Temperature Transducer Based on a Low-Voltage Organic Thin-Film Transistor Detecting Pyroelectric Effect. IEEE Electron. Dev. Lett. 2014, 35, 1296-1298. [CrossRef]

53. Tien, N.T.; Jeon, S.; Kim, D.-I.; Trung, T.Q.; Jang, M.; Hwang, B.-U.; Byun, K.-E.; Bae, J.; Lee, E.; Tok, J.B.-H.; et al. A Flexible Bimodal Sensor Array for Simultaneous Sensing of Pressure and Temperature. Adv. Mater. 2014, 26, 796-804. [CrossRef] [PubMed]

54. Kim, D.-H.; Wang, S.; Keum, H.; Ghaffari, R.; Kim, Y.-S.; Tao, H.; Panilaitis, B.; Li, M.; Kang, Z.; Omenetto, F.; et al. Thin, Flexible Sensors and Actuators as "Instrumented" Surgical Sutures for Targeted Wound Monitoring and Therapy. Small 2012, 8, 3263-3268. [CrossRef] [PubMed]

55. Jeon, J.; Lee, H.-B.-R.; Bao, Z. Flexible Wireless Temperature Sensors Based on Ni Microparticle-Filled Binary Polymer Composites. Adv. Mater. 2013, 25, 850-855. [CrossRef] [PubMed]

56. Yoon, S.; Sim, J.K.; Cho, Y.-H. A Flexible and Wearable Human Stress Monitoring Patch. Sci. Rep. 2016, 6, 23468. [CrossRef] [PubMed] 
57. Harada, S.; Honda, W.; Arie, T.; Akita, S.; Takei, K. Fully Printed, Highly Sensitive Multifunctional Artificial Electronic Whisker Arrays Integrated with Strain and Temperature Sensors. ACS Nano 2014, 8, 3921-3927. [CrossRef] [PubMed]

58. Chandra, V.; Yu, S.U.; Kim, S.H.; Yoon, Y.S.; Kim, D.Y.; Kwon, A.H.; Meyyappan, M.; Kim, K.S. Highly selective $\mathrm{CO} 2$ capture on $\mathrm{N}$-doped carbon produced by chemical activation of polypyrrole functionalized graphene sheets. Chem. Commun. 2012, 48, 735-737. [CrossRef] [PubMed]

59. Kim, J.; Lee, M.; Shim, H.J.; Ghaffari, R.; Cho, H.R.; Son, D.; Jung, Y.H.; Soh, M.; Choi, C.; Jung, S.; et al. Stretchable silicon nanoribbon electronics for skin prosthesis. Nat. Commun. 2014, 5, 5747. [CrossRef] [PubMed]

60. Bendi, R.; Bhavanasi, V.; Parida, K.; Nguyen, V.C.; Sumboja, A.; Tsukagoshi, K.; Lee, P.S. Self-powered graphene thermistor. Nano Energ. 2016, 26, 586-594. [CrossRef]

61. Yu, C.; Wang, Z.; Yu, H.; Jiang, H. A stretchable temperature sensor based on elastically buckled thin film devices on elastomeric substrates. Appl. Phys. Lett. 2009, 95, 141912. [CrossRef]

62. Honda, W.; Harada, S.; Arie, T.; Akita, S.; Takei, K. Wearable, Human-Interactive, Health-Monitoring, Wireless Devices Fabricated by Macroscale Printing Techniques. Adv. Funct. Mater. 2014, 24, 3299-3304. [CrossRef]

63. Yang, J.; Wei, D.; Tang, L.; Song, X.; Luo, W.; Chu, J.; Gao, T.; Shi, H.; Du, C. Wearable temperature sensor based on graphene nanowalls. RSC Adv. 2015, 5, 25609-25615. [CrossRef]

64. Khan, Y.; Garg, M.; Gui, Q.; Schadt, M.; Gaikwad, A.; Han, D.; Yamamoto, N.A.D.; Hart, P.; Welte, R.; Wilson, W.; et al. Flexible Hybrid Electronics: Direct Interfacing of Soft and Hard Electronics for Wearable Health Monitoring. Adv. Funct. Mater. 2016, 26, 8764-8775. [CrossRef]

65. Mannsfeld, S.C.B.; Tee, B.C.-K.; Stoltenberg, R.M.; Chen, C.V.H.-H.; Barman, S.; Muir, B.V.O.; Sokolov, A.N.; Reese, C.; Bao, Z. Highly sensitive flexible pressure sensors with microstructured rubber dielectric layers. Nat. Mater. 2010, 9, 859-864. [CrossRef] [PubMed]

66. Schwartz, G.; Tee, B.C.-K.; Mei, J.; Appleton, A.L.; Kim, D.H.; Wang, H.; Bao, Z. Flexible polymer transistors with high pressure sensitivity for application in electronic skin and health monitoring. Nat. Commun. 2013, 4, 1859. [CrossRef] [PubMed]

67. Dagdeviren, C.; Shi, Y.; Joe, P.; Ghaffari, R.; Balooch, G.; Usgaonkar, K.; Gur, O.; Tran, P.L.; Crosby, J.R.; Meyer, M.; et al. Conformal piezoelectric systems for clinical and experimental characterization of soft tissue biomechanics. Nat. Mater. 2015, 14, 728-736. [CrossRef] [PubMed]

68. Yuan, J.; Dagdeviren, C.; Shi, Y.; Ma, Y.; Feng, X.; Rogers, J.A.; Huang, Y. Computational models for the determination of depth-dependent mechanical properties of skin with a soft, flexible measurement device. Proc. R. Soc. A 2016, 472, 20160225. [CrossRef] [PubMed]

69. Lipomi, D.J.; Vosgueritchian, M.; Tee, B.C.-K.; Hellstrom, S.L.; Lee, J.A.; Fox, C.H.; Bao, Z. Skin-like pressure and strain sensors based on transparent elastic films of carbon nanotubes. Nat. Nanotechnol. 2011, 6, 788-792. [CrossRef] [PubMed]

70. Zirkl, M.; Sawatdee, A.; Helbig, U.; Krause, M.; Scheipl, G.; Kraker, E.; Ersman, P.A.; Nilsson, D.; Platt, D.; Bodö, P.; Bauer, S.; Domann, G.; Stadlober, B. An All-Printed Ferroelectric Active Matrix Sensor Network Based on Only Five Functional Materials Forming a Touchless Control Interface. Adv. Mater. 2011, 23, 2069-2074. [CrossRef] [PubMed]

71. Lee, J.S.; Shin, K.-Y.; Cheong, O.J.; Kim, J.H.; Jang, J. Highly Sensitive and Multifunctional Tactile Sensor Using Free-standing ZnO/PVDF Thin Film with Graphene Electrodes for Pressure and Temperature Monitoring. Sci. Rep. 2015, 5, 7887. [CrossRef] [PubMed]

72. Persano, L.; Dagdeviren, C.; Su, Y.; Zhang, Y.; Girardo, S.; Pisignano, D.; Huang, Y.; Rogers, J.A. High performance piezoelectric devices based on aligned arrays of nanofibers of poly(vinylidenefluoride-co-trifluoroethylene). Nat. Commun. 2013, 4, 1633. [CrossRef] [PubMed]

73. Park, J.; Lee, Y.; Hong, J.; Ha, M.; Jung, Y.-D.; Lim, H.; Kim, S.Y.; Ko, H. Giant Tunneling Piezoresistance of Composite Elastomers with Interlocked Microdome Arrays for Ultrasensitive and Multimodal Electronic Skins. ACS Nano 2014, 8, 4689-4697. [CrossRef] [PubMed]

74. Kang, D.; Pikhitsa, P.V.; Choi, Y.W.; Lee, C.; Shin, S.S.; Piao, L.; Park, B.; Suh, K.-Y.; Kim, T.; Choi, M. Ultrasensitive mechanical crack-based sensor inspired by the spider sensory system. Nature 2014, 516, 222-226. [CrossRef] [PubMed] 
75. Sun, J.-Y.; Keplinger, C.; Whitesides, G.M.; Suo, Z. Ionic skin. Adv. Mater. 2014, 26, 7608-7614. [CrossRef] [PubMed]

76. Park, S.; Kim, H.; Vosgueritchian, M.; Cheon, S.; Kim, H.; Koo, J.H.; Kim, T.R.; Lee, S.; Schwartz, G.; Chang, H.; et al. Stretchable Energy-Harvesting Tactile Electronic Skin Capable of Differentiating Multiple Mechanical Stimuli Modes. Adv. Mater. 2014, 26, 7324-7332. [CrossRef] [PubMed]

77. Zang, Y.; Zhang, F.; Huang, D.; Gao, X.; Di, C.; Zhu, D. Flexible suspended gate organic thin-film transistors for ultra-sensitive pressure detection. Nat. Commun. 2015, 6, 6269. [CrossRef] [PubMed]

78. Trung, T.Q.; Lee, N.-E. Flexible and Stretchable Physical Sensor Integrated Platforms for Wearable Human-Activity Monitoringand Personal Healthcare. Adv. Mater. 2016, 28, 4338-4372. [CrossRef] [PubMed]

79. Amjadi, M.; Kyung, K.-U.; Park, I.; Sitti, M. Stretchable, Skin-Mountable, and Wearable Strain Sensors and Their Potential Applications: A Review. Adv. Funct. Mater. 2016, 26, 1678-1698. [CrossRef]

80. Smith, C.S. Piezoresistance Effect in Germanium and Silicon. Phys. Rev. 1954, 94, 42-49. [CrossRef]

81. Lu, N.; Lu, C.; Yang, S.; Rogers, J. Highly Sensitive Skin-Mountable Strain Gauges Based Entirely on Elastomers. Adv. Funct. Mater. 2012, 22, 4044-4050. [CrossRef]

82. Yan, C.; Wang, J.; Kang, W.; Cui, M.; Wang, X.; Foo, C.Y.; Chee, K.J.; Lee, P.S. Highly Stretchable Piezoresistive Graphene-Nanocellulose Nanopaper for Strain Sensors. Adv. Mater. 2014, 26, 2022-2027. [CrossRef] [PubMed]

83. Lee, T.; Lee, W.; Kim, S.-W.; Kim, J.J.; Kim, B.-S. Flexible Textile Strain Wireless Sensor Functionalized with Hybrid Carbon Nanomaterials Supported ZnO Nanowires with Controlled Aspect Ratio. Adv. Funct. Mater. 2016, 26, 6206-6214. [CrossRef]

84. Xiao, X.; Yuan, L.; Zhong, J.; Ding, T.; Liu, Y.; Cai, Z.; Rong, Y.; Han, H.; Zhou, J.; Wang, Z.L. High-Strain Sensors Based on ZnO Nanowire/Polystyrene Hybridized Flexible Films. Adv. Mater. 2011, 23, 5440-5444. [CrossRef] [PubMed]

85. Boland, C.S.; Khan, U.; Backes, C.; O’Neill, A.; McCauley, J.; Duane, S.; Shanker, R.; Liu, Y.; Jurewicz, I.; Dalton, A.B.; Coleman, J.N. Sensitive, High-Strain, High-Rate Bodily Motion Sensors Based on Graphene-Rubber Composites. ACS Nano 2014, 8, 8819-8830. [CrossRef] [PubMed]

86. Wang, Y.; Wang, L.; Yang, T.; Li, X.; Zang, X.; Zhu, M.; Wang, K.; Wu, D.; Zhu, H. Wearable and Highly Sensitive Graphene Strain Sensors for Human Motion Monitoring. Adv. Funct. Mater. 2014, 24, 4666-4670. [CrossRef]

87. Hwang, B.-U.; Lee, J.-H.; Trung, T.Q.; Roh, E.; Kim, D.-I.; Kim, S.-W.; Lee, N.-E. Transparent Stretchable Self-Powered Patchable Sensor Platform with Ultrasensitive Recognition of Human Activities. ACS Nano 2015, 9, 8801-8810. [CrossRef] [PubMed]

88. Gong, S.; Lai, D.T.H.; Su, B.; Si, K.J.; Ma, Z.; Yap, L.W.; Guo, P.; Cheng, W. Highly Stretchy Black Gold E-Skin Nanopatches as Highly Sensitive Wearable Biomedical Sensors. Adv. Electron. Mater. 2015, 1, 1400063. [CrossRef]

89. Saha, B.; Baek, S.; Lee, J. Highly Sensitive Bendable and Foldable Paper Sensors Based on Reduced Graphene Oxide. ACS Appl. Mater. Interfaces 2017, 9, 4658-4666. [CrossRef] [PubMed]

90. Cohen, D.J.; Mitra, D.; Peterson, K.; Maharbiz, M.M. A Highly Elastic, Capacitive Strain Gauge Based on Percolating Nanotube Networks. Nano Lett. 2012, 12, 1821-1825. [CrossRef] [PubMed]

91. Cai, L.; Song, L.; Luan, P.; Zhang, Q.; Zhang, N.; Gao, Q.; Zhao, D.; Zhang, X.; Tu, M.; Yang, F.; et al. Super-stretchable, Transparent Carbon Nanotube-Based Capacitive Strain Sensors for Human Motion Detection. Sci. Rep. 2013, 3, 3048. [CrossRef] [PubMed]

92. Frutiger, A.; Muth, J.T.; Vogt, D.M.; Mengüç, Y.; Campo, A.; Valentine, A.D.; Walsh, C.J.; Lewis, J.A. Capacitive Soft Strain Sensors via Multicore-Shell Fiber Printing. Adv. Mater. 2015, 27, 2440-2446. [CrossRef] [PubMed]

93. Choi, D.Y.; Kim, M.H.; Oh, Y.S.; Jung, S.-H.; Jung, J.H.; Sung, H.J.; Lee, H.W.; Lee, H.M. Highly Stretchable, Hysteresis-Free Ionic Liquid-Based Strain Sensor for Precise Human Motion Monitoring. ACS Appl. Mater. Interfaces 2017, 9, 1770-1780. [CrossRef] [PubMed]

94. Cooper, C.B.; Arutselvan, K.; Liu, Y.; Armstrong, D.; Lin, Y.; Khan, M.R.; Genzer, J.; Dickey, M.D. Stretchable Capacitive Sensors of Torsion, Strain, and Touch Using Double Helix Liquid Metal Fibers. Adv. Funct. Mater. 2017, 27, 1605630. [CrossRef]

95. Wu, J.M.; Chen, C.-Y.; Zhang, Y.; Chen, K.-H.; Yang, Y.; Hu, Y.; He, J.-H.; Wang, Z.L. Ultrahigh Sensitive Piezotronic Strain Sensors Based on a ZnSnO3 Nanowire/Microwire. ACS Nano 2012, 6, 4369-4374. [CrossRef] [PubMed] 
96. Lee, S.; Bae, S.-H.; Lin, L.; Yang, Y.; Park, C.; Kim, S.-W.; Cha, S.N.; Kim, H.; Park, Y.J.; Wang, Z.L. Super-Flexible Nanogenerator for Energy Harvesting from Gentle Wind and as an Active Deformation Sensor. Adv. Funct. Mater. 2013, 23, 2445-2449. [CrossRef]

97. Lee, S.; Hinchet, R.; Lee, Y.; Yang, Y.; Lin, Z.-H.; Ardila, G.; Montès, L.; Mouis, M.; Wang, Z.L. Ultrathin Nanogenerators as Self-Powered/Active Skin Sensors for Tracking Eye Ball Motion. Adv. Funct. Mater. 2014, 24, 1163-1168. [CrossRef]

98. Zhong, J.; Zhong, Q.; Hu, Q.; Wu, N.; Li, W.; Wang, B.; Hu, B.; Zhou, J. Stretchable Self-Powered Fiber-Based Strain Sensor. Adv. Funct. Mater. 2015, 25, 1798-1803. [CrossRef]

99. Son, D.; Lee, J.; Qiao, S.; Ghaffari, R.; Kim, J.; Lee, J.E.; Song, C.; Kim, S.J.; Lee, D.J.; Jun, S.W.; et al. Multifunctional wearable devices for diagnosis and therapy of movement disorders. Nat. Nanotechnol. 2014, 9, 397-404. [CrossRef] [PubMed]

100. Lin, P.; Yan, F. Organic thin-film transistors for chemical and biological sensing. Adv. Mater. 2012, $24,34-51$. [CrossRef] [PubMed]

101. Sokolov, A.N.; Roberts, M.E.; Bao, Z. Fabrication of low-cost electronic biosensors. Mater. Today 2009, 12, 12-20. [CrossRef]

102. Roberts, M.E.; Sokolov, A.N.; Bao, Z. Material and device considerations for organic thin-film transistor sensors. J. Mater. Chem. 2009, 19, 3351-3363. [CrossRef]

103. Oliver, N.S.; Toumazou, C.; Cass, A.E.G.; Johnston, D.G. Glucose sensors: a review of current and emerging technology. Diabet. Med. 2009, 26, 197-210. [CrossRef] [PubMed]

104. Liu, C.; Hsu, P.-C.; Lee, H.-W.; Ye, M.; Zheng, G.; Liu, N.; Li, W.; Cui, Y. Transparent air filter for high-efficiency PM2.5 capture. Nat. Commun. 2015, 6, 6205. [CrossRef] [PubMed]

105. Kaushik, A.; Kumar, R.; Arya, S.K.; Nair, M.; Malhotra, B.D.; Bhansali, S. Organic-Inorganic Hybrid Nanocomposite-Based Gas Sensors for Environmental Monitoring. Chem. Rev. 2015, 115, 4571-4606. [CrossRef] [PubMed]

106. Wang, C.; Yin, L.; Zhang, L.; Xiang, D.; Gao, R. Metal Oxide Gas Sensors: Sensitivity and Influencing Factors. Sensors (Basel) 2010, 10, 2088-2106. [CrossRef] [PubMed]

107. Jin, X.; Yu, L.; Garcia, D.; Ren, R.X.; Zeng, X. Ionic Liquid High-Temperature Gas Sensor Array. Anal. Chem. 2006, 78, 6980-6989. [CrossRef] [PubMed]

108. Chiu, C.-S.; Gwo, S. Quantitative surface acoustic wave detection based on colloidal gold nanoparticles and their bioconjugates. Anal. Chem. 2008, 80, 3318-3326. [CrossRef] [PubMed]

109. Korotcenkov, G. Materials for Electrochemical Gas Sensors with Liquid and Polymer Electrolytes. In Handbook of Gas Sensor Materials; Springer: New York, NY, USA, 2013; pp. 353-364.

110. Wang, T.; Guo, Y.; Wan, P.; Sun, X.; Zhang, H.; Yu, Z.; Chen, X. A flexible transparent colorimetric wrist strap sensor. Nanoscale 2017, 9, 869-874. [CrossRef] [PubMed]

111. Zhao, J.; Chen, G.; Zhu, L.; Li, G. Graphene quantum dots-based platform for the fabrication of electrochemical biosensors. Electrochem. Commun. 2011, 13, 31-33. [CrossRef]

112. Rumyantsev, S.; Liu, G.; Shur, M.S.; Potyrailo, R.A.; Balandin, A.A. Selective gas sensing with a single pristine graphene transistor. Nano Lett. 2012, 12, 2294-2298. [CrossRef] [PubMed]

113. Zhang, Y.-H.; Chen, Y.-B.; Zhou, K.-G.; Liu, C.-H.; Zeng, J.; Zhang, H.-L.; Peng, Y. Improving gas sensing properties of graphene by introducing dopants and defects: a first-principles study. Nanotechnology 2009, 20, 185504. [CrossRef] [PubMed]

114. Liu, H.; Li, M.; Voznyy, O.; Hu, L.; Fu, Q.; Zhou, D.; Xia, Z.; Sargent, E.H.; Tang, J. Physically flexible, rapid-response gas sensor based on colloidal quantum dot solids. Adv. Mater. 2014, 26, 2718-2724. [CrossRef] [PubMed]

115. Forleo, A.; Francioso, L.; Capone, S.; Siciliano, P.; Lommens, P.; Hens, Z. Synthesis and gas sensing properties of $\mathrm{ZnO}$ quantum dots. Sens. Actuators B Chem. 2010, 146, 111-115. [CrossRef]

116. Levine, P.M.; Gong, P.; Levicky, R.; Shepard, K.L. Active CMOS Sensor Array for Electrochemical Biomolecular Detection. IEEE J. Solid State Circ. 2008, 43, 1859-1871. [CrossRef]

117. Mu, X.; Wang, Z.; Zeng, X.; Mason, A.J. A Robust Flexible Electrochemical Gas Sensor Using Room Temperature Ionic Liquid. IEEE Sens. J. 2013, 13, 3976-3981. [CrossRef]

118. Lehnhardt, A.; Kemper, M.J. Pathogenesis, diagnosis and management of hyperkalemia. Pediatr. Nephrol. 2011, 26, 377-384. [CrossRef] [PubMed] 
119. Bandodkar, A.J.; Jia, W.; Yardımcı, C.; Wang, X.; Ramirez, J.; Wang, J. Tattoo-Based Noninvasive Glucose Monitoring: A Proof-of-Concept Study. Anal. Chem. 2015, 87, 394-398. [CrossRef] [PubMed]

120. Curto, V.F.; Fay, C.; Coyle, S.; Byrne, R.; O’Toole, C.; Barry, C.; Hughes, S.; Moyna, N.; Diamond, D.; Benito-Lopez, F. Real-time sweat $\mathrm{pH}$ monitoring based on a wearable chemical barcode micro-fluidic platform incorporating ionic liquids. Sens. Actuators B Chem. 2012, 171-172, 1327-1334. [CrossRef]

121. Steinberg, M.D.; Kassal, P.; Steinberg, I.M. System Architectures in Wearable Electrochemical Sensors. Electroanalysis 2016, 28, 1149-1169. [CrossRef]

122. Parrilla, M.; Cánovas, R.; Jeerapan, I.; Andrade, F.J.; Wang, J. A Textile-Based Stretchable Multi-Ion Potentiometric Sensor. Adv. Healthc. Mater. 2016, 5, 996-1001. [CrossRef] [PubMed]

123. Yun, S.Y.; Hong, Y.K.; Oh, B.K.; Cha, G.S.; Nam, H.; Lee, S.B.; Jin, J.-I. Potentiometric Properties of Ion-Selective Electrode Membranes Based on Segmented Polyether Urethane Matrices. Anal. Chem. 1997, 69, 868-873. [CrossRef] [PubMed]

124. Cosofret, V.V.; Erdosy, M.; Raleigh, J.S.; Johnson, T.A.; Neuman, M.R.; Buck, R.P. Aliphatic polyurethane as a matrix for $\mathrm{pH}$ sensors: Effects of native sites and added proton carrier on electrical and potentiometric properties. Talanta 1996, 43, 143-151. [CrossRef]

125. Kwan, R.C.H.; Leung, H.F.; Hon, P.Y.T.; Cheung, H.C.F.; Hirota, K.; Renneberg, R. Amperometric biosensor for determining human salivary phosphate. Anal. Biochem. 2005, 343, 263-267. [CrossRef] [PubMed]

126. Park, J.-U.; Nam, S.; Lee, M.-S.; Lieber, C.M. Synthesis of monolithic graphene-graphite integrated electronics. Nat. Mater. 2012, 11, 120-125. [CrossRef] [PubMed]

127. Nyein, H.Y.Y.; Gao, W.; Shahpar, Z.; Emaminejad, S.; Challa, S.; Chen, K.; Fahad, H.M.; Tai, L.-C.; Ota, H.; Davis, R.W.; et al. A Wearable Electrochemical Platform for Noninvasive Simultaneous Monitoring of Ca2+ and pH. ACS Nano 2016, 10, 7216-7224. [CrossRef] [PubMed]

128. Robertson, W.G.; Marshall, R.W.; Bowers, G.N. Ionized Calcium in Body Fluids. CRC Crit. Rev. Clin. Lab. Sci. 1981, 15, 85-125. [CrossRef] [PubMed]

129. Jung, I.Y.; Kim, J.S.; Choi, B.R.; Lee, K.; Lee, H. Hydrogel Based Biosensors for In Vitro Diagnostics of Biochemicals, Proteins, and Genes. Adv. Healthc. Mater. 2017, 6, 1601475. [CrossRef] [PubMed]

130. Kudo, H.; Sawada, T.; Kazawa, E.; Yoshida, H.; Iwasaki, Y.; Mitsubayashi, K. A flexible and wearable glucose sensor based on functional polymers with Soft-MEMS techniques. Biosens. Bioelectron. 2006, 22, 558-562. [CrossRef] [PubMed]

131. Kim, J.; Valdés-Ramírez, G.; Bandodkar, A.J.; Jia, W.; Martinez, A.G.; Ramírez, J.; Mercier, P.; Wang, J. Non-invasive mouthguard biosensor for continuous salivary monitoring of metabolites. Analyst 2014, 139, 1632-1636. [CrossRef] [PubMed]

132. Panneer Selvam, A.; Muthukumar, S.; Kamakoti, V.; Prasad, S. A wearable biochemical sensor for monitoring alcohol consumption lifestyle through Ethyl glucuronide (EtG) detection in human sweat. Sci. Rep. 2016, 6, 23111. [CrossRef] [PubMed]

133. Wang, J. Electrochemical Glucose Biosensors. Chem. Rev. 2008, 108, 814-825. [CrossRef] [PubMed]

134. Windmiller, J.R.; Wang, J. Wearable Electrochemical Sensors and Biosensors: A Review. Electroanalysis 2013, 25, 29-46. [CrossRef]

135. Windmiller, J.R.; Bandodkar, A.J.; Parkhomovsky, S.; Wang, J. Stamp transfer electrodes for electrochemical sensing on non-planar and oversized surfaces. Analyst 2012, 137, 1570-1575. [CrossRef] [PubMed]

136. Jia, W.; Bandodkar, A.J.; Valdés-Ramírez, G.; Windmiller, J.R.; Yang, Z.; Ramírez, J.; Chan, G.; Wang, J. Electrochemical Tattoo Biosensors for Real-Time Noninvasive Lactate Monitoring in Human Perspiration. Anal. Chem. 2013, 85, 6553-6560. [CrossRef] [PubMed]

137. Alonso-Lomillo, M.A.; Domínguez-Renedo, O.; Arcos-Martínez, M.J. Screen-printed biosensors in microbiology; a review. Talanta 2010, 82, 1629-1636. [CrossRef] [PubMed]

138. Matsumoto, A.; Miyahara, Y. Current and emerging challenges of field effect transistor based bio-sensing. Nanoscale 2013, 5, 10702-10718. [CrossRef] [PubMed]

139. Karthick Kannan, P.; Late, D.J.; Morgan, H.; Sekhar Rout, C. Recent developments in 2D layered inorganic nanomaterials for sensing. Nanoscale 2015, 7, 13293-13312. [CrossRef] [PubMed]

140. You, X.; Pak, J.J. Graphene-based field effect transistor enzymatic glucose biosensor using silk protein for enzyme immobilization and device substrate. Sens. Actuators B Chem. 2014, 202, 1357-1365. [CrossRef]

141. Minami, T.; Sato, T.; Minamiki, T.; Fukuda, K.; Kumaki, D.; Tokito, S. A novel OFET-based biosensor for the selective and sensitive detection of lactate levels. Biosens. Bioelectron. 2015, 74, 45-48. [CrossRef] [PubMed] 
142. Badugu, R.; Lakowicz, J.R.; Geddes, C.D. Ophthalmic glucose sensing: a novel monosaccharide sensing disposable and colorless contact lens. Analyst 2004, 129, 516-521. [CrossRef] [PubMed]

143. Badugu, R.; Lakowicz, J.R.; Geddes, C.D. A glucose-sensing contact lens: from bench top to patient. Curr. Opin. Biotechnol. 2005, 16, 100-107. [CrossRef] [PubMed]

144. Ruan, J.-L.; Chen, C.; Shen, J.-H.; Zhao, X.-L.; Qian, S.-H.; Zhu, Z.-G. A Gelated Colloidal Crystal Attached Lens for Noninvasive Continuous Monitoring of Tear Glucose. Polymers 2017, 9, 125. [CrossRef]

145. Speedy, D.B.; Noakes, T.D.; Schneider, C. Exercise-associated hyponatremia: a review. Emerg. Med. 2001, 13, 17-27. [CrossRef]

146. Talary, M.S.; Dewarrat, F.; Huber, D.; Caduff, A. In vivo life sign application of dielectric spectroscopy and non-invasive glucose monitoring. J. Non-Cryst. Solids 2007, 353, 4515-4517. [CrossRef]

147. Derbyshire, P.J.; Barr, H.; Davis, F.; Higson, S.P. Lactate in human sweat: a critical review of research to the present day. J. Physiol. Sci. 2012, 62, 429-440. [CrossRef] [PubMed]

148. Sprigle, S.; Linden, M.; McKenna, D.; Davis, K.; Riordan, B. Clinical skin temperature measurement to predict incipient pressure ulcers. Adv. Skin Wound Care 2001, 14, 133-137. [CrossRef] [PubMed]

149. Lee, Y.K.; Jang, K.-I.; Ma, Y.; Koh, A.; Chen, H.; Jung, H.N.; Kim, Y.; Kwak, J.W.; Wang, L.; Xue, Y.; et al. Chemical Sensing Systems that Utilize Soft Electronics on Thin Elastomeric Substrates with Open Cellular Designs. Adv. Funct. Mater. 2017, 27, 1605476. [CrossRef]

150. Ho, J.S.; Yeh, A.J.; Neofytou, E.; Kim, S.; Tanabe, Y.; Patlolla, B.; Beygui, R.E.; Poon, A.S.Y. Wireless power transfer to deep-tissue microimplants. Proc. Natl. Acad. Sci. USA 2014, 111, 7974-7979. [CrossRef] [PubMed]

151. Chen, P.-J.; Rodger, D.C.; Saati, S.; Humayun, M.S.; Tai, Y.-C. Microfabricated implantable parylene-based wireless passive intraocular pressure sensors. J. Microelectromech. Syst. 2008, 17, 1342-1351. [CrossRef]

152. Mei, H.; Irazoqui, P.P. Miniaturizing wireless implants. Nat. Biotechnol. 2014, 32, 1008-1010. [CrossRef] [PubMed]

153. Park, S.I.; Brenner, D.S.; Shin, G.; Morgan, C.D.; Copits, B.A.; Chung, H.U.; Pullen, M.Y.; Noh, K.N.; Davidson, S.; Oh, S.J.; et al. Soft, stretchable, fully implantable miniaturized optoelectronic systems for wireless optogenetics. Nat. Biotechnol. 2015, 33, 1280-1286. [CrossRef] [PubMed]

154. Majumder, S.; Mondal, T.; Deen, M.J. Wearable Sensors for Remote Health Monitoring. Sensors 2017, 17, 130. [CrossRef] [PubMed]

155. Zhang, T.; Lu, J.; Hu, F.; Hao, Q. Bluetooth low energy for wearable sensor-based healthcare systems. In Proceedings of the 2014 IEEE Healthcare Innovation Conference (HIC), Seattle, WA, USA, 8-10 October 2014; pp. 251-254.

156. Malhi, K.; Mukhopadhyay, S.C.; Schnepper, J.; Haefke, M.; Ewald, H. A Zigbee-Based Wearable Physiological Parameters Monitoring System. IEEE Sens. J. 2012, 12, 423-430. [CrossRef]

157. Kim, J.; Salvatore, G.A.; Araki, H.; Chiarelli, A.M.; Xie, Z.; Banks, A.; Sheng, X.; Liu, Y.; Lee, J.W.; Jang, K.-I.; et al. Battery-free, stretchable optoelectronic systems for wireless optical characterization of the skin. Sci. Adv. 2016, 2, e1600418. [CrossRef] [PubMed]

158. Tao, H.; Brenckle, M.A.; Yang, M.; Zhang, J.; Liu, M.; Siebert, S.M.; Averitt, R.D.; Mannoor, M.S.; McAlpine, M.C.; Rogers, J.A.; et al. Silk-Based Conformal, Adhesive, Edible Food Sensors. Adv. Mater. 2012, 24, 1067-1072. [CrossRef] [PubMed]

159. Mannoor, M.S.; Tao, H.; Clayton, J.D.; Sengupta, A.; Kaplan, D.L.; Naik, R.R.; Verma, N.; Omenetto, F.G.; McAlpine, M.C. Graphene-based wireless bacteria detection on tooth enamel. Nat. Commun. 2012, 3, 763. [CrossRef] [PubMed]

160. Huang, X.; Liu, Y.; Cheng, H.; Shin, W.-J.; Fan, J.A.; Liu, Z.; Lu, C.-J.; Kong, G.-W.; Chen, K.; Patnaik, D.; et al. Materials and Designs for Wireless Epidermal Sensors of Hydration and Strain. Adv. Funct. Mater. 2014, 24, 3846-3854. [CrossRef]

161. Kim, J.; Banks, A.; Xie, Z.; Heo, S.Y.; Gutruf, P.; Lee, J.W.; Xu, S.; Jang, K.-I.; Liu, F.; Brown, G.; et al. Miniaturized Flexible Electronic Systems with Wireless Power and Near-Field Communication Capabilities. Adv. Funct. Mater. 2015, 25, 4761-4767. [CrossRef]

162. Huang, X.; Liu, Y.; Chen, K.; Shin, W.-J.; Lu, C.-J.; Kong, G.-W.; Patnaik, D.; Lee, S.-H.; Cortes, J.F.; Rogers, J.A. Stretchable, wireless sensors and functional substrates for epidermal characterization of sweat. Small 2014, 10, 3083-3090. [CrossRef] [PubMed] 
163. Jun, J.; Oh, J.; Shin, D.H.; Kim, S.G.; Lee, J.S.; Kim, W.; Jang, J. Wireless, Room Temperature Volatile Organic Compound Sensor Based on Polypyrrole Nanoparticle Immobilized Ultrahigh Frequency Radio Frequency Identification Tag. ACS Appl. Mater. Interfaces 2016, 8, 33139-33147. [CrossRef] [PubMed]

164. Cheng, S.; Wu, Z. A Microfluidic, Reversibly Stretchable, Large-Area Wireless Strain Sensor. Adv. Funct. Mater. 2011, 21, 2282-2290. [CrossRef]

165. Tang, J.; Guo, H.; Zhao, M.; Yang, J.; Tsoukalas, D.; Zhang, B.; Liu, J.; Xue, C.; Zhang, W. Highly Stretchable Electrodes on Wrinkled Polydimethylsiloxane Substrates. Sci. Rep. 2015, 5, 16527. [CrossRef] [PubMed]

166. Yi, X.; Cho, C.; Cooper, J.; Wang, Y.; Tentzeris, M.M.; Leon, R.T. Passive wireless antenna sensor for strain and crack sensing-Electromagnetic modeling, simulation, and testing. Smart Mater. Struct. 2013, 22, 085009. [CrossRef]

167. Govil, J. 4G Mobile Communication Systems: Turns, Trends and Transition. In Proceedings of the 2007 International Conference on Convergence Information Technology (ICCIT 2007), Gyeongju, Korea, 21-23 November 2007; pp. 13-18.

168. Tröster, G. The Agenda of Wearable Healthcare. Yearb. Med. Inform. 2005, 125-138.

169. Laine, T.H.; Lee, C.; Suk, H. Mobile Gateway for Ubiquitous Health Care System Using ZigBee and Bluetooth. In Proceedings of the 2014 Eighth International Conference on Innovative Mobile and Internet Services in Ubiquitous Computing, Birmingham, UK, 2-4 July 2014; pp. 139-145.

170. Dementyev, A.; Hodges, S.; Taylor, S.; Smith, J. Power Consumption Analysis of Bluetooth Low Energy, ZigBee, and ANT Sensor Nodes in a Cyclic Sleep Scenario. In Proceedings of the 2013 IEEE International Wireless Symposium (IWS), Beijing, China, 14-18 April 2013.

171. Barnes, S.J. Under the skin: short-range embedded wireless technology. Int. J. Inf. Manag. 2002, 22, 165-179. [CrossRef]

172. Coskun, V.; Ozdenizci, B.; Ok, K. A Survey on Near Field Communication (NFC) Technology. Wirel. Pers. Commun. 2013, 71, 2259-2294. [CrossRef]

173. Sonner, Z.; Wilder, E.; Heikenfeld, J.; Kasting, G.; Beyette, F.; Swaile, D.; Sherman, F.; Joyce, J.; Hagen, J.; Kelley-Loughnane, N.; et al. The microfluidics of the eccrine sweat gland, including biomarker partitioning, transport, and biosensing implications. Biomicrofluidics 2015, 9, 031301. [CrossRef] [PubMed]

174. Touati, F.; Tabish, R. U-Healthcare System: State-of-the-Art Review and Challenges. J. Med. Syst. 2013, 37, 9949. [CrossRef] [PubMed]

175. Choi, S.-J.; Kim, S.-J.; Kim, I.-D. Ultrafast optical reduction of graphene oxide sheets on colorless polyimide film for wearable chemical sensors. NPG Asia Mater. 2016, 8, e315. [CrossRef]

176. Lee, J.W.; Xu, R.; Lee, S.; Jang, K.-I.; Yang, Y.; Banks, A.; Yu, K.J.; Kim, J.; Xu, S.; Ma, S.; et al. Soft, thin skin-mounted power management systems and their use in wireless thermography. Proc. Natl. Acad. Sci. USA 2016, 113, 6131-6136. [CrossRef] [PubMed]

177. Koh, A.; Kang, D.; Xue, Y.; Lee, S.; Pielak, R.M.; Kim, J.; Hwang, T.; Min, S.; Banks, A.; Bastien, P.; et al. A soft, wearable microfluidic device for the capture, storage, and colorimetric sensing of sweat. Sci. Trans. Med. 2016, 8, 366ra165. [CrossRef] [PubMed]

178. Araki, H.; Kim, J.; Zhang, S.; Banks, A.; Crawford, K.E.; Sheng, X.; Gutruf, P.; Shi, Y.; Pielak, R.M.; Rogers, J.A. Materials and Device Designs for an Epidermal UV Colorimetric Dosimeter with Near Field Communication Capabilities. Adv. Funct. Mater. 2017, 27, 1604465. [CrossRef]

179. Muth, J.T.; Vogt, D.M.; Truby, R.L.; Mengüç, Y.; Kolesky, D.B.; Wood, R.J.; Lewis, J.A. Embedded 3D printing of strain sensors within highly stretchable elastomers. Ad. Mater. 2014, 26, 6307-6312. [CrossRef] [PubMed]

180. Lipson, H.; Kurman, M. Fabricated: The new World of 3D Printing; John Wiley \& Sons: Weinheim, Germany, 2013.

181. Gross, B.C.; Erkal, J.L.; Lockwood, S.Y.; Chen, C.; Spence, D.M. Evaluation of 3D Printing and Its Potential Impact on Biotechnology and the Chemical Sciences. Anal. Chem. 2014, 86, 3240-3253. [CrossRef] [PubMed]

182. Yamada, T.; Hayamizu, Y.; Yamamoto, Y.; Yomogida, Y.; Izadi-Najafabadi, A.; Futaba, D.N.; Hata, K. A stretchable carbon nanotube strain sensor for human-motion detection. Nat. Nanotechnol. 2011, 6, $296-301$. [CrossRef] [PubMed]

183. Sitti, M.; Fearing, R.S. Synthetic gecko foot-hair micro/nano-structures as dry adhesives. J. Adhes. Sci. Technol. 2003, 17, 1055-1073. [CrossRef]

184. Kim, S.; Sitti, M. Biologically inspired polymer microfibers with spatulate tips as repeatable fibrillar adhesives. Appl. Phys. Lett. 2006, 89, 261911. [CrossRef] 
185. Murphy, M.P.; Aksak, B.; Sitti, M. Gecko-Inspired Directional and Controllable Adhesion. Small 2009, 5, 170-175. [CrossRef] [PubMed]

186. Glass, P.; Chung, H.; Washburn, N.R.; Sitti, M. Enhanced reversible adhesion of dopamine methacrylamide-coated elastomer microfibrillar structures under wet conditions. Langmuir 2009, 25, 6607-6612. [CrossRef] [PubMed]

187. Jung, S.; Lee, J.; Hyeon, T.; Lee, M.; Kim, D.-H. Fabric-Based Integrated Energy Devices for Wearable Activity Monitors. Adv. Mater. 2014, 26, 6329-6334. [CrossRef] [PubMed]

188. Luo, J.; Fan, F.R.; Zhou, T.; Tang, W.; Xue, F.; Wang, Z.L. Ultrasensitive self-powered pressure sensing system. Extrem. Mech. Lett. 2015, 2, 28-36. [CrossRef]

189. Yi, F.; Wang, X.; Niu, S.; Li, S.; Yin, Y.; Dai, K.; Zhang, G.; Lin, L.; Wen, Z.; Guo, H.; et al. A highly shape-adaptive, stretchable design based on conductive liquid for energy harvesting and self-powered biomechanical monitoring. Sci. Adv. 2016, 2, e1501624. [CrossRef] [PubMed]

C 2017 by the authors. Licensee MDPI, Basel, Switzerland. This article is an open access article distributed under the terms and conditions of the Creative Commons Attribution (CC BY) license (http:/ / creativecommons.org/licenses/by/4.0/). 